\title{
Review
}

\section{From the Golgi-Cajal mapping to the transmitter-based characterization of the neuronal networks leading to two modes of brain communication: Wiring and volume transmission ${ }^{\text {is }}$}

\author{
Kjell Fuxe ${ }^{a, *}$, Annica Dahlström ${ }^{b}$, Malin Höistad ${ }^{a}$, Daniel Marcellino $^{a}$, Anders Jansson $^{a}$, \\ Alicia Rivera ${ }^{c}$, Zaida Diaz-Cabiale ${ }^{d}$, Kirsten Jacobsen ${ }^{e}$, Barbro Tinner-Staines ${ }^{e}$, \\ Beth Hagman ${ }^{a}$, Giuseppina Leo ${ }^{f}$, William Staines ${ }^{e}$, Diego Guidolin ${ }^{g}$, Jan Kehr ${ }^{h}$, \\ Susanna Genedani ${ }^{f}$, Natale Belluardo ${ }^{i}$, Luigi F. Agnati ${ }^{f}$ \\ ${ }^{a}$ Department of Neuroscience, Karolinska Institutet, 17177 Stockholm, Sweden \\ ${ }^{\mathrm{b} D e p a r t m e n t}$ of Anatomy and Cell Biology, Göteborg University, 40530 Göteborg, Sweden \\ 'Department of Cell Biology, University of Málaga, Campus Teatinos s/n, 29071 Málaga, Spain \\ ${ }^{\mathrm{d} D e p a r t m e n t}$ of Human Physiology, University of Malaga, Campus Teatinos s/n, 29071 Malaga, Spain \\ e Department of Cellular and Molecular Medicine, University of Ottawa, Ottawa, Canada K1H 8M5 \\ ${ }^{\mathrm{f}}$ Department of Biomedical Sciences, University of Modena, Modena, Italy \\ gDepartment of Human Anatomy and Physiology, University of Padova, Padova, Italy \\ ${ }^{\mathrm{h}}$ Department of Physiology and Pharmacology, Karolinska Institutet, 17177 Stockholm, Sweden \\ ${ }^{\mathrm{i}}$ Department of Human Physiology, University of Palermo, Palermo, Italy
}

\section{A R T I C L E I N F O}

Article history:

Accepted 27 February 2007

Available online 13 March 2007

Keywords:

5-Hydroxytryptamine

Amygdala

Brain function

Brain uncoupling protein-2

Catecholamines

CA turnover

Clearance

Diffusion

\section{A B S T R A C T}

After Golgi-Cajal mapped neural circuits, the discovery and mapping of the central monoamine neurons opened up for a new understanding of interneuronal communication by indicating that another form of communication exists. For instance, it was found that dopamine may be released as a prolactin inhibitory factor from the median eminence, indicating an alternative mode of dopamine communication in the brain. Subsequently, the analysis of the locus coeruleus noradrenaline neurons demonstrated a novel type of lower brainstem neuron that monosynaptically and globally innervated the entire CNS. Furthermore, the ascending raphe serotonin neuron systems were found to globally innervate the forebrain with few synapses, and where deficits in serotonergic function appeared to play a major role in depression. We propose that serotonin reuptake inhibitors may produce antidepressant effects through increasing serotonergic neurotrophism in serotonin nerve cells and their targets by transactivation of receptor tyrosine kinases (RTK), involving direct or indirect receptor/RTK interactions. Early

This paper is dedicated to the memory of our mothers Mrs. Linnea (Nea) Fuxe and Mrs. Giovanna Agnati, the finest in the world who gave us their never-ceasing love in their proud struggle for the survival of our families.

* Corresponding author.

E-mail address: Kjell.Fuxe@ki.se (K. Fuxe). 
Dopamine

Dorsal raphe

Dual probe microdialysis

Extracellular space

Extrasynaptic receptors

Histofluorescence

Local circuits

Locus coeruleus

Mapping of monoamine neurons

Microdensitometry

Microfluorimetry

Neurological and mental disorders

Noradrenaline

Nucleus accumbens

Pressure gradients

Receptor mosaics

Receptor-receptor interactions

Substantia nigra

Thermal gradients

Tortuosity

Transmitter-receptor mismatches

Volume fraction

Volume transmission

Wiring transmission chemical neuroanatomical work on the monoamine neurons, involving primitive nervous systems and analysis of peptide neurons, indicated the existence of alternative modes of communication apart from synaptic transmission. In 1986, Agnati and Fuxe introduced the theory of two main types of intercellular communication in the brain: wiring and volume transmission (WT and VT). Synchronization of phasic activity in the monoamine cell clusters through electrotonic coupling and synaptic transmission (WT) enables optimal VT of monoamines in the target regions. Experimental work suggests an integration of WT and VT signals via receptor-receptor interactions, and a new theory of receptor-connexin interactions in electrical and mixed synapses is introduced. Consequently, a new model of brain function must be built, in which communication includes both WT and VT and receptor-receptor interactions in the integration of signals. This will lead to the unified execution of information handling and trophism for optimal brain function and survival.

(c) 2007 Elsevier B.V. All rights reserved.

\section{Contents}

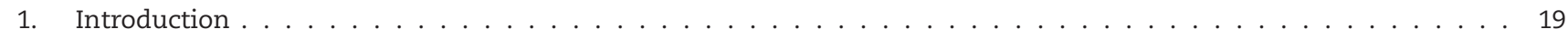

2. Discovery and characterization of the chemical neuroanatomy of neural circuits based on the Falck-Hillarp

technique for the cellular localization of monoamines . . . . . . . . . . . . . . . . . . 19

2.1. The discovery and mapping of the central dopamine, noradrenaline and 5-hydroxytryptamine neurons . . . 20

2.1.1. Dopamine neurons . . . . . . . . . . . . . . . . . . . . . . . . 20

2.1.2. Noradrenaline neurons. . . . . . . . . . . . . . . . . . . . . . . . . . 23

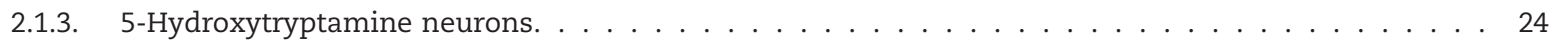

3. The 5-HT raphe-forebrain neuron systems and depression . . . . . . . . . . . . . . . . . . 26

3.1. Neurotrophic factors . . . . . . . . . . . . . . . . . . . . . . . . . 27

3.2. Intramembrane receptor-receptor interactions among GPCRs . . . . . . . . . . . . . . . . . . . . . . . . . 27

3.3. Transactivation of receptor tyrosine kinases following G-protein-coupled receptor (GPCR) activation

via GPCR/RTK receptor interactions . . . . . . . . . . . . . . . . . . . . . . . . . . . . . . 27

3.4. Serotonin receptor subtypes and the possible transactivation of the FGF-2/FGFR1 neurotrophic system . . . . 28

4. Two modes of brain communication: wiring and volume transmission . . . . . . . . . . . . . . . . . . 29

4.1. The foundations leading up to the 1986 proposal of wiring and volume transmission . . . . . . . . . . 29

4.2. Further experimental evidence for the existence of volume transmission . . . . . . . . . . . . . . . . 31

4.2.1. Failure of storage of transmitters/modulators in synaptic vesicles . . . . . . . . . . . . . . . . . . 31

4.2.2. Lack of calcium-dependent vesicular release of transmitters . . . . . . . . . . . . . . . . . . . . . 31

4.2.3. Release of transmitters not in strict contiguity with postsynaptic membranes . . . . . . . . . . . . 31

4.2.4. Location of transmitter receptors outside the postsynaptic density . . . . . . . . . . . . . . . . 32

4.2.5. Deficits of fast inactivation mechanisms of the transmitter . . . . . . . . . . . . . 33

4.3. The extracellular space and cerebrospinal fluid . . . . . . . . . . . . . . . . . . . . 34

4.3.1. The channels for volume transmission . . . . . . . . . . . . . . . . . . . . . . . 34

4.3.2. Dopamine diffusion in the striatum. . . . . . . . . . . . . . . . . . . . . . . 35

4.3.3. Fluid movements within the extracellular space. . . . . . . . . . . . . . . . . . . . . 36

4.3.4. The cerebrospinal fluid system as a communication channel . . . . . . . . . . . . . . . 37

5. The integration of WT and VT via receptor-receptor interactions . . . . . . . . . . . . . . . . . . . . . . 37

5.1. Hypothesis on receptor-connexin interactions in mixed synapses: a possible mechanism for integration

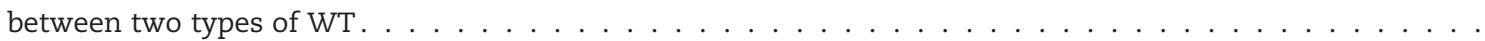


5.2. On the role of WT and VT and their integration in the monoamine neurons . . . . . . . . . . . . . . 39

5.2.1. The nigro-striatal dopamine system. . . . . . . . . . . . . . . . . . . . . . . 39

5.2.2. The locus coeruleus noradrenaline system . . . . . . . . . . . . . . . . . . . . . . 40

5.2.3. The dorsal raphe 5 -HT neuron system . . . . . . . . . . . . . . . . . . . . . . . . 41

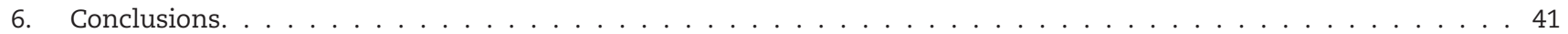

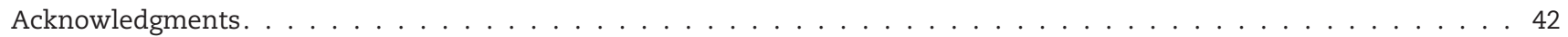

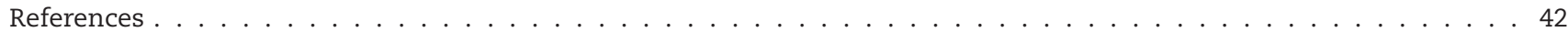

\section{Introduction}

Golgi's and Cajal's outstanding and classic contributions to the neural circuit mapping are well known. As to the complementarity of their views on brain communication, the reader is referred to the Agnati et al. paper in this special issue covering one century of progress in neuroscience. This review deals with the breakthrough in chemical neuroanatomy given by the Swedish groups of neurobiologists, and their subsequent development of new concepts on intercellular communication. These researchers presented the first original mapping of transmitter-identified neural circuits in the brain. The discovery and mapping of central monoamine neurons (Dahlström and Fuxe, 1964a,b, 1965; Fuxe, 1963, 1964, 1965a,b; Carlsson et al., 1962, 1964; Andén et al., 1964a, 1965a) opened up a new understanding of interneuronal communication by giving indications that the synapse, termed so by Sherrington to describe the nexus between two neurons (see Fig. 1), is not the only existing form of interneuronal communication. The ground-breaking discovery of central monoamine neurons paved the way for our present knowledge on neuropsychiatric diseases (e.g., Parkinson's disease, schizophrenia and depression) and contributed to the development of new concepts which have been introduced as the result of common and equal efforts by Agnati and Fuxe (see also Agnati et al., this special issue). In particular, these authors have proposed the existence of:

(i) Two complementary modes of brain communication: wiring versus volume transmission (WT and VT), with volume transmission taking place in the extracellular fluid (ECF) and cerebrospinal fluid (CSF) of the central nervous system (see Agnati et al., 1986a; Agnati and Fuxe, 1996).

(ii) Receptor-receptor interactions (Agnati et al., 1980; Fuxe et al., 1981; Fuxe and Agnati, 1985), which represent a mechanism to integrate signals at the plasma membrane level via formation of heteromers.

(iii) Receptor mosaics (RM) in the plasma membrane (highorder heteromers), which may represent a molecular basis of learning and memory (Agnati et al., 1982, 2003b).

(iv) Global molecular networks (GMNs) in the brain (Agnati et al., 2006c, 2007), which postulates the existence of intracellular and extracellular three-dimensional molecular networks, built up mainly of proteins and carbohydrates, that interact at the plasma membrane to form GMNs pervading the entire central nervous system. It may contribute to the "binding phenomenon" and the glio-neuronal network morphology and function.

The major part of this review will deal with the Agnati and Fuxe proposal of the two complimentary modes of intercellular communication in the brain (concept (i) above). Volume transmission makes communication possible between all the cells of the brain via diffusion and flow of neurotransmitters, neuromodulators and trophic factors in the extracellular fluid (ECF) and cerebrospinal fluid (CSF), respectively, where they act as VT signals enabling information handling and trophic communication between all cells, including neuron-glia and glia-glia interactions. Criteria for VT features and experimental evidence for its existence and its functional implications will be provided, with VT becoming integrated with WT via receptor-receptor interactions which are based on the existence of heteromers and receptor mosaics located synaptically and extrasynaptically (see books edited by Fuxe and Agnati, 1991b; Agnati et al., 2000a). Also, the impact of G-protein-coupled receptor/receptor tyrosine kinase interactions as mediators of VT signaling in neuronal plasticity and trophism is introduced, and the critical role of receptor-receptor interactions as integrators of WT and VT is emphasized. A new hypothesis on the functional implications of receptor-receptor interactions at the level of electrical and mixed synapses is proposed, which could play a role in synchronization of entire brain areas. Hence, it could be involved in the so-called "binding phenomenon", which has been proposed to be the basic mechanism that allows the creation of a global workspace and eventually of conscious experience (see, e.g., Agnati et al., 2006a). This new perspective on information handling and trophism via WT and VT may have a great impact on neurophysiology, neuropathology and neuro-pschopharmacology.

\section{Discovery and characterization of the chemical neuroanatomy of neural circuits based on the Falck-Hillarp technique for the cellular localization of monoamines}

The great neurohistologists Camillo Golgi and Santiago Ramon y Cajal were the ones who discovered the neuronal circuits and provided the first neuronal maps of the nervous system by means of the Golgi technique and its modifications, involving a first step of an osmium-dichromate mixture followed by a second step of impregnation with a silver nitrate solution (see DeFelipe and Jones, 1992). For this truly fundamental work they received the Nobel Prize in 1906 with the 
A

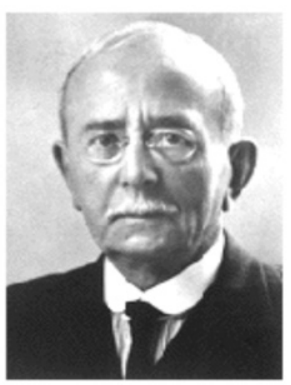

B
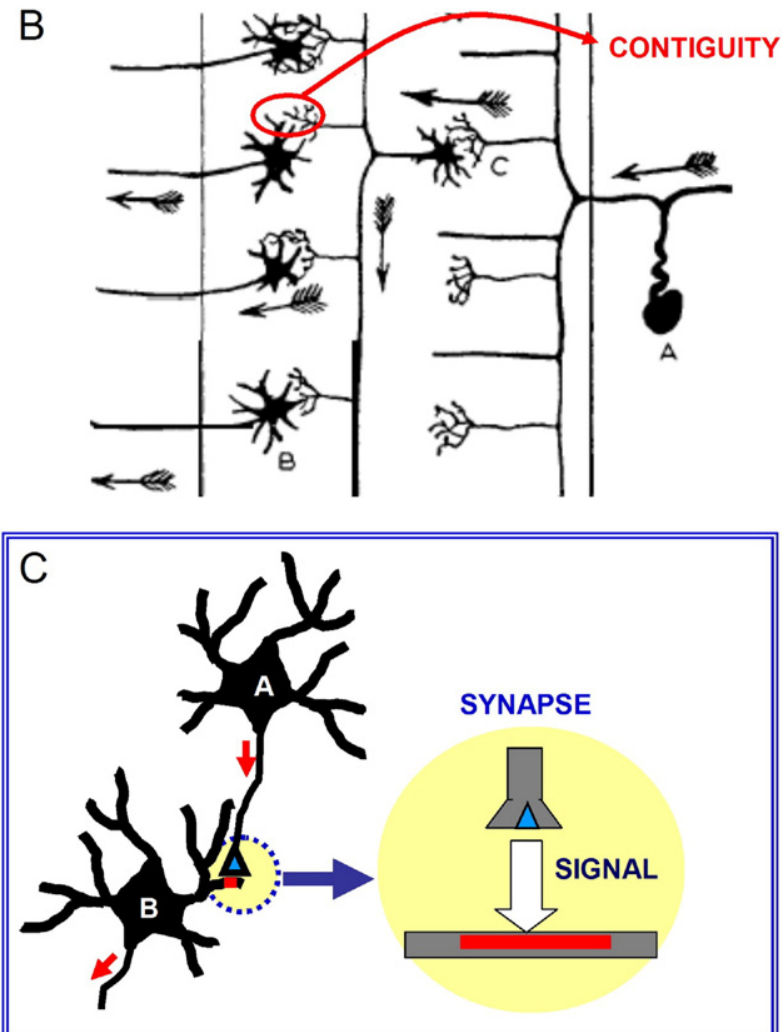

Fig. 1 - Illustration of the historical development of the concept of synaptic transmission. (A) Sherrington CS (1857-1952). (B) Cajal obtained indications that the relationship between neuronal processes was one of contiguity and not of continuity. (C) This nexus was called synapse by Sherrington in his book on the "Integrative Action of the Nervous System" in 1906: “... if at the nexus between neuron and neuron there does not exist actual confluence of the conductive part of one cell with the conductive part of the other, ... there must be a surface of separation... In view, therefore, of the probable importance physiologically of this mode of nexus between neuron and neuron it is convenient to have a term for it. The term introduced has been synapse...".

statement "In recognition of their work on the structure of the nervous system".

Another major breakthrough came with the discovery and mapping of the central monoamine neurons (Dahlström and Fuxe, 1964a,b, 1965; Fuxe, 1963, 1964, 1965a,b) based on the introduction of monoamine transmitter histochemistry, the so-called catecholamine (CA) and 5-hydroxytryptamine (5-HT) formaldehyde histofluorescence method of Falck and Hillarp (Falck et al., 1962; see Fuxe and Jonsson, 1973). With this technique, the hypothalamic noradrenaline (NA) nerve terminal networks had already been demonstrated in 1962 (Carlsson et al., 1962). The standardization of the histochemical formaldehyde reaction by Hamberger et al. (1965), including also the role of water, had a strong and persistent impact for the work in this field. The chemistry of this method was characterized early on by Falck, Hillarp, Corrodi, Jonsson and colleagues (see review by Fuxe et al., 1970b; Fuxe and Jonsson, 1973). The histochemical reaction between e.g., CA and formaldehyde involves a condensation of the amine with formaldehyde leading to the formation of a 1,2,3,4-dihydroisoquinoline, which is subsequently dehydrogenated to the corresponding 3,4-dihydroisoquinoline in a protein promoted reaction. This latter form is in equilibrium with its quinoidal form, which predominates and is responsible for the green fluorescence emission at $480 \mathrm{~nm}$ found in the brain sections upon excitation of this fluorophore.

2.1. The discovery and mapping of the central dopamine, noradrenaline and 5-hydroxytryptamine neurons

\subsubsection{Dopamine neurons}

2.1.1.1. The nigro-striatal dopamine pathway. A crucial observation was the existence of nerve cell bodies in the rat substantia nigra and especially in the zona compacta with a green cytoplasmatic CA fluorescence (Fig. 2, Dahlström and Fuxe, 1964a). By means of biochemical correlates and a pharmacological analysis, it was shown to represent a dopamine (DA) fluorescence and became known as the A9 DA cell group (Dahlström and Fuxe, 1964a). A large mass of diffuse to dotted green CA fluorescence was observed in the caudate putamen and shown to represent a DA fluorescence

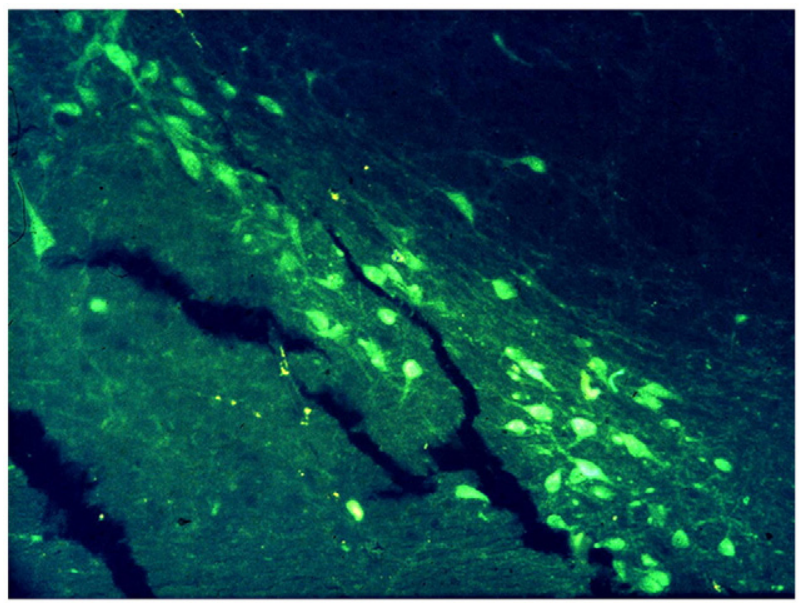

Fig. 2 - Dopaminergic nerve cells are seen with greenish CA fluorescence in their cell bodies and processes in the zona compacta of the substantia nigra (A9) of the rat, using the Falck-Hillarp formaldehyde fluorescence method for the cellular localization of monoamines. Dahlström and Fuxe (1964a,b), previously unpublished material. 
in densely packed nerve terminals (Andén et al., 1964b, Fuxe, 1965a,b). By means of the method developed by Dahlström and Fuxe (1964b) using lesions and striatal ablations, it became possible to visualize the ascending DA fiber bundles from the substantia nigra to the caudate putamen on the cell body side of the lesion (Andén et al., 1964b, 1965a,b). Here they became strongly green fluorescent as a result of the blockade of the transport of DA storage vesicles in the DA axons to the terminals, leading to their accumulation in the DA fiber bundles of the posterior medial forebrain bundle and the internal capsule. In this way, the existence of the nigro-striatal DA pathway was demonstrated, with the lesions also leading to a marked disappearance of the nigral DA cell bodies showing DA fluorescence. With this discovery, it became clear that the disappearance of the nigral DA stores in Parkinson's disease (Hornykiewicz, 1963) was likely caused by the degeneration of the nigro-striatal DA pathway in this disease. This view was further underlined by the work of Andén et al. (1966b) using mechanical lesions in the rat indicating a role of this pathway in motor function and by the elegant work of Ungerstedt $(1968,1971)$ using 6-OH-DA induced lesions of the ascending DA pathways.

Another important breakthrough came with the discovery of striatal islands of DA nerve terminal systems in 1972 with the Falck-Hillarp technique (Olson et al., 1972; Tennyson et al., 1972) showing for the first time the organization of the striatum into two compartments, the diffuse and islandic compartments. This work was elegantly pursued by Graybiel and her group (Graybiel and Ragsdale, 1978; Graybiel et al., 2000) and by Gerfen and his group (Gerfen, 1984, 2000) with the islands called striosomes (Graybiel's group) or patches (Gerfen's group) and the remainder called matrix. These groups established the input/output relationships of the striatal islands and the expression of a number of markers. The discovery of the limbic-prefrontal-striatal island circuitry indicated that the striatal islands participated in reward based motor learning (Eblen and Graybiel, 1995; Gerfen, 2000), while parallel work indicated that the matrix is involved in sensory-motor processing (Gerfen, 1993; Canales, 2005). A number of observations have indicated that the striatal islands play a crucial role in motor learning responsible for the development of L-dopa induced dyskinesias (Graybiel et al., 2000; Agnati et al., 2003b) and habit acquisition in drug addiction (Graybiel et al., 2000; Everitt and Robbins, 2005; Canales, 2005). The dopamine D4 receptors enriched in the striatal islands may have an especially important role among the D2-like receptors as to the function of the striatal islands (Rivera et al., 2002). For further aspects on nigro-striatal DA neurons and Parkinson's disease, see Fuxe et al. (2006).

2.1.1.2. The meso-limbic dopamine pathway. Large numbers of CA cell bodies with green CA fluorescence were also discovered in the ventral tegmental area with the pharmacological analysis using $\alpha$-methyl- $m$-tyrosine, indicating it to be a possible dopaminergic fluorescence (Dahlström and Fuxe, 1964a). A high density of DA nerve terminals was also demonstrated with the Falck-Hillarp technique in the nucleus accumbens and olfactory tubercle forming a large mass of diffuse to dotted DA fluorescence at these locations (Fuxe, 1965a,b). By means of lesions (e.g., between the cell body and terminal regions in the lateral hypothalamus involving the medial forebrain bundle), CA fluorescence histochemistry and biochemical DA and NA analysis, the existence of a DA pathway from the ventral tegmental area to the nucleus accumbens and the olfactory tubercle running in the medial forebrain bundle was discovered, called the meso-limbic DA pathway (Andén et al., 1965a,b, 1966a,c,d; Fuxe et al., 1970c; Ungerstedt, 1971). A dysfunction of this DA system was early on proposed to be involved in mental disorders like schizophrenia (see Fuxe et al., 1970c; Fuxe, 1970), in view of the demonstration that DA receptor antagonism may be the mechanism of action for classical antipsychotic drugs like chlorpromazine and haloperidol as first indicated by Carlsson and Lindquist in 1963 (see Carlsson, 1988). This work was further extended in combined functional and neurochemical experiments by Andén and colleagues (Andén et al., 1966b, 1970). Subsequently, the DA hypothesis of schizophrenia was strongly supported by the observations that all anti-schizophrenic drugs had the ability to bind and block D2/D3 receptors (Seeman et al., 1975; see Kapur and Mamo, 2003) and in the brains of schizophrenic patients D2 receptor occupancy is correlated to antipsychotic drug effects (Farde et al., 1988; Nordström et al., 1993). In the 1990s, indications for enhanced striatal DA responsitivity had been obtained in schizophrenic patients with PET imaging (see Laruelle et al., 1996, 2003). In 1980, the glutamate hypothesis of schizophrenia was introduced (Kim et al., 1980) and was supported by the observations that the drug phencyclidine promoted psychotic states and acted as a non-competitive NMDA receptor antagonist (see Jentsch and Roth, 1999; Svensson, 2000).

It is of particular interest that treatment with this type of drugs causes a rise of burst firing in the meso-limbic DA neurons as recorded from the A10 DA cells located in the ventral tegmental area (Murase et al., 1993), which is related to a reduction in the prefrontal glutamate input to GABA interneurons controlling the firing pattern of the VTA DA cells projecting to subcortical limbic regions (Carr and Sesack, 2000). Such results emphasize an important role of mesolimbic DA neuron hyperfunction in schizophrenia and blockade of D2-like receptors in the limbic subcortical system may in fact be the major target for known antipsychotic drugs. Of special importance are the inhibitory D2-like receptors on the ventral striato-pallidal GABA pathway, operating in a circuit which via the GABA projection from the ventral pallidum to the mediodorsal thalamic nucleus (Heimer, 2000) regulates the firing of the cortical glutamate projections from this nucleus. Thus, blockade of these D2-like receptors by antipsychotic drugs will increase the activity of these prefrontal glutamate projections and may help to cope with sensory overload which may contribute to the development of psychosis, as first discussed by Carlsson (1988). It should also be noted that a reduced prefrontal activity predicts enhanced striatal DA function in schizophrenia (Meyer-Lindenberg et al., 2002). In contrast, NMDA receptor antagonists reduce burst firing in the VTA DA cells projecting to the prefrontal cortex since they receive direct monosynaptic glutamate projections from the prefrontal cortex causing their excitation (Murase et al., 1993; Carr and Sesack, 2000). Thus, hypofrontality in schizophrenia may produce reduced function in the meso-cortical DA 
systems which may contribute to the negative symptoms of schizophrenia (Jentsch and Roth, 1999; Svensson, 2000).

The major role of the meso-limbic DA afferents in schizophrenia involving mainly D2/D3 receptor mediated effects in the ventral striatal complex, including the ventral pallidum, amygdala, extended amygdala and the septal area (Heimer, 2000), may be to regulate the emotional impact of the subcortical limbic networks on the cerebral cortex, especially the prefrontal cortex, involving the ventral striatum-ventral pallidum-mediodorsal thalamic nucleus circuit to the disturbed prefrontal cortex. In line with this view, parts of the meso-accumbens DA system represent a reward system able to also predict the time of future rewards (Schultz, 2002; Montague et al., 1996; Agnati et al., 2007; Guidolin et al., this special issue), mediating natural rewards like food and the hedonic effects of drugs of abuse like cocaine (Robinson and Berridge, 1993; see Hurd, 2006; Ivanov et al., 2006). However, it is clear that the meso-limbic DA neurons are activated also in response to negative reinforcement (Fuxe and Hanson, 1967; see Salamone et al., 1997). Thus, what matters is the salient nature of the reinforcer (Ungless, 2004). The molecular mechanisms that lead from acute rewarding effects of drugs like cocaine to drug addiction are still unclear. They may involve plastic changes in the receptor networks of the local circuits in the ventral striatum, with alterations in the D2 and D3 containing receptor mosaics (RM) and their receptorreceptor interactions and integrated signaling (RM; highorder heteromers or homomers), leading to changes in the gene expression including adapter proteins contributing to enduring changes in the DA RM, due to their stabilization by the adapter proteins formed (see Fuxe et al., 2007; Marcellino et al., 2007). As to genetic risk factors in DA receptor subtypes and evidence based dopaminergic treatments of substance abuse disorders, see Hurd (2006) and Ivanov et al. (2006), respectively.

2.1.1.3. The tubero-infundibular dopamine neurons. Already in 1963, a substantial number of small-sized nerve cell bodies with a weak to medium CA fluorescence were observed in the arcuate nucleus and the ventral part of the periventricular hypothalamic region (Fig. 3), as well as a strong mass of CA fluorescence in the external layer of the median eminence, probably representing densely packed CA nerve terminals as in the striatum with its dense DA innervations. These results indicated the existence of tubero-infundibular DA neurons, as also supported by the pharmacological analysis (Fuxe, 1963, 1964; Fuxe and Hökfelt, 1966; Löfström et al., 1976a). Biochemical correlates were subsequently obtained in collaboration with Wiesel et al. (1978) and also made it possible to develop a method to determine DA levels and turnover rate in discrete DA nerve terminal systems by quantitative use of the FalckHillarp DA fluorescence method (Agnati et al., 1979; Andersson et al., 1985b). Histofluorimetric quantitation of CA fluorescence in the median eminence was first made in 1976 (Löfström et al., 1976a,b), demonstrating it as a reliable method for CA quantitation in discrete terminal systems in this region. These methods have played an important role in the characterization of the changes in DA turnover using the tyrosine hydroxylase inhibition method in the nerve terminals of the medial and lateral palisade zone (MPZ and LPZ) of

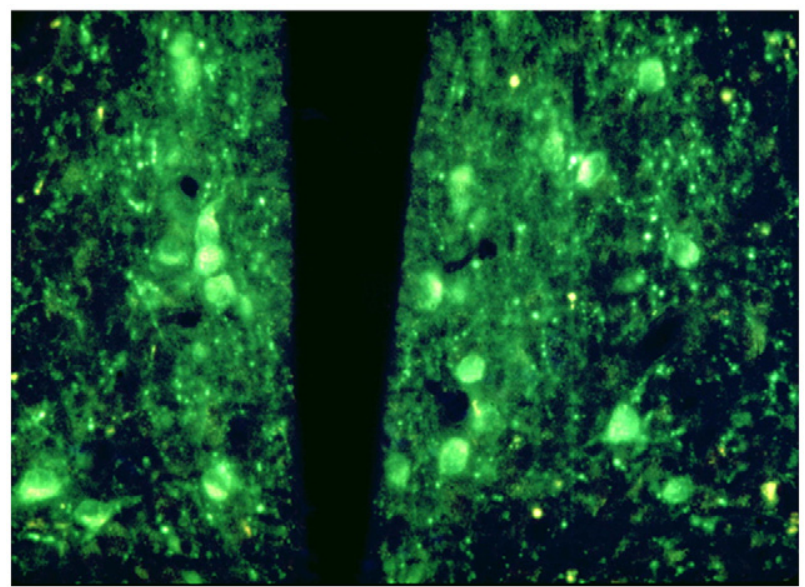

Fig. 3 - Dopaminergic nerve cells are seen with greenish CA fluorescence in the cell bodies in the arcuate nucleus (A12) and the most ventral part of the periventricular hypothalamic region close to the third ventricle (in the center) just dorsal to the median eminence of the rat. The DA cell bodies lie in a nerve terminal plexus of medium density with varicosities appearing as puncta with strong greenish CA fluorescence. Falck-Hillarp technique from Dahlström and Fuxe in the early 1960s previously unpublished material.

the external layer of the median eminence, in various hormonal states including tonic and phasic hypersecretion of LHRH. They have amplified the results of the early work using semiquantitation and pharmacological analysis and underline an inhibitory role of LPZ DA nerve terminals in LHRH release and suggest that MPZ DA nerve terminals release DA as a prolactin inhibitory factor (PIF) into the hypophyseal portal vessels (for reviews, see Fuxe et al., 1978, 1980a,c, 1985).

DA receptors were subsequently identified in the anterior pituitary and were shown to inhibit prolactin secretion (MacLeod and Lehmeyer, 1974). DA were also demonstrated in the portal vessels (Ben-Jonathan et al., 1977) and in the hypophysectomized rat, where prolactin produced a rapid and discrete increase of DA turnover in the MPZ (Andersson et al., 1981). The involvement of the MPZ DA nerve terminals as a PIF system was first indicated in the analysis of the nicotineinduced inhibition of prolactin secretion (Fuxe et al., 1977a). All these observations have established DA as a PIF, which at least in the rat appears to be released from the DA nerve terminals of the MPZ, which in agreement have the highest DA turnover of all DA terminals so far analyzed (Andersson et al., 1985b). This research, showing DA to be a neurohormone, had a substantial impact also on understanding the mode of DA communication in the brain. It strengthened the idea that DA may not only operate in synaptic signaling, but also via diffusion in the extracellular fluid and thus via VT (Agnati et al., 1986a; see Agnati et al., this issue and below). Similar conclusions also arose when discovering prolactin-like IR nerve terminals in the hypothalamus and other parts of the brain (Fuxe et al., 1977b; Paut-Pagano et al., 1993), indicating that prolactin may not only be a hormone but also a transmitter in the brain that may operate via diffusion in the 
extracellular fluid and represent a VT signal (Agnati et al., 1986a; see Agnati et al., this issue and below).

The above neuroendocrine work has emphasized the importance of special types of local circuits in the external layer of the median eminence in understanding the regulation of hypothalamic hormone release, like the DA regulation of LHRH release in the LPZ (Fuxe et al., 1980a, 1985; Andersson et al., 1984). The concept of the existence of "medianosomes" was introduced, present in the external layer as functional modules built up of domains of different types of nerve terminals centered around a hypothalamic hormone-containing nerve terminal, like the LHRH nerve terminal, and controlling its release. Medianosomes were postulated to be the fundamental integrative units in the LPZ and MPZ, where the brain-borne and blood-borne signals became integrated with neuronal signals via transmitter receptors and hormonal receptors like hypothalamic and hypophyseal hormone receptors in the plasma membranes of the participating terminals. In view of the existence of different types of transmitter and hormonal receptors in the various medianosomes, their individual regulation could be obtained leading to an integrated signal capable of releasing the various hypothalamic hormones according to the needs of the organism. Another important component of the medianosomes is the tanycytes, which may help in the structural organization of the medianosomes and also in their regulation by having transmitter and hormone receptors and releasing modulators to fine-tune the information handling in these special types of local circuits (Bjelke and Fuxe, 1993).

In fact, local circuits in the external layer (medianosomes) are unique in having no synapses and only communicate via VT signaling, and therefore the term medianosome is more appropriate. Thus, here all the plasma membrane receptors are extrasynaptic and are reached by transmitters and hormones diffusing in the extracellular space around the terminals and tanycytes. Via diffusion of transmitters and hypothalamic hormones from one type of medianosome to an adjacent one, different types of medianosomal cross-talk develop and can assist in causing a coordinated secretion of hypothalamic hormones. DA terminals appear to participate in several types of medianosomes like the LHRH (Andersson et al., 1984; Fuxe et al., 1980a, 1985), TRH (Andersson et al., 1985a), somatostatin (Andersson et al., 1983) and PIF medianosomes, and in the PIF medianosome they represent the "hub" (crucial) terminal releasing DA as a PIF. The modulatory role of DA in the median eminence is also supported by the existence of D1 receptors in this region (Fuxe et al., 1983b) and by the demonstration of DARPP-32 IR in the tanycytes (Ouimet et al., 1984). It is of substantial interest that LHRH in the hypophysectomized rat can produce a rapid increase of DA turnover in the LPZ DA terminals, indicating that diffusing LHRH in its medianosome can exert an ultrashort feedback on its own secretion by increasing DA release from the DA terminals of the LHRH medianosome via activation of LHRH receptors (Andersson et al., 1984). This early work is of fundamental interest and indicated that in the local circuits of the brain both wiring and volume transmission participate in information handling (see below). The clinical impact of dysfunction of the tubero-infundibular DA neurons projecting to the MPZ releasing DA as a PIF is clear. A deficit in this DA transmission leads to hyperprolactinemia leading to inhibition of LHRH and of ovulation. This mechanism may involve prolactin-induced activation of DA release in the LPZ from the DA nerve terminals within the LHRH medianosomes (for a review, see Fuxe et al., 1980a, 1985).

\subsubsection{Noradrenaline neurons}

2.1.2.1. The locus coeruleus noradrenaline system. The locus coeruleus was shown to be built up of CA cell bodies in 1964 (Dahlström and Fuxe, 1964a,b), showing a medium to strong greenish-yellowish CA fluorescence in the cytoplasm mainly concentrated to perinuclear rings (Fig. 4). The relative slow recovery of amine fluorescence after $\alpha$-methyl- $m$-tyrosine treatment in the locus coeruleus (group A6) versus the mesencephalic and arcuate DA cells made it possible that the CA fluorescence represented an NA fluorescence. Lesions in the lateral hypothalamus within the medial forebrain bundle and in the caudal tegmentum of the midbrain, in combination with CA histochemical fluorescence and DA and NA biochemical analysis, provided evidence of the disappearance of NA but not of DA stores and of extrastriatal CA nerve terminals in the tel- and diencephalon (Fuxe, 1965a,b), correlated with retrograde changes in the $\mathrm{A} 6$ cells, initially characterized also by increases in CA fluorescence (Andén et al., 1966a,b). These results indicated that the locus coeruleus was built up of NA cells, subsequently confirmed with dopamine- $\beta$-hydroxylase immunocytochemistry (Fuxe et al., 1970a) and gave rise to ascending NA pathways which could be elegantly visualized caudal to lesions in the medial forebrain bundle and the tegmentum as swollen strongly green fluorescent CA axons that could be traced towards the locus coeruleus as a dorsal

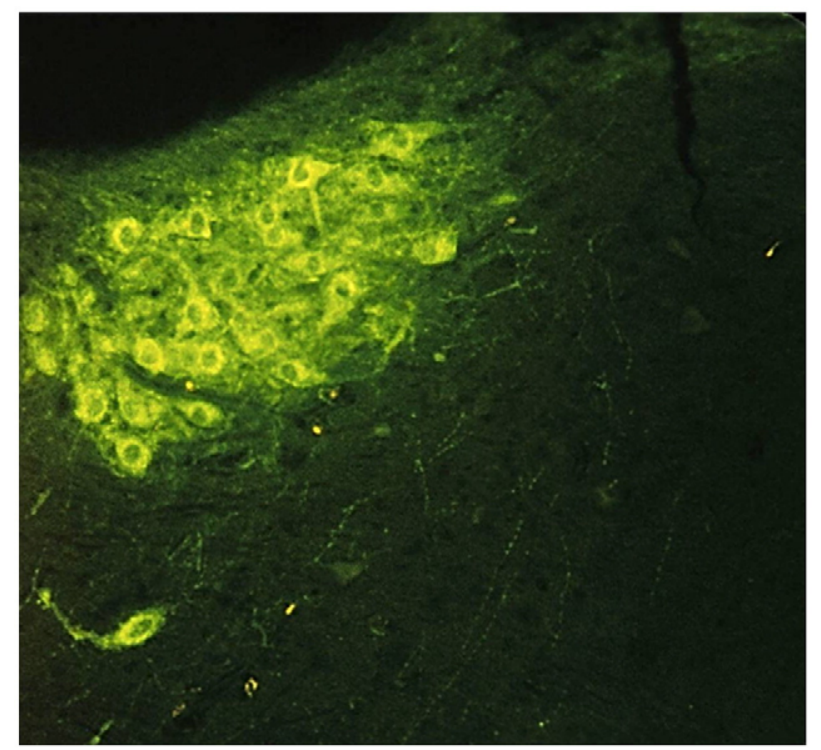

Fig. 4 - A cluster of noradrenergic nerve cells are seen with greenish cytoplasmic CA fluorescence in their cell bodies and processes with perinuclear rings of strong CA fluorescence in the locus coeruleus of the rat. Falck-Hillarp technique. Dahlström and Fuxe, 1964a,b, previously unpublished material. 
NA bundle (see Fuxe et al., 1970c; Ungerstedt, 1971). Thus, the A6 NA cell group via long ascending NA axons appeared to monosynaptically give rise to large numbers of extrastriatal fine varicose NA terminals in the tel- and diencephalon.

Of special interest were the findings of Andén et al. (1966d), who demonstrated that after large lesions in the border between di- and mesencephalon, increased CA fluorescence appeared in large number of CA nerve terminal networks in the lower brain stem, in the cerebellar cortex and even in the spinal cord. These terminals probably represented collateral NA nerve terminals given off from the ascending NA axons caudal to the lesion, and showing increased NA levels due to rerouting of the flow of NA storage vesicles into the collaterals. These results opened up the possibility that NA cells with ascending projections in the pons and medulla oblongata could give rise to a large number of collaterals and also to descending projections to the spinal cord and projections to the cerebellum. At this moment of time, at least some NA neurons in the pons and medulla oblongata represented a novel type of neuron that could monosynaptically and globally innervate the entire CNS from the spinal cord to the forebrain. In 1971-72, the evidence emerged that locus coeruleus NA neurons were indeed giving rise to nerve terminal networks in the entire cerebral and cerebellar cortex and participated in the innervation of many subcortical and brain stem regions (Ungerstedt, 1971; Olson and Fuxe, 1971; Maeda and Shimizu, 1972; Lindvall and Björklund, 1974). Furthermore, in 1977 it was shown that locus coeruleus gave rise also to large NA projections to the spinal cord innervating the ventral and dorsal horns (Nygren and Olson, 1977). Thus, NA neurons of the locus coeruleus appear not only to be involved in coordinating cortical activities to promote tonic arousal (Jouvet, 1972; Lidbrink and Fuxe, 1973; Fuxe and Lidbrink, 1973), but also to link such cortical activities to reflex activities in the spinal cord to improve their performance in states of arousal.

The role of the locus coeruleus NA neurons in arousal was further clarified by Aston-Jones and Bloom (1981a,b), linking high firing of these neurons to waking with a reduction of activity in slow wave sleep and absence of activity in paradoxical sleep. Relevant sensory stimuli cause their phasic activation in the awake state. Recently, evidence has been obtained that the phasic mode of LC activation helps in optimizing task performance by assisting in the development of focused attention, the phasic firing being driven by the outcome of decision making (Aston-Jones and Cohen, 2005a,b; Aston-Jones, 2005). It is of substantial interest that the maintenance of LC NA neuron firing and of tonic arousal is dependent on light exposure, thus contributing to a circadian regulation of arousal (Gonzalez and Aston-Jones, 2006; AstonJones, 2005). The circuit involved in this mechanism runs from the suprachiasmatic nucleus via the dorsomedial hypothalamic nucleus (DMH) to the LC, with hypocretin cells in the DMH giving an excitatory input to the LC.

2.1.2.2. The non-locus coeruleus noradrenaline systems. These systems originate from the remaining NA cell groups in the medulla oblongata (groups A1 and A2) and pons (A4A5, A7 and subcoeruleus area; Dahlström and Fuxe, 1964a,b). They give rise to ascending and descending projections to the tel- and diencephalon (Andén et al., 1965b, 1966a,b; Unger- stedt, 1971) and the spinal cord, respectively (Dahlström and Fuxe, 1965; Nygren and Olson, 1977) as shown in lesion experiments in combination with the Falck-Hillarp technique. The ascending NA fibers formed a ventral NA bundle mainly distinct from the dorsal NA bundle in the tegmentum (Fuxe et al., 1970c; Ungerstedt, 1971) consisting of two components, the subcoeruleus and the medulla oblongata (including ventral pons) NA fiber bundles (Maeda and Shimizu, 1972; Olson and Fuxe, 1972), giving rise to fairly thick NA nerve terminal plexa with large and strongly fluorescent varicosities in the hypothalamus, the preoptic area, the extended amygdala and other parts of the subcortical limbic system (Carlsson et al., 1962; Fuxe, 1965a,b; Ungerstedt, 1971; Olson and Fuxe, 1972).

The bulbo-spinal NA fibers (Dahlström and Fuxe, 1965) from these NA cell groups mainly give rise to the NA innervations of the sympathetic lateral column and of the dorsal part of the dorsal horn (Nygren and Olson, 1977), with the preganglionic sympathetic neurons surrounded by densely packed nerve terminals with large varicosities of an intense green fluorescence. A large number of observations are compatible with the view that many of these non-LC cells may give rise to both ascending and descending NA axons, which via collaterals may innervate also brain stem nuclei like the nucleus tractus solitarius, an important visceral center in the dorsal medulla oblongata (Fuxe, 1965a,b). Thus, these types of NA neurons may be important coordinators of autonomic and neuroendocrine functions in central autonomic networks at the hypothalamic-limbic, lower brainstem and spinal cord level (Olson and Fuxe, 1972). One interesting cross-talk between the LC and non-LC NA neuron systems at the network level can occur in the $\mathrm{DMH}$ which is richly innervated by non-LC NA terminals. At this level, the non-LC NA system can modify the light-activated pathway which relays in this nucleus on its way to the LC, where it increases its firing (see above). Thus, non-LC NA systems controlling visceral and neuroendocrine function can via this cross-talk also modify the alertness and attention via an indirect influence on the LC NA neurons, linking autonomic activities to arousal and cognitive performance. In addition, dysfunction of the LC and non-LC NA neuron systems has been suggested to contribute to stress and attention deficit hyperactivity disorders (ADHD) (Oades et al., 2005), where disturbances in the meso-limbic-cortical DA neurons also have been considered as a major mechanism (Forssberg et al., 2006). Nicotine has been proposed to be a possible treatment of ADHD since it enhances CA release from these two NA and DA systems (Granon and Changeux, 2006).

\subsubsection{5-Hydroxytryptamine neurons}

The fluorophore formed by the condensation of 5-HT with formaldehyde with the Falck-Hillarp technique gave upon excitation rise to a yellowish fluorescence with the filters used with an emission peak at $530 \mathrm{~nm}$ (Falck et al., 1962, for a review, see Fuxe et al., 1970b). It was again a two-step reaction with a ring closure leading to the formation of a $\beta$-carboline followed by a secondary dihydrogenation. However, in spite of improvements of the Falck-Hillarp technique for the cellular demonstration of 5-HT (Fuxe and Jonsson, 1967) it never reached the sensitivity of the cellular demonstration of CA. 
In 1964, Dahlström and Fuxe discovered the 5-HT nerve cell bodies in the brain with their ascending and descending axons to the tel- and diencephalon and the spinal cord, respectively. The 5-HT cell bodies were located in the raphe systems of the lower brainstem, and some were also located in a para-raphe position. Microspectrofluorimetry further established that the vast majority of these nerve cells contained 5-HT (Jonsson et al., 1975). The largest collection of yellow fluorescent 5-HT nerve cells was found in the dorsal raphe of the midbrain, where also several subgroups were identified (Fig. 5). The visualization of the 5-HT nerve cells and their axons was markedly enhanced by monoamine oxidase inhibition which allowed to trace e.g., the ascending 5-HT tracts for long distances rostrally along the medial forebrain bundle and how they turned dorsally in front of the septal area to sweep back along the dorsal surface of the external capsule together with the NA axons running especially in the cingulum (Fig. 5) (Dahlström and Fuxe, 1964a; Andén et al., 1965a,b, 1966a,b).

Fairly large numbers of varicose yellow fluorescent 5-HT nerve terminal networks were observed in the lower brainstem (Fuxe, 1965b) and especially in the spinal cord (Carlsson et al., 1964; Fuxe, 1965b; Dahlström and Fuxe, 1965). In contrast, in the tel- and diencephalon only some nuclei contained considerable numbers of fine 5-HT nerve terminal systems, like the suprachiasmatic nucleus (Fuxe, 1965b), while only scattered and very fine 5-HT terminals were found in the cortical regions, probably due to the relative insensitivity of the Falck-Hillarp 5-HT fluorescence technique. It was only with the introduction of the 5-HT immunofluorescence technique (Steinbusch et al., 1978) that it became possible to study the 5-HT nerve terminal networks in considerable detail, and this was especially true for the tel- and diencephalon

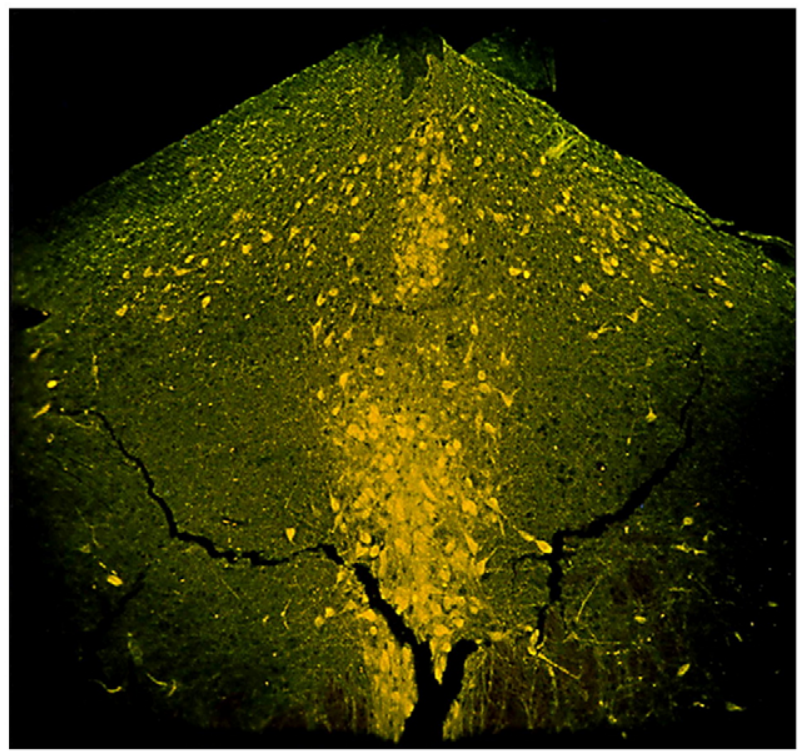

Fig. 5 - Several clusters of serotonergic nerve cells are seen with strong yellowish 5-HT fluorescence in the cell bodies and processes in the dorsal raphe region (B7) of the rat after monamine oxidase inhibition with nialamide. Three B7 subgroups are seen. Falck-Hillarp technique. Dahlström and Fuxe, 1964a,b, previously unpublished material.
(Steinbusch, 1981; Steinbusch et al., 1981; Steinbusch and Nieuwenhuys, 1981). 5-HT nerve terminal networks in various densities and patterns were present in practically all parts of the brain and the spinal cord, as had previously been found for the NA nerve terminal networks, underlining their global innervation of the CNS. For an excellent review, see Jacobs and Azmitia (1992).

2.1.3.1. The ascending 5-HT pathways. By means of electrical and indolamine neurotoxin (5,6- and 5,7-dihydroxytryptamine) induced lesions, in combination with the 5-HT histofluorescence method and biochemical techniques with measurements of 5-HT levels, it became possible to show that the mesencephalic 5-HT cell groups and associated cell groups in the pons, via large numbers of monosynaptic projections mainly traveling in known fiber bundles like the medial forebrain bundle, gave rise to the 5-HT innervation of the tel- and diencephalon including the cerebral cortex (Andén et al., 1965b, 1966a,b; Daly et al., 1973, 1974; see Fuxe and Jonsson, 1974). The ascending NA and 5-HT axons from the pons and medulla oblongata were using similar fiber routes to monosynatically and globally but in distinct patterns innervate the tel- and diencephalon (Fig. 6). The 5-HT cell groups involved were group B7 in the dorsal raphe and its caudal extension into the pons, group B6 (caudal dorsal raphe), group B8 in the area of the median raphe and the caudal linear nucleus and its caudal extension into the pons, reaching group B5 (area of nucleus raphe pontis). The minor $\mathrm{B} 9$ cell group located in a more ventral and rostral position mainly located in the supralemniscal nucleus was also involved in providing ascending 5-HT axons.

A major observation was made in 1975 with the demonstration that the majority of the serotonin nerve terminals in the adult rat cortex lacked junctional complexes and thus were asynaptic (Descarries et al., 1975), and it was suggested that 5-HT can be liberated from all varicosities. This interpretation was in line with prior results showing that electrical stimulation of the amygdala leads to reduction of amine fluorescence in varicosities of brain CA nerve terminals (Fuxe and Gunne, 1964) due to their excessive release with insufficient resynthesis and reuptake. Likewise, electrical stimulation in the medulla oblongata leads to reduction of CA and 5HT fluorescence in varicosities of NA and 5-HT nerve terminal networks of the spinal cord (Dahlström et al., 1965). Also, in the autonomic ground plexus of the iris lacking junctional complexes, electrical stimulation causes disappearance of amine fluorescence from practically all varicosities (Malmfors, 1965). Such observations gave experimental support to the introduction by Agnati and Fuxe and colleagues of the concept of two modes of communication in the CNS, wiring and volume transmission (Agnati et al., 1986a; see Fuxe et al., 1988a,b,c).

2.1.3.2. The bulbo-spinal 5-HT pathways. In 1965, the bulbospinal 5-HT neurons (Dahlström and Fuxe, 1965) were demonstrated which gave rise to the rich $5-\mathrm{HT}$ terminal spinal networks built up of varicosities, showing a yellow fluorescence with the Falck-Hillarp technique and found especially in the ventral and lateral horns (Carlsson et al., 1964; Fuxe, 1965b). Using various types of spinal cord transections in combination 


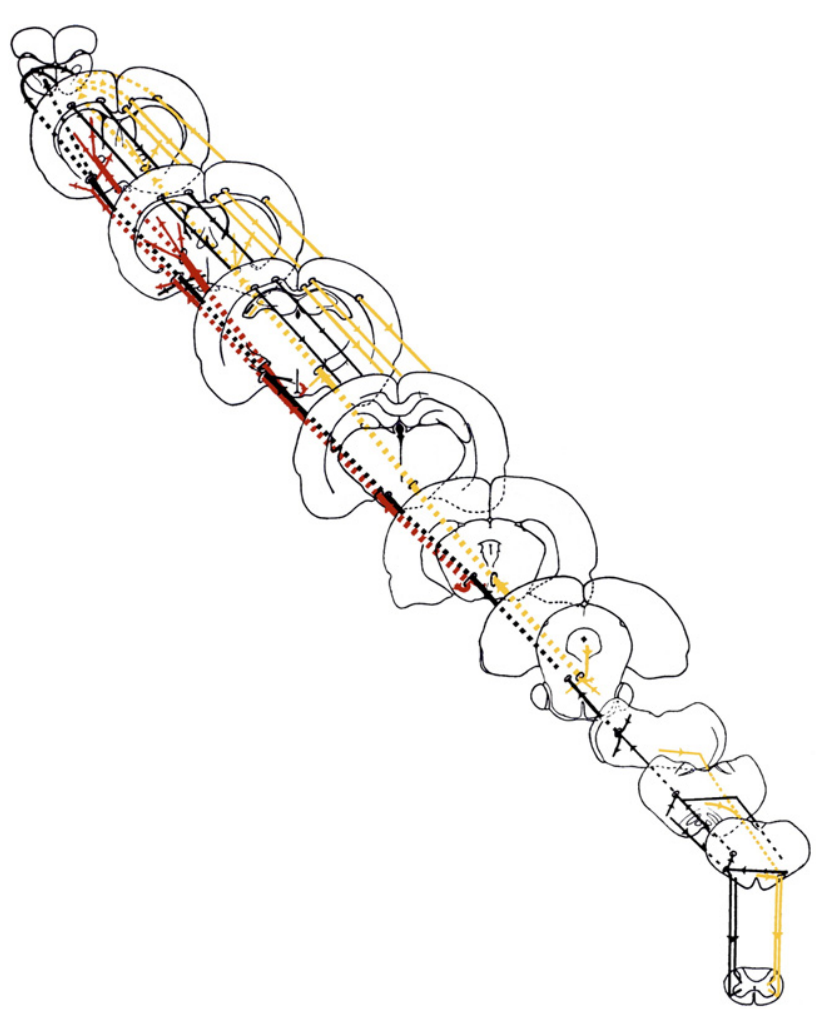

Fig. 6 - Original schematic description of the DA, NA and 5-HT pathways from 1965. It was prepared by Dahlström and Fuxe in the spring of 1965 and presented by them at the Second International Catecholamine Symposium in Milan, July 4-9, 1965. It was mainly based on papers by Dahlström and Fuxe (1964a,b, 1965), Fuxe (1963, 1964, 1965a,b), Andén et al. (1964a,b, 1965a,b, 1966a,b). The long ascending and descending monosynaptic projections from the lower brainstem to the tel- and diencephalon and the spinal cord, respectively, are illustrated as red: DA pathways; green: NA pathways; yellow: 5-HT pathways.

with Falck-Hillarp 5-HT fluorescence histochemistry and monoamine oxidase inhibition, the 5-HT cell groups B1 and B2 in the area of the nucleus raphe pallidus and of the nucleus raphe obscurus, respectively, together with the large 5-HT cell group B3 in the area of the nucleus raphe magnus and adjacent ventrolateral reticular formation were shown to give rise to large numbers of descending 5-HT axons. They traveled all the way down to the sacral cord in the lateral and anterior funiculi, sending off collaterals to the dorsal, lateral and ventral horns of the cervical, thoracic, lumbar and sacral cord.

In 1964, Andén et al. (1964a,b) had obtained evidence that the spinal 5-HT terminals participated in the modulation of spinal cord reflexes with liberation of $5-\mathrm{HT}$, causing a marked enhancement of extensor reflex activity. This model proved of substantial interest since it made it possible to discover in 1968 that hallucinogens of the indolalkylamine type like d-LSD can act as postjunctional 5-HT receptor agonists at certain 5HT receptor subtypes in the forebrain, which may substantially contribute to their hallucinogenic properties (Andén et al., 1968, 1971; Fuxe et al., 1976). These observations, together with demonstrations of reductions of $5-\mathrm{HT}$ turnover by the hallucinogens, led to the discovery of the molecular mechanism of action of d-LSD and related hallucinogens. In addition, recent work using single unit responses of 5-HT medullary raphe neurons has shown that the descending bulbo-spinal 5HT neurons are primarily involved in motor control (MartinCora et al., 2005).

\section{The 5-HT raphe-forebrain neuron systems and depression}

In 1967, it was possible to demonstrate with the Falck-Hillarp technique the existence of a plasma membrane uptakeconcentration mechanism for 5-HT in the 5-HT neurons with intraventricular injections of 5-HT (Fuxe and Ungerstedt, 1967, 1968). The next year, it was shown by the Carlsson-FuxeUngerstedt teams that the classical antidepressant drug imipramine could block this uptake mechanism (Carlsson et al., 1968). The same was shown to be true also for other antidepressants (Carlsson et al., 1969a,b). Overall, two groups of antidepressants could be distinguished, one which preferentially blocked the 5-HT uptake mechanism and one which preferentially blocked the NA uptake mechanism. This discovery led to the development of new antidepressants based on their selective ability to block the 5-HT uptake mechanism, the so-called selective serotonin reuptake inhibitors (SSRI) that introduced a new era in antidepressant therapy with the success of fluoxetine. These novel antidepressants produce a therapeutic action with chronic drug administration, probably when the inhibitory 5-HT1A autoreceptors in the raphe cell bodies have become desensitized with a restoration of their firing rate, by enhancing 5 -HT neurotransmission in the limbic and prefrontal 5-HT terminal networks. These results indicated a dysfunction of the ascending 5-HT neuron systems to the forebrain in depressive disorders, with antidepressants increasing the transmission and restoring function of these 5HT neurons resulting in mood elevation and rescue from depression. For further historical aspects, see (Fuxe and Agnati (2006). In view of the sleep disturbances present in depression, it should be noted that, in this period, the global 5-HT innervation was shown to also play a role in the maintenance of slow wave sleep 2 (Jouvet, 1972) which was subsequently supported in work on sleep using selective lesions of the ascending 5-HT pathways with the neurotoxin 5,7-dihydroxytryptamine (Kiianmaa and Fuxe, 1977).

The uptake-concentration mechanism for 5-HT, as previously found for $\mathrm{CA}$, is present in the plasma membrane of the entire neuron including cell bodies, dendrites, axons and nerve terminals, as shown with the Falck-Hillarp technique, leading to probable increases in extracellular 5-HT after 5-HT uptake blockade by antidepressants close to all parts of the 5-HT neuron (Carlsson et al., 1968). These observations opened up the possibility that monoamines may operate also via diffusion in the ECS and not only via synapses, as subsequently also strongly indicated in the work of Descarries et al. (1975). Using the Falck-Hillarp technique, microinjections of monoamines or application of monoamine substance into the caudate putamen demonstrated a spread of monoamines in the striatum, with the development of concentration gradients from the site of injection (Routtenberg et al., 1968; Ungerstedt 
et al., 1969). These results again indicated that monoamines can in fact diffuse in the brain tissue. Taken together, this early work gave experimental support to the theory of Agnati and Fuxe and colleagues in 1986 that there exists another mode of communication in the brain besides wiring transmission, namely volume transmission (see below).

Today, neurobiological basic research as well as clinical studies have further established that the 5-HT and also the NA neuron systems are involved in the etiology and therapy of affective disorders (see Charney, 1998). Thus, the current pharmacotherapy is based on the discovery of the enhancement of serotonergic and/or noradrenergic neurotransmission by either inhibiting the intracellular degradation of the monoamines with monoamine oxidase inhibitors or blocking their reuptake back into the 5-HT and/or NA nerve terminal by selective serotonin/norepinephrine reuptake inhibitors, or tricyclic antidepressants (see Fuxe et al., 1983d; Duman et al., 1997; Skolnick, 1999; Nestler et al., 2002; Manji et al., 2001; Nemeroff, 1998), that in turn lead to an increase of extracellular monoamines (Iversen, 2000; Taylor et al., 2005; Schloss and Henn, 2004).

The therapeutic action of antidepressant drugs is of proven effectiveness, but the mechanisms underlying their effect are still unclear. It is known that, although biochemical changes produced by antidepressant drugs occur within hours of administration, therapeutic effects become evident only after a latency of about 2-3 weeks, suggesting that adaptive processes induced via activation of patterns of 5-HT and NA receptor subtypes, including the regulation of specific genes, are necessary for the long-term effects of these drugs (Coyle and Duman, 2003; Nestler et al., 2002). Therefore, after the previously dominating interest in the effects of antidepressants on extracellular neurotransmitter levels in the brain, the focus of research into antidepressant drug action has over recent years shifted towards their gradually developing effects on intraneuronal signal transduction and cellular plasticity (Manji et al., 2001; Coyle and Duman, 2003). Several data suggest that antidepressants facilitate activity-dependent selection of functional synaptic connections in the brain, and through their neurotrophic effects improve information processing within neuronal networks compromised in mood disorders (D'Sa and Duman, 2002). According to a current view, antidepressants induce processes of neuroplasticity that lead to a reorganization of central neural networks thus and thereby generating their therapeutic effects (Kempermann and Kronenberg, 2003; Nestler et al., 2002; Duman, 2002).

\subsection{Neurotrophic factors}

Increasing evidence suggests that antidepressant drugs via actions on the 5-HT and NA neurons may exert their therapeutic activity, at least in part, through the enhancement of neurotrophic factor expression and function (Nibuya et al., 1995; Saarelainen et al., 2003; Duman, 2002). In this context, several lines of converging evidence suggest that brain derived neurotrophic factor (BDNF) and its receptor tyrosine kinase trkB play a central role in the mechanism of antidepressant action, including electroconvulsive shock treatment (Nestler et al., 2002; D'Sa and Duman, 2002; Saarelainen et al., 2003; Shirayama et al., 2002). Recently, an involvement of the fibroblast growth factors (FGFs) has been proposed in mood disorders (Turner et al., 2006). Antidepressant drugs and chronic electroconvulsive shock treatment may increase the expression of fibroblast growth factor-2 (FGF-2) in frontal cortices and hippocampus (Mallei et al., 2002; Maragnoli et al., 2004), suggesting that potentially also the FGF-2 expression could mediate the antidepressant effects, in line with these results chronic antidepressant treatment increases neurogenesis in adult rat hippocampus (Duman et al., 2001) and recently evidence has been provided that increased neurogenesis might play a role in the mechanism of antidepressant drug action (Santarelli et al., 2003). Depression is associated with reduced cortical thickness and neuronal size (Rajkowska et al., 1999) and may even be caused by cortical neuronal atrophy with the accompanying loss of neuronal communication in prefrontal cortex.

\subsection{Intramembrane receptor-receptor interactions among GPCRs}

5-HT and NA receptor subtypes may not modulate neurotrophism alone, but may do so by being part of heteromeric receptor complexes (receptor mosaics) with other GPCRs. Within the early 1980s, indications were obtained for the existence of intramembrane receptor-receptor interactions among GPCRs (Agnati et al., 1980, 1983; Fuxe et al., 1981, 1983c). Of special interest for depression was the discovery of reciprocal galanin receptor galR/5-HT1A receptor-receptor interactions in the plasma membranes of ascending 5-HT neuron systems (Fuxe et al., 1988c, 1991; see Hedlund and Fuxe, 1996). This research, using also animal models of depression (Bellido et al., 2002), led to the proposal that galanin receptor antagonists represent novel antidepressant drugs by increasing 5-HT neurotransmission by actions at the cell body/dendritic level, leading to increased firing of the 5-HT neurons and by enhancing postjunctional 5-HT1A mediated signaling in the limbic system by blockade of the antagonistic galR/5-HT1A receptor interactions in postulated galR/5-HT1A heteromers (Fuxe et al., 2007).

\subsection{Transactivation of receptor tyrosine kinases following G-protein-coupled receptor (GPCR) activation via GPCR/RTK receptor interactions}

Receptor tyrosine kinases are a family of membrane-spanning receptors in mammals that mediate the transmembrane signaling from ligands that include the majority of growth factor receptors, such as platelet-derived growth factor (PDGF), epidermal growth factor (EGF), neurotrophins (e.g., BDNF) and FGFs (Hubbard, 2004). In each case, dimerization and tyrosine phosphorylation of receptor tyrosine kinases occur, and this phosphorylation serves as docking sites of adaptor proteins that lead to the activation of intracellular signaling pathways (Luttrell et al., 1997; Hackel et al., 1999) such as Ras-mitogenactivated protein kinase (MAPK) cascade (Patapoutian and Reichardt, 2001).

There is a new awareness that receptor tyrosine kinase (RTK) and G-protein-coupled receptor (GPCR) possess the capacity for transactivation not only via GPCR induced release of neurotrophic factors, but also during signal initiation and 
propagation, using shared signaling pathways or for GPCRs using receptor tyrosine kinase themselves as signaling platforms via direct receptor-receptor interactions (Fig. 7). Thus, over the past decade many examples of transactivation of mitogenic growth factor receptors in response to GPCR signaling have recently been reported indicating that there are alternative modes of activating receptor tyrosine kinases in the absence of neurotrophic factor binding at the cell surface (Luttrell et al., 1999; Marinissen and Gutkind, 2001; Lee et al., 2002a,b; Luttrell, 2002; Lowes et al., 2002).

The receptors for epidermal growth factor, platelet-derived growth factor, insulin-like growth factor-1, FGFs and neurotrophins can thus be transactivated in response to GPCR activation in the absence of neurotrophic factor binding at the cell surface via direct (heteromeric receptor complexes) and/or indirect GPCR/RTK receptor interactions (Kang and Schuman, 1995; Luttrell et al., 1999; Lee and Chao, 2001; Lee et al., 2002a,b; Kotecha et al., 2002; Ferguson, 2003; Rauch et al., 2004; Shah and Catt, 2004; Rajagopal et al., 2004; Berghuis et al., 2005). This RTK transactivation via GPCR-RTK receptor interactions (Fig. 7) can lead to effects on cell proliferation, differentiation and synaptic plasticity and may play crucial roles in the induction of enduring change in the nervous system trophism via VT signals operating through GPCR.

Thus, there appears to exist a general mechanism of receptor-receptor interactions between these two receptor systems, but the molecular mechanisms by which a GPCR may directly and indirectly interact with and activate receptor

\section{GPCR TRANSACTIVATION OF TRK WITHOUT NTF BINDING}

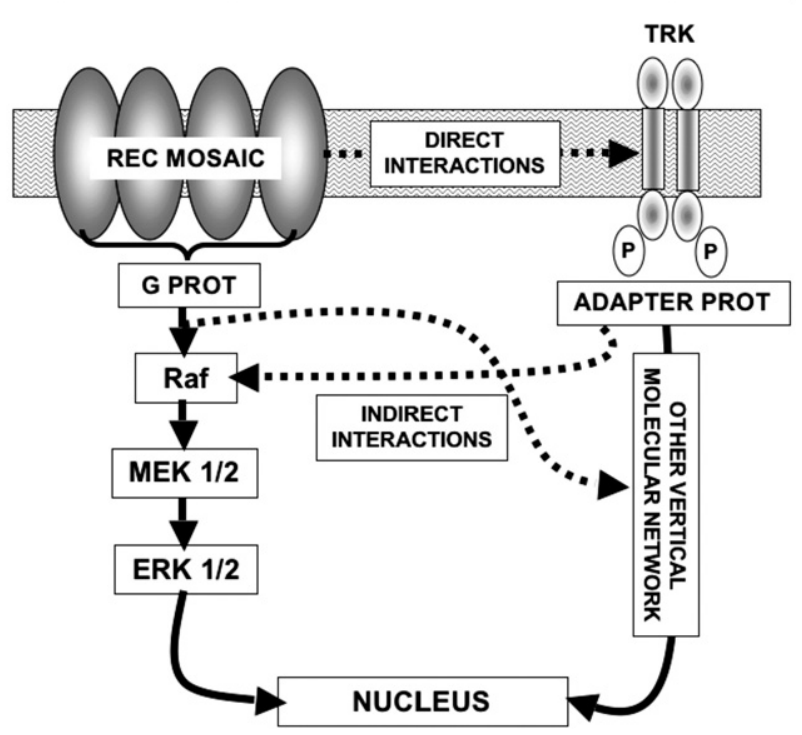

Fig. 7 - Illustration of GPCR-tyrosine receptor kinase (TRK) receptor interactions as a mechanism for GPCR transactivation of TRK receptors without neurotrophic factor binding to TRK. Direct receptor-receptor interactions may develop in the cell surface membrane or indirect receptor-receptor interactions may take place in the intracellular signaling cascades formed by vertical molecular networks reaching into the nucleus, involving e.g., the Raf-MEK-ERK cascade. The GPCR is shown as a receptor mosaic (Rec Mosaic), in this case a high-order homomer. tyrosine kinases in the absence of neurotrophic factor binding are not fully understood. The research reviewed above is of special interest to this article since it serves to demonstrate how VT transmitters via activation of GPCRs can strongly modulate trophism via the GPCR-RTK receptor interactions (Fig. 7).

\subsection{Serotonin receptor subtypes and the possible transactivation of the FGF-2/FGFR1 neurotrophic system}

FGFR1 is constitutively expressed in neurons of target brain regions involved in depression, including the raphe nuclei (Belluardo et al., 1997). FGF-2, a trophic factor binding to FGFR1, is widely expressed in the brain both in astrocytes and neurons (Fuxe et al., 1996) and is co-expressed in the perikarya of practically all raphe 5-HT nerve cells (Chadi et al., 1993; Fuxe et al., 1996). Furthermore, antidepressant drugs and chronic electroconvulsive shock treatment increase the expression of FGF-2 in frontal cortices and hippocampus (Follesa et al., 1994; Mallei et al., 2002; Gwinn et al., 2002; Maragnoli et al., 2004), suggesting a beneficial role of FGF-2 in mood disorders.

Compelling evidence shows that the alleviation of depression caused by serotonin selective reuptake inhibitors is produced by increasing the availability of serotonin at the postjunctional 5-HT receptor subtypes involving a downregulation of the 5 -HT1A autoreceptors in the raphe regions (Artigas et al., 1996; Albert et al., 1996). It seems possible that a certain pattern of activity at different 5-HT receptor subtypes of the seven 5-HT receptor families identified (Hoyer et al., 2002) is necessary to counteract the depression since certain antidepressant drugs can even block certain 5-HT2 like receptors (Fuxe et al., 1977c; Ogren et al., 1979; Peroutka and Snyder, 1979, 1980).

Taken together, these findings open up the possibility that antidepressant drugs by the indirect stimulation of the 5-HT receptor subtypes located on the mesencephalic 5-HT raphe cells, mainly of the 5-HT1 type, can cause an activation of the FGF-2/FGFR1 mechanism in these 5-HT nerve cells. Such an activation may involve also a 5-HT receptor subtype mediated transactivation of the FGFR1. Events of this type may improve 5-HT neurotrophism with regeneration of 5-HT terminal systems lost during depression and result in improved 5-HT communication, explaining the crucial impact of activation of certain 5-HT receptor subtypes in the 5-HT nerve cells to alleviate depression. In line with this hypothesis, extended treatment with a selective 5-HT uptake blocker zimelidine causes increases in 5-HT immunofluorescence in the dorsal raphe (Fuxe et al., 1983a). It is of substantial interest that inescapable shock causes a widespread c-fos activation of the 5-HT nerve cells of the entire raphe system of the lower brain stem (Takase et al., 2004). This may represent a compensatory mechanism to cause upregulation of the neurotrophic mechanism in the 5-HT nerve cells to help their survival and function to counteract depression development.

As a consequence of increased activity in the ascending 5HT pathways and increased 5-HT release in the target regions after prolonged treatment with antidepressant drugs, the increased stimulation of certain postjunctional 5-HT receptor subtypes may also cause activation of neurotrophic factor systems in the target regions like the limbic system. It is 
postulated that also here the FGF-2/FGFR1 system can be activated and a transactivation of the FGFR1 may occur. In fact, previous studies have indicated that 5-HT can exert neuroprotective effects on a variety of neurons from the central nervous system (Lesch, 2001). Azmitia and colleagues have emphasized the importance of astroglial 5-HT1A receptors in the neurotrophic actions of neuronal 5-HT (WhitakerAzmitia et al., 1990; Azmitia and Whitaker-Azmitia, 1991; Azmitia, 2001), and 5-HT appears to function in a cooperative manner with neurotrophins when regulating survival and neuronal plasticity (Galter and Unsicker, 1999; Mattson et al., 2004). Therefore, neurotrophins are considered as mediators of antidepressant effects (Castren, 2004). A deficiency in monoamines like 5-HT, which occurs in depression, would probably result in reduced cellular plasticity as a consequence of decreased expression of trophic factors in different brain structures (Manji et al., 2003). Serotonin receptors have also been involved in transactivation of the receptor tyrosine kinase ApTrk linked to biochemical events leading to longterm facilitation in aplysia (Ormond et al., 2004) and in transactivation of the epidermal growth factor receptor (Grewal et al., 2001; Luttrell, 2002).

In conclusion, the neurotrophic system FGF-2/FGFR1 may be a good candidate to mediate antidepressant induced improvement in 5-HT neuronal communication and neurotrophism with regeneration of connections lost during depression (Kitayama et al., 2004). Receptor tyrosine kinase transactivation in response to antidepressant drug treatment is postulated to take place via a new receptor-receptor mechanism between serotonin receptor subtypes and FGFR1 activation. Novel research in this field may increase our understanding of the mechanisms of antidepressant drug action and lead to the development of new strategies for treatment of depression. For the first time, it seems possible to identify the molecular neurotrophic mechanisms in the 5-HT nerve cells the activation of which causes a relief from depression. Future work based on the present hypothesis may identify if this neurotrophic system (FGF-2/FGFR1) can mediate improvement in 5-HT neuronal communication and neurotrophism. It may in fact reveal the existence of receptor tyrosine kinase transactivation in response to antidepressant drug treatment, by demonstration of a new receptor-receptor interaction mechanism between serotonin receptor subtypes and FGFR1 activation. These expected results will increase our understanding of the mechanisms of antidepressant drug action and lead to the development of new strategies for treatment of depression.

\section{Two modes of brain communication: wiring and volume transmission}

\subsection{The foundations leading up to the 1986 proposal of wiring and volume transmission}

Interneuronal communication is a basic feature of the CNS and is defined as the transmission of signals from one neuron to the next in a neuronal network via a specialized contact between two neurons. This contact has been called the synapse and was based on the neuron doctrine of Cajal. Synaptic transmission is the prototype of wiring transmission and has been the main foundation of neuroscience as we know it. The chemical synapse (see Fig. 1) is a specialized presynaptic nerve ending rich in transmitter-containing synaptic vesicles, contacting a specialized plasma membrane of the postsynaptic neuron. Synaptic transmission is therefore a point-to-point transmission between neurons. The synaptic organization of the neuronal networks of the brain was first proposed by Cajal using the Golgi technique (1906) and subsequently by Sherrington (1947) using electrophysiological techniques. Today, through electron microscopy work, the discontinuity gap between the pre- and postsynaptic elements is known to mainly range from 30 to $50 \mathrm{~nm}$ with a synaptic delay of 0.3 to $5 \mathrm{~ms}$ or longer. It should be noted that Golgi held an opposite view, namely the existence of a diffuse neuronal network enabling interneuronal communication (see Jacobson, 1993).

In the 1970s and 1980s, the functional assumption of a diffuse mode of interneuronal communication affecting the activity of entire brain regions was gaining support by the observations made on monoaminergic neurons as discussed above (see also Geffen et al., 1976) and on peptidergic neurons (De Wied and Jolles, 1982; Bloom and Segal, 1980; Burbach, 1982; Fuxe et al., 1977b, 1980b,c, 1986; Agnati et al., 1986b). Phylogenetic studies also pointed to the appearance of a diffuse interneuronal communication in primitive nervous systems (Nieuwenhuys, 1985). Neurons arose during evolution from cells with elongated processes secreting informational molecules into the extracellular fluid (ECF) to reach close-by target cells. Thus, synaptic transmission was not involved in the beginning of the development of the nervous system. The diffuse type of neuronal organization was easily detected in lower organisms (Haskins et al., 1981; Mayeri et al., 1985). As an example, bag cell axons in the abdominal ganglia of the mollusc aplysia only reach the surrounding connective tissue of the ganglia. Thus, the activity of the ganglionic cells is controlled by peptides, released from the far away axons, which diffuse into the ganglion to reach the receptors on the ganglionic cells. Thus, communication via the ECF appears to be a common mode within the invertebrate nervous system (see, e.g., Branton et al., 1978). It has also been shown in amphibian autonomic ganglia that LHRH released from preganglionic fibers can affect excitability and calcium influx of groups of neurons without direct innervations by LHRH containing nerve terminals (Jan and Jan, 1982, 1983). Thus, this mode of communication may also be used in the mammalian nervous system.

Thus, there was a need for a new classification for interneuronal communication in the brain since the classical criteria stated for synaptic transmission could not be maintained. Ultrastructural findings in the mammalian nervous system had a special value in this regard showing e.g., that large core vesicles which are especially enriched in neuropeptides can be located outside synapses and preferentially associated with non-synaptic membranes (Zhu et al., 1986). Another important ultrastructural observation was the findings of small vesicles in high densities in monoamine varicosities lacking synaptic specializations, indicating the existence of both non-junctional and junctional monoamine varicosities releasing monoamines in various brain regions (Descarries et al., 1975, 1977; Beaudet and Descarries, 1978). A 
high incidence of non-junctional varicosities was found e.g., all over the cerebral cortex (Descarries et al., 1975, 1977) and in the external layer of the median eminence (see Buma and Nieuwenhuys, 1988), where various types of local circuits had been postulated to form different types of medianosomes (Fuxe et al., 1980a, 1985). In line with these results, Mobley and Greengard (1985) demonstrated widespread effects of noradrenaline on the metabolism of terminals in the cerebral cortex since NA release via $\beta$-adrenergic receptors could increase synapsin 1 phosphorylation present in almost all terminals of the cerebral cortex. Early indications of the existence of CA diffusion in the brain and their release into the extracellular fluid using the Falck-Hillarp technique also strongly supported the theory of a widespread mode of communication besides synaptic transmission (Routtenberg et al., 1968; Fuxe and Ungerstedt, 1968, 1970; Ungerstedt et al., 1969; Butcher et al., 1970).

Of high relevance for introducing a new classification of intercellular communication was also the potential existence of chemical networks of peptides in the extracellular fluid, through formation of biologically active peptide fragments via extracellular peptidases (De Wied and Jolles, 1982; Agnati et al., 1983; Fuxe et al., 1980b, 1986). The evidence in the 1986 study (Agnati et al., 1986a) also indicated that the opioid peptides mainly communicated via VT, which was supported by the apparent lack of reuptake mechanisms in peptide neurons. Thus, once released, peptides would diffuse from the site of release until degraded by peptidases or converted into active fragments.

A number of proposals, although different from each other, were therefore made in this period to indicate that other modes of interneuronal communication may operate in the brain besides the synaptic transmission (Guillemin, 1978; Nicholson and Phillips, 1981; Cuello, 1983; Schmitt, 1984; Vizi, 1984). These alternative ways of interneuronal communication were called non-synaptic transmission between neurons (Vizi, 1984), non-classical neuronal communication (Cuello, 1983) or parasynaptic transmission operating in parallel with the synaptic system (Schmitt, 1984). However, such terms overlooked the importance of neuron-glia and glia-glia communication in the CNS and that point-to-point communication in the CNS involves also gap junctions and membrane juxtapositions (Bennett and Goodenough, 1978; see Shepherd, 1991). Guillemin pointed out that nerve cells also behave as endocrine cells for local actions (Guillemin, 1978) and Vizi focused on the existence of cross-talk between close-by axon terminals via the ECF (Vizi, 1984).

In 1986, Agnati and Fuxe and their team made the important observation that the distribution pattern of $\mu$-opioid receptors in the brain, as studied with quantitative receptor autoradiography, failed to correlate with the distribution pattern of enkephalin and $\beta$-endorphin immunoreactive terminal networks, as studied with semiquantitative immunocytochemistry and image analysis (Agnati et al., 1986a). Transmitter-receptor mismatches discovered by receptor autoradiography and transmitter immunohistochemistry had previously been observed by Kuhar et al. (1985). Taken together, the above observations were very inspiring to Agnati and Fuxe since in their mind they provided impressive evidence that transmitters after release from their terminals may reach their unique receptors via diffusion for short and long distances in the extracellular fluid of the brain. Using a correlation analysis, their results obtained were also not very dependent on the sensitivity of the chemical anatomical techniques used. Based on these and previous observations (see above), they therefore proposed in their 1986 paper (Agnati et al., 1986a) that there exist two main types of intercellular communication in the CNS: wiring and volume transmission (WT and VT), see Tables 1-3.

WT was defined by the presence of physically distinct communication channels within the neuronal circuits. Thus, communication occurs as in a "wire", which represents relatively fixed structures well suited for the rapid and safe conduction of the action potentials. The prototype for WT was the classical synaptic transmission with point-to-point transfer of chemical signals in the synaptic gap, representing a discrete transmission with low to moderate divergency and plasticity (see Tables 1-3). VT was defined as the intercellular communications between nerve cells, and/or glial cells (including endothelial and ependymal cells), characterized by diffusion of chemical signals and flow of ionic currents in the fluid of the extracellular space, the latter representing electrotonic signals (Agnati et al., 1986a; Fuxe et al., 1988a; Agnati and Fuxe, 2000). The flow of extracellular ionic current generated by nerve cells has been called volume conduction (Martin, 1985). This term made it reasonable to us to introduce the term volume transmission to describe the general phenomenon of signal transfer in the extracellular space, including the diffusion of chemical signals like transmitters and modulators in the extracellular fluid (Fig. 8, Table 1). In fact, the neuronalglial networks of the CNS are immersed in the volume of the extracellular space rich in chemical signals modulating their activity. Thus, information flows in the extracellular space. Important work in the field of volume conduction was early made by Nicholson (1979), providing evidence that the brain cell microenvironment is a communication channel for ions, and demonstrated that ion diffusion can be modified by the properties of the extracellular environment (Nicholson and Phillips, 1981). Indications were also obtained that neuroactive substances may migrate along microvessels in paravascular channels (Brightman, 1965; Rennels et al., 1985).

The Agnati-Fuxe team (Agnati et al., 1986a; see also Agnati et al., this issue) characterized VT as a widespread (diffuse),

Table 1 - Features of volume transmission

Type of signals

Chemical: neurotransmitters, neuromodulators, growth factors, ions, gases

Physical: electrotonic currents, pressure gradients, temperature gradients

Pathways

ECS, isotropic and anisotropic migration

CSF, vector-assisted migration

Energy gradients for signal migration

Concentration gradients, electrical potential gradients (charged signal)

Temperature gradients

Pressure gradients

Decoding systems

Receptors, enzymes, ion channels 
Table 2 - Differential properties of wiring transmission (WT) and volume transmission (VT) communication channels

\section{WT}

VT
Ions (electrical synapses) and neurotransmitters (e.g., amino acids)

Concentration of chemical signal at receiver Receiver affinity for the chemical signal Transmission code ${ }^{a}$ Transmission delay
Usually high ( $\mu \mathrm{M})$ Usually low (high nM to $\mu \mathrm{M}$ ) Rate and temporal code Low (ms)
Ions (e.g., $\mathrm{K}^{+}, \mathrm{H}^{+}$), neurotransmitters, growth factors, gases and neuromodulators (e.g., monoamines, neuropeptides, NO, adenosine, neurosteroids) Usually low (nM) Usually high (pM to low $\mathrm{nM}$ ) Rate code High (s to min)

\footnotetext{
${ }^{a}$ Rate code models hold that changes in the firing rate signal an event (a train of impulses) which in the VT can be equated to the arrival of the VT signal at the receptor at suprathreshold concentration. The average rate of impulses in the train codes the strength of the stimulus which in the VT can be equated to the VT signal concentration at the target receptor level. Temporal codes hold that information is encoded by the precise occurrence of spikes over time. This constraint makes it unlikely that this type of code is used in VT.
}

slow and rather unsafe mode of intercellular communication in the extracellular fluid of the CNS, including also the cerebrospinal fluid with a high to very high divergence and plasticity. The VT communication was described to consist of migration of transmitters, modulators, trophic factors and ions from the source cells to the receptor containing target cells, along extracellular channels shaped by the packing of the glial and neuronal cell mass and by the vascular architecture (Fig. 8, Tables 1-3). VT was proposed to be preferentially involved in long-term actions and a holistic elaboration of information, with long-lasting modulation of large neuronal-glial cellular networks for information handling and trophism. Conversely, WT was preferentially involved in elementary elaboration and short-term actions. The essence of the pioneering theory introduced in 1986 was that the operation of the neuronal-glial networks of the brain builds on two complementary modes of communication for information handling, wiring transmission and volume transmission, interacting with each other (Fig. 8, Tables 1-3) (Agnati et al., 1986a; see also Agnati et al., this issue). With the acceptance of this theory the Golgi-Cajal conflict on brain communication has come to an end, and their opposing views on brain communication can now become united in this theory on wiring and volume transmission as the two major modes of communication in the brain.

\subsection{Further experimental evidence for the existence of volume transmission}

\subsubsection{Failure of storage of transmitters/modulators in} synaptic vesicles

Nerve cells are not the only sources of transmitters and modulators since it has been found that neuroactive com-

\section{Table 3 - Differential properties of WT and VT circuits}

$$
\text { WT }
$$

VT

\begin{tabular}{|c|c|c|}
\hline Cell composition & $\begin{array}{l}\text { Mainly between } \\
\text { neurons and } \\
\text { between astrocytes }\end{array}$ & $\begin{array}{l}\text { Any cell type in } \\
\text { the CNS }\end{array}$ \\
\hline Divergence & Low & Potentially high \\
\hline Type of connectivity & Preferentially serial & Preferentially parallel \\
\hline Space filling & High & Low \\
\hline Time scale & $\mathrm{ms}$ to $\mathrm{s}$ & $\mathrm{s}$ to $\min$ \\
\hline Biological effect & Typically phasic & Typically tonic \\
\hline
\end{tabular}

pounds can be stored and released also from glial cells (see Murphy et al., 1993; Martin, 1992; Nedergaard, 1994). It has also been shown that the gas NO may function as an interneuronal signal in the brain, being synthesized on demand from its precursor L-arginine by NO synthase and freely diffusing out from the source cell (see Garthwaite et al., 1989; Gally et al., 1990; Snyder and Bredt, 1991; Murphy et al., 1993). The same appears to be true also for $\mathrm{CO}$ and $\mathrm{H}_{2} \mathrm{~S}$, which may act as gaseous transmitters (Wang, 2002). Furthermore, an important modulator of brain function like prostaglandin D2 is formed from prostaglandin $\mathrm{D}$, which is mainly located in leptomeninges, choroid plexus and oligodendrocytes (Urade et al., 1993; Hayaishi, 1991). Thus, it seems as if all non-neuronal cells of the CNS can give rise to VT signals.

\subsubsection{Lack of calcium-dependent vesicular release of transmitters}

Calcium-independent non-vesicular release of transmitters may occur e.g., for GABA, glutamate, glycine and monoamines via a reversal of the uptake-transporter mechanisms, which thus can operate in reverse to transport the transmitters out of the cell into the extracellular fluid (Amara and Kuhar, 1993; Attwell et al., 1993; Hansra et al., 2004). Also cystin/glutamate exchange serves as a source of extracellular glutamate to act as a VT signal (Baker et al., 2001). For a review on the classical synaptic transmitters glutamate and GABA as VT signals, see Del Arco et al. (2003).

\subsubsection{Release of transmitters not in strict contiguity with postsynaptic membranes}

After 1986, the ultrastructural analysis in several studies strengthened the evidence that large dense core vesicles rich in neuropeptides were preferentially associated with nonsynaptic membranes (Matteoli et al., 1988; Sossin et al., 1989; Thureson-Klein and Klein, 1990; Barinaga, 1993; see Koob et al., 1990). Thus, the release of peptides commonly occurs extrasynaptically (Golding, 1994). However, transmitters also become VT signals via a spillover from leaking (open) synapses (Fuxe and Agnati, 1991a; Zoli and Agnati, 1996; Rusakov et al., 1999). The elegant work showing the high incidence of non-junctional monoamine varicosities has continued to also include the demonstration of non-junctional DA varicosities in the neostriatum (see Descarries et al., 1991, 1996; Descarries and Mechawar, 2000). Ultrastructural evidence for a particularly high frequency of non-junctional 


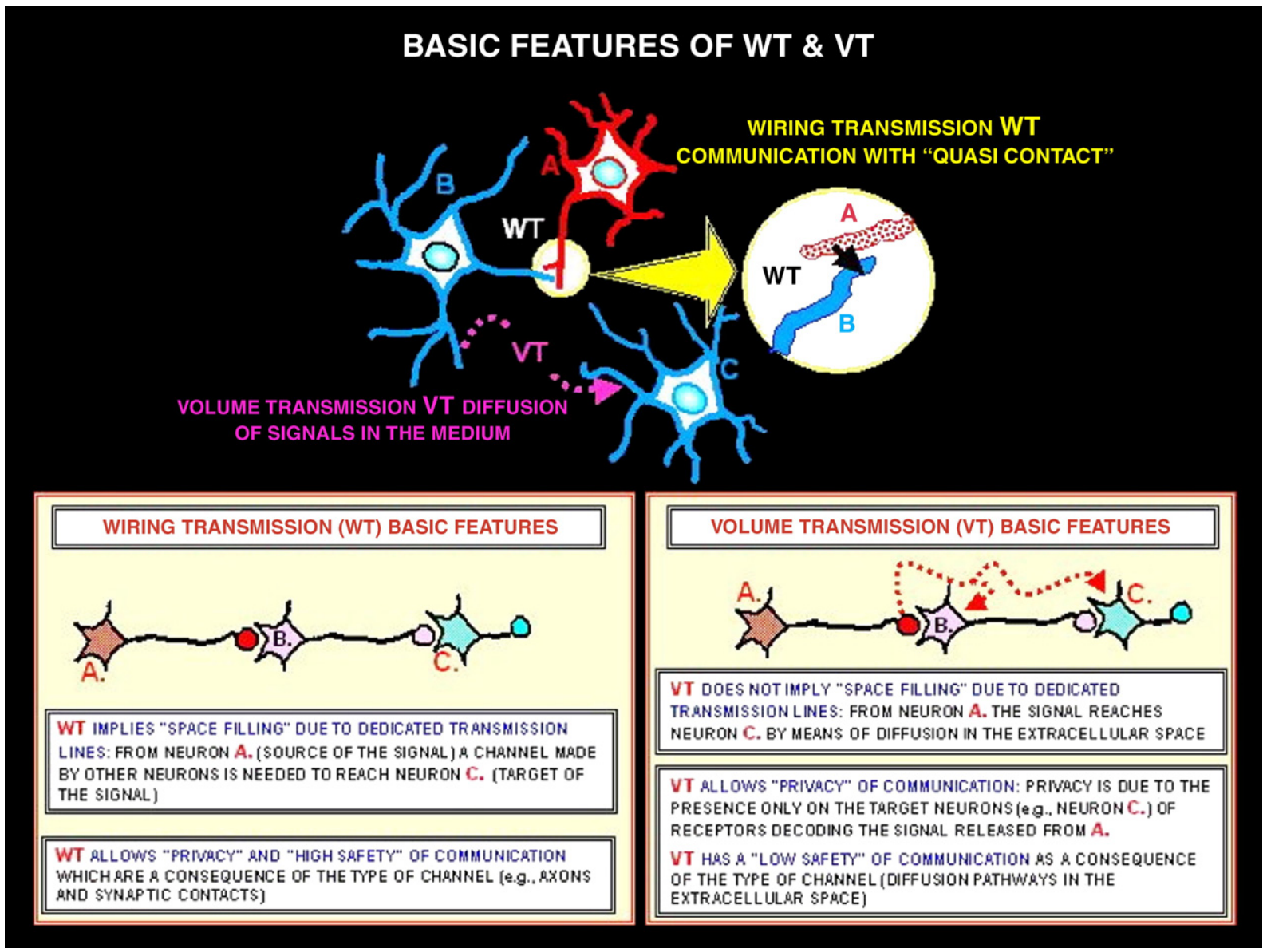

Fig. 8 - Some basic features of the wiring and volume transmission (WT and VT) are illustrated in terms of space filling and safety of transmission.

varicosities has been found in the cholinergic terminal systems (Umbriaco et al., 1994; Descarries and Mechawar, 2000; Descarries, 1998). Thus, like in the monoamine systems, VT appears to be the major mode of operation in the cortical acetylcholine nerve terminal systems and a global modulation of large cell populations becomes possible. Descarries and colleagues (see Descarries and Mechawar, 2000) refer to volume transmission as a "diffuse transmission", which is part of the characteristics of volume transmission (Agnati et al., 2000a; Fuxe and Agnati, 1991a; Agnati and Fuxe, 2000). It should be noted that the isoform of acetylcholinesterase existing in the central cholinergic systems is not as effective in breaking down acetylcholine as in the neuromuscular cholinergic synapses, making it possible to have a widespread VT in operation. The existence of a high frequency of non-junctional varicosities in the dorsal horn was further documented (Ridet et al., 1992). The existence of non-junctional varicosities in the CNS implies that VT also plays an important role in the local circuits of the brain and especially in the cerebral cortex, the dorsal horn and the external layer of the median eminence. It should be noted however that, in the ventral horn, the monoamine terminal varicosities mainly form synapses (Ridet et al., 1992), which is in line with early work of Carlsson et al. (1964) and Fuxe (1965a,b) showing CA terminals with green fluorescent varicosities outlining the cell bodies and dendrites.
4.2.4. Location of transmitter receptors outside the postsynaptic density

The ultrastructural analysis based on transmitter and receptor immunocytochemistry has repeatedly demonstrated short distance transmitter/receptor mismatches for the peptide and classical transmitters with the receptor labeling outside synapses (Dana et al., 1989; Pasquini et al., 1992; Levey et al., 1993; Liu et al., 1994; Sesack et al., 1994; Aoki, 1992; Aoki and Pickel, 1992; Yung et al., 1995; Caillé et al., 1996; Aoki et al., 1998; Azmitia and Whitaker-Azmitia, 1991; Azmitia et al., 1996; Boudin et al., 1998; Baude and Shigemoto, 1998; Dournaud et al., 1998). Extrasynaptic location of receptors has been observed mainly for G-protein-coupled receptors, but also for ion channel linked receptors (Aoki et al., 1994). Both these types of receptors have been observed on astroglia which generally lack synapses, giving evidence for neuron-glia communication via VT (see Kimelberg, 1988; Stone and Ariano, 1989; Murphy and Pearce, 1987; Sontheimer et al., 1988; Barres et al., 1990; Aoki, 1992; Azmitia and Whitaker-Azmitia, 1991). These studies emphasize the impact of VT in the information handling of the local circuits.

As an example, dual immunolabeling of $\beta$-adrenergic receptors and CA nerve terminal networks in the cerebral cortex using electron microscopic immunocytochemistry showed membrane contacts between CA nerve terminals rich in vesicles and $\beta$-adrenergic immunoreactive (IR) astro- 
cytes, giving evidence for neuroglia communication via VT (Aoki, 1992). It was of interest that these $\beta$-adrenergic receptor IR astrocytes also surrounded asymmetric axo-spinous synapses, where the astroglia $\beta$-adrenergic receptors may modulate e.g., glutamate spillover by modulating the activity of the glial glutamate transporters and/or the permeability of the astroglial gap junctions, and thus the sphere of astroglia activation (see Aoki, 1992). In another study with similar techniques, Aoki and colleagues also demonstrated that prefrontal NA terminal networks can interact via VT with astroglia, dendritic shafts and axon terminals through their $\alpha 2$-adrenergic receptors as well as in synaptic interactions through $\alpha 2$-adrenergic receptors located in postsynaptic membranes at spines of pyramidal cells (Aoki et al., 1998).

Another example from the monoamine neurons is the analysis of the cellular localization of 5-HT1A receptors in the brain by Azmitia et al. (1996). Using immunocytochemistry on brain sections, 5-HT1A IR was shown to be located in both neurons and cell bodies and processes of astroglia (Azmitia et al., 1996). 5-HT neurons may therefore via VT modulate the astroglia function through their 5-HT1A receptors, and these astroglia 5-HT1A receptors are known to release serotonin growth factors like protein S-100 (Whitaker-Azmitia et al., 1990). In this way, via 5-HT1A mediated VT involving astroglia, 5-HT may induce its own trophic support.

Continued structural analysis, using double immunolabeling receptor and immunohistochemistry or transmitter histochemistry together with receptor autoradiography, has given evidence for the frequent existence of long-distance transmitter/receptor mismatches (topological mismatches) in the monoamine and peptide systems (see Herkenham, 1987; Fuxe et al., 1988b, 2003b; Zoli et al., 1989; Bunnemann et al., 1991; Ferré et al., 1996; Jansson et al., 1998, 1999, 2001, 2002; Schwartz et al., 1998; Caberlotto et al., 1998; Fuxe et al., 2005; Jacobsen et al., 2006). Such observations strongly indicate the existence of long-distance VT in the brain. Although Bowers in 1994 suggested that mismatch high-affinity receptors represent superfluous receptors, the fact that mismatch and match receptors have similar binding characteristics suggests that the mismatch receptors in fact are reached by their transmitter.

The distinct architecture of the transmitter/receptor mismatch compartments also favors their involvement in VT. This is particularly true for the dopamine D1 and D3 receptor mismatch compartments in nerve cell populations of the nucleus accumbens shell, the intercalated islands of the amygdala and the islands of Calleja surrounded by DA nerve terminal plexa (Diaz et al., 1995; Jansson et al., 1999; Fuxe et al., 2003b, 2005). It now seems clear that transmitter-receptor mismatch is the architecture of volume transmission. It should be noted that the dopamine D4 IR nerve cells and dendrites of the rat cerebral cortex are mainly intermingled with NA nerve terminals, indicating that the source of diffusing DA may be the NA terminals from which also the precursor DA may be released (Rivera, Fuxe et al., unpublished data). The diffusion of DA is favored versus the diffusion of NA since DA unlike NA is not a substrate for the NA transporter.

Studies on the vertebrate retina have given one of the most clear-cut examples of transmitter-receptor mismatches in DA transmission. The amacrine and/or the inner plexiform DA nerve cells are located in the inner nuclear layer, with their terminal branches mainly innervating the inner plexiform layer and with very few radial branches into the outer plexiform layer which contain a high density of dopamine D1 and D2 receptors. Mismatch DA receptors are also found within the outer segment of the photoreceptors and in the ganglionic cell layer (Djamgoz and Wagner, 1992; Witkovsky et al., 1993; Bjelke et al., 1996). These results had inter alia been obtained by DA D1 and D2 receptor immunocytochemistry in combination with tyrosine hydroxylase immunocytochemistry and by dopamine D1 and D2 receptor autoradiography. These DA receptors have also been shown to be biologically active by influencing slow light/dark adaptation in horizontal cells involving regulation of adenylate cyclase activity. Thus, DA VT exists in the retina, especially in its outer part.

Spatial uncoupling between sites for signal release and detection is also true for NO transmission. NO is a rapidly diffusible signal which easily crosses cell membranes to activate the cytosolic enzyme guanylate cyclase, resulting in cGMP formation with modulation of membrane function and the intracellular phosphorylation/dephosphorylation cascades and thereby gene expression (Garthwaite et al., 1989; Gally et al., 1990; Snyder and Bredt, 1991). A single source of the NO signal can thus tune the activity of a set of nerve and glial cells in the immediate surrounding of the NO source independently of WT.

\subsubsection{Deficits of fast inactivation mechanisms of the transmitter}

Using antibody microprobes, a marked release, spread and persistence of immunoreactive neurokinin A were found all over the dorsal horn after noxious cutaneous stimulation by Duggan et al. (1990). These results provided strong evidence for long-distance VT in peptide neurons as far as neurokinin A was concerned. In contrast, substance P (SP) remained in the substantia gelatinosa where the SP/neurokinin A IR terminals are concentrated. It seemed likely that the slow degradation of neurokinin A versus SP was responsible for these differential effects on neurokinin A (Duggan et al., 1990). This proposal was elegantly supported by the demonstration that a peptidase inhibitor microinjected into the dorsal horn demonstrated the spread of immunoreactive SP over the entire dorsal horn after noxious cutaneous stimulation (Duggan et al., 1992). It is of special interest that calcitonin-gene related peptide (CGRP) co-stored with SP in the primary afferents in the dorsal horn via peptidase inhibition can modulate VT in the SP primary afferents involved in mediation of pain. Via such an action, CGRP can increase the intraspinal spread of SP following peripheral nerve activation (Schaible et al., 1992). Thus, the ratio of co-stored peptides can be of importance for their actions through VT. These observations give evidence that peptides when released from their nerve terminal varicosities can diffuse in the extracellular fluid for up to millimeters dependent on their rate of degradation by extracellular peptidases. Their major mode of communication appears to be VT, which according to the above findings plays an important role in nociception in the spinal cord.

These results also show that extracellular enzymes may have an important role in limiting the diffusion of peptides in the extracelluar space (ECS) and thus to peptide VT (see also Jansson et al., 2002). Glial forms of the endoprotease 3.4.24.16 
are soluble and secreted into the ECS and therefore ideally located for such actions (Vincent et al., 1996). However, secreted endopeptidases or endoproteases may either terminate or enhance peptide signaling through the formation of inactive or active fragments, respectively, as suggested e.g., for galanin (Hedlund et al., 1992, 1994; Hedlund and Fuxe, 1996). Extracellular enzymes, attached to plasma membranes or located in the ECS, are also regionally distributed in the brain. They will therefore produce regionally different chemical networks of peptides in the ECS, leading to formation of multiple VT lines with different ratios depending on region. Therefore, the spreading and function of peptides as VT signals can be understood in a better way by subdividing them into presignals, syndromic signals and enzyme modulatory signals (see above; De Wied and Jolles, 1982; Koob et al., 1990; Agnati et al., 1986a,b, 2000a; Fuxe et al., 1980b, 1986, 1988a; Fuxe and Agnati, 1991a,b; Davis and Konings, 1993; Brownlees and Williams, 1993; Burbach et al., 1981). The presignal is a peptide released in an inactive form. The syndromic signal is a large peptide molecule which may be active as such and in addition under the influence of peptidases to form a set of active fragments capable of triggering a set of concerted responses (syndromic response). As examples $\beta$-endorphin, neurotensin, cholecystokinin and neuropeptide $\mathrm{Y}$ derived peptides may be mentioned.

One of the best examples of a long-distance VT signal is $\beta$ endorphin. As already discussed, there was a lack of correlation between the distribution of $\beta$-endorphin nerve terminal plexa versus the $\mu$ - and $\partial$-opioid receptor distribution with clear-cut transmitter-receptor mismatches in the cerebral cortex and the striatum having few if any $\beta$-endorphin terminals (Agnati et al., 1986a; Mansour et al., 1986, 1988; Fuxe et al., 1988a, 2005; Herkenham, 1987; Jansson et al., 2002). Based on these observations, it was suggested by the AgnatiFuxe team that $\beta$-endorphin can act as a long-distance VT signal (Agnati et al., 1986a; see also Herkenham, 1987; Fuxe et al., 1988a). Based on this work, Duggan and co-workers (MacMillan et al., 1998) performed experiments with electrical stimulation of the arcuate $\beta$-endorphin IR nerve cell population (MacMillan et al., 1998). In these experiments they observed that $\beta$-endorphin IR could be detected in remote brain areas lacking $\beta$-endorphin IR terminals, like the cerebral cortex, 60-90 min after the initial stimulation of the arcuate nucleus. These results gave strong indications that $\beta$-endorphin could migrate for long distances in the extracellular fluid after its release from $\beta$-endorphin IR nerve terminals. Recently, it was found that $\beta$-endorphin microinjected intrastriatally can be detected in the cerebrospinal fluid with radioimmunoassay and mass spectrometry with a peak at 30 min post-injection (Höistad et al., 2005). The $\beta$-endorphin IR material in the CSF existed mainly as the intact $\beta$-endorphin peptide and immunohistochemically $\beta$-endorphin IR appeared in globus pallidus cell bodies colocated with $\mu$ opioid receptor IR at the surface membrane (Höistad et al., 2005). This is in line with previous results indicating internalization of $\beta$-endorphin in paraventricular nerve cell populations and in tanycytes of the median eminence after intra-cerebroventricular injection of $\beta$-endorphin (Agnati et al., 1992; Bjelke and Fuxe, 1993). Taken together, the evidence indicates that $\beta$-endorphin can migrate for long distances as a
VT signal via diffusion in the extracellular fluid and flow in the cerebrospinal fluid. Thus the $\beta$-endorphin neurons of the brain (Bloom et al., 1978) mainly act via VT.

The anti-nociception elicited by electrical stimulation of the mesencephalic gray (stimulation-produced analgesia) can be observed only seconds after the stimulation has begun. In contrast, it may last for hours after the stimulation is terminated. For example, in humans stimulation induced analgesia can produce relief from chronic pain that persists up to $24 \mathrm{~h}$ after the stimulation period (Bonica, 1990). The mechanism has been postulated to be a stimulation evoked release of a VT signal which reaches its receptor after diffusion and acts for long periods in view of its slow degradation (Agnati et al., 1991, 1993). Based on the above discussion, we postulate that $\beta$-endorphin may be an important VT signal in this phenomenon involving flow in the CSF.

It should be mentioned that also cytokines like interleukin-1 $\beta$ (IL-1 $\beta$ ) can be a powerful long-distance VT signal (see Jansson et al., 2000) mainly of a glial origin (Licinio and Wong, 1997; Sykova et al., 1998). This is supported by the presence of soluble extracellular IL-1 $\beta$ receptor antagonist ligands and decoy receptors (Colotta et al., 1993; Schobitz et al., 1994), suggesting a strictly regulated IL-1 $\beta$ transmission in the ECF. Local microinjections of IL- $1 \beta$ into the neostriatum have given observations that striatal IL-1 $\beta$ exerts local and distant effects on microglial cells, and distant effects on paraventricular hypothalamic nerve cells, suggesting that IL$1 \beta$ is a VT signal capable of long-distance diffusion and convection through the extracellular space and cerebrospinal fluid, acting on IL-1 $\beta$ receptors in the ependymal cells, the choroid plexus, the meninges and the brain capillaries (Jansson et al., 2000, submitted for publication). Thus, locally formed IL-1 $\beta$ in the brain may via VT produce fever responses (Alheim et al., 1997) and pro-inflammatory events (Andersson et al., 1992), contributing to increases in blood-brain barrier permeability and leading to neuroimmune interactions (Anthony et al., 1997).

\subsection{The extracellular space and cerebrospinal fluid}

\subsubsection{The channels for volume transmission}

The VT signals diffuse within the ECF of the brain, and features of the extracellular channels building up the extracellular space therefore deeply affect VT. The extracellular space is a porous fluid-filled space with a foam-like structure (Nicholson and Sykova, 1998) that contains the migrating VT signals, extracellular enzymes and the extracellular matrix, where hyaluronan and lecticans are the major building blocks that via protein-protein and protein-carbohydrate interactions form a three-dimensional network modulating the diffusion pathways of VT (Agnati et al., 2006b,c). Diffusion in the ECS has been studied with a number of extracellular tracers (Fenstermacher and Kaye, 1988; Nicholson, 2001; Sykova, 2004). From such an analysis, diffusion in the extracellular space can be characterized by the three parameters volume fraction $\alpha$, tortuosity $\lambda$ and clearance $\kappa$ (Nicholson and Phillips, 1981), see Fig. 9. These classical diffusion parameters may be different among brain regions and species and may be altered by neural activity, ageing and in pathological conditions (Sykova et al., 1998; Sykova, 2004). 


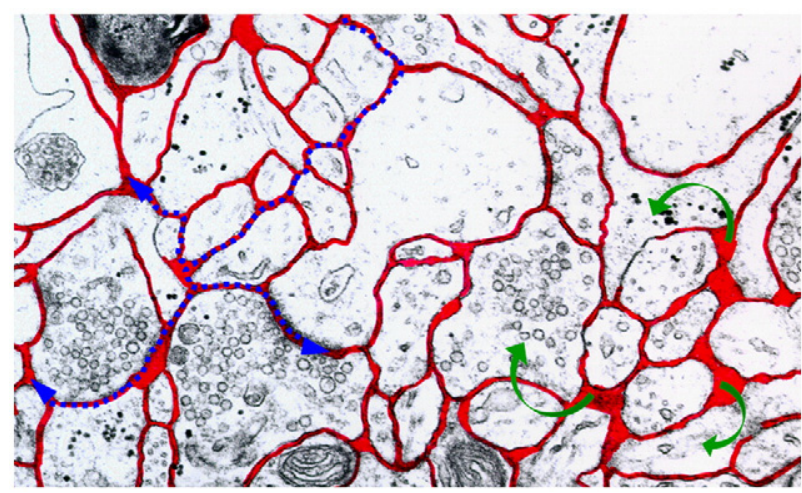

Fig. 9 - Electron micrograph of the extracellular space. The classical diffusion parameters are depicted in colors as the volume fraction $\alpha$ (red), the tortuosity $\lambda$ (blue) derived from $D^{*}=D / \lambda^{2}$, and the clearance $\kappa$ (green). Modified from Nicholson and Sykova (1998). Tortuosity shows the increase in path length compared to a straight course (see text).

Volume fraction $\alpha$ : the volume fraction (size of the extracellular space) on average represents $20 \%$ of the brain volume (Van Harreveld, 1972; Nicholson and Sykova, 1998) and has been given the term volume fraction $\alpha$. In the early days, electron microscopic images had indicated the volume fraction to be only $5 \%$, however this was rather due to shrinkage artefacts during fixation (Fig. 9).

Tortuosity $\lambda$ : molecules migrating in the ECS are exposed to obstacles which leads to an increase in path length compared to a straight course (Fig. 9). This increase is characterized by the tortuosity factor $\lambda$. The obstacles include the viscosity of the extracellular matrix, the structural boundaries of nerve and glia cells and chemical obstacles like electrical charges (Rusakov and Kullmann, 1998). A rise of tortuosity decreases the free diffusion coefficient $D$ to an apparent diffusion coefficient $D^{*}$ by the formula $D^{*}=D / \lambda^{2}$ (Nicholson and Sykova, 1998), leading to a slowing down of diffusion and thus a reduction of VT.

Clearance $\kappa$ : The clearance factor $\kappa$ represents the overall removal of molecules in the ECS as they migrate towards their targets (Fig. 9). Several mechanisms are in operation in the clearance process, namely clearance through the brain-blood barrier, clearance through the brain-cerebrospinal barrier, catabolic enzymes in the ECS and uptake systems in the CNS cells like reuptake transporters (Hoffman et al., 1998; Höistad et al., 2002).

Recently it has been possible to quantify the classical diffusion parameters in brain in vivo not only with the realtime iontophoresis method (see Nicholson and Sykova, 1998), but also with the dual-probe microdialysis technique (Höistad et al., 2002; Chen et al., 2002), using an extracellular tracer, ${ }^{3} \mathrm{H}$ mannitol, and dilute agar as a reference medium (dilute agar prevents convection processes without affecting diffusion; Nicholson and Phillips, 1981). In these experiments, diffusion was studied using dual-probe microdialysis with continuous delivery and recovery of ${ }^{3} \mathrm{H}$-mannitol for $2 \mathrm{~h}$ at different concentrations with an interprobe distance of $1 \mathrm{~mm}$ in the rat striatum (Höistad et al., 2002). The generated diffusion profiles (concentration versus time curves) can be empirically ana- lyzed generating the quantitative parameters $C_{\text {out2 }}$ (ss) representing semi-steady state concentration levels, and $t_{50 \%}$ representing the time required to reach the half of the semisteady state levels (Höistad et al., 2000, 2002). These empirical data from the microdialysis diffusion curves were transformed into quantitative tissue parameters using a mathematical model elaborated in a companion paper (Chen et al., 2002). A fitting program was developed to fit the data from the ${ }^{3} \mathrm{H}$-mannitol diffusion curves with theoretical curves, based on the equation for diffusion in the brain developed by Nicholson and Phillips (1981):

$\frac{\partial C}{\partial t}=D^{*} \nabla^{2} C+\frac{s}{\alpha}-\kappa^{\prime} C$

This diffusion equation, which states that the change in concentration $C$ over time is faster the larger the concentration gradient, was applied to the dual-probe microdialysis setting (Chen et al., 2002; Eqs 2 and 10):

$\partial C_{\mathrm{e} 1} / \partial t=$ and $\partial C_{\mathrm{e} 2} / \partial t=$

thus expressed for the two probes separately. These equations were then solved to give the extracellular concentration in space and time (Chen et al., 2002; Eqs 5 and 14):

$C_{\mathrm{e} 1}(r, t)=$ and $C_{\mathrm{e} 2}(r, t)=$

Performing simulations by varying the classical diffusion parameters will show how such variations would affect the diffusion curves (Chen et al., 2002; Höistad, 2004). The major advantage of the dual-probe microdialysis technique versus the real-time iontophoretic technique in diffusion experiments is the ability to use a large number of highly relevant molecules like transmitters and neuropsychopharmacological drugs, in particular in awake animals, which cannot be studied with the real-time iontophoresis technique (see Höistad et al. (2002) and Höistad (2004)).

\subsubsection{Dopamine diffusion in the striatum}

Using the dual-probe microdialysis method as described above, it was also tested whether intact ${ }^{3} \mathrm{H}$-DA would diffuse over $1 \mathrm{~mm}$ in the rat striatum. However, depending on the experimental conditions, we found that it was not possible to detect diffusion of intact DA at the $1 \mathrm{~mm}$ distance after the infusion of low nanomolar concentrations into the delivery probe, either in the intact or dopamine denervated striatum (Höistad et al., 2000). In agreement, Westerink and De Vries (2001), also using microdialysis, demonstrated that potassium-evoked striatal DA release could not be detected at a $1 \mathrm{~mm}$ distance from the site of release. However, since a substantial spread of DA has been observed in the striatum after striatal micro-injections of high concentrations of DA (Ungerstedt et al., 1969; Agnati et al., 1992), diffusion of ${ }^{3} \mathrm{H}-$ DA using dual-probe microdialysis may potentially have been possible, if using higher infusion concentrations of ${ }^{3} \mathrm{H}$ DA. Local diffusion of DA is well-known to exist in the intact striatum as shown with voltammetry (Garris et al., 1994), and DA transporters have been shown to reduce the clearance half-life of extracellular DA (Wang et al., 1996; Rice, 2000). 
Furthermore, studies on intrastriatal adenohypophyseal transplants in dopamine denervated or intact striata also suggest that DA operates via VT (Bjelke et al., 1988, 1989). These transplants secrete prolactin which diffuses into the surrounding neuropil and form a zone of prolactin IR (Fig. 10). This zone is increased after DA denervation by injection of 6$\mathrm{OH}-\mathrm{DA}$ into the substantia nigra and reduced by amphetamine-induced DA release or by the injection of dopamine D2 receptor agonists like bromocriptine (Bjelke et al., 1988, 1989). These results strongly indicate the existence of extracellular DA in the striatum, which can diffuse into the transplant and activate high-affinity D2 receptors on the prolactin containing gland cells, resulting in the inhibition of secretion of prolactin (Fig. 10). These studies also demonstrate that prolactin can diffuse for long distances in the striatum, indicating that the prolactin-like protein released from prolactin IR neurons in the brain may act as a long-distance VT signal. Also, studies on host-graft interactions using adrenal medulla transplants and embryonic midbrain transplants in the striatum indicate the DA communication with WT and VT working together to produce their anti-parkinsonian effects (see Strömberg et al., 2000).

It is of interest that in DA denervated rats, dopamine metabolites such as DOPAC and HVA were more rapidly cleared from the extracellular space compared to control rats after infusion of ${ }^{3} \mathrm{H}$-DA into the striatum (Höistad et al., 2000). This may be due to an increased clearance of the DA metabolites into the striatal capillaries after removal of the DA terminals. In fact, it has been shown that DA terminals may exert a vasoconstrictor action on the microvessels of the brain (Iadecola, 1998). Thus, via VT dopamine released from striatal nerve terminals may regulate striatal microcirculation including its permeability.

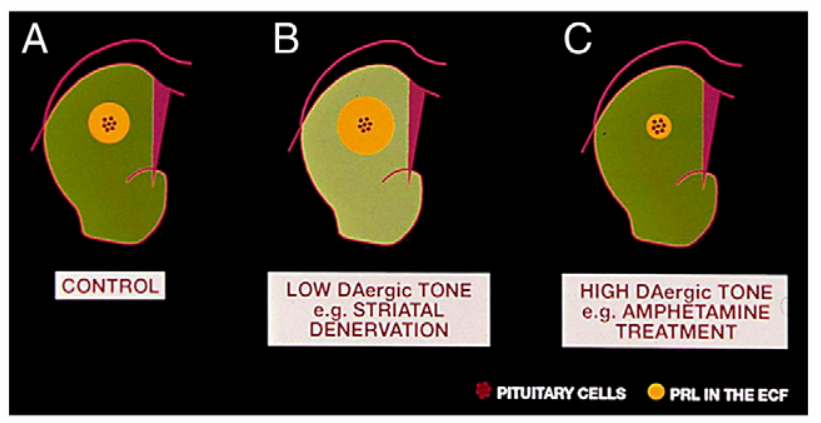

Fig. 10 - Illustration from the work of Bjelke et al. $(1988,1989)$ of how striatal DA VT signals modulate the migration of prolactin in the rat striatum after transplantation of adenohypophyseal tissue containing prolactin cells with D2 receptors secreting prolactin into the striatal ECF. The halo (area outside the transplant) of prolactin immunoreactivity (A, control rats) is markedly increased after striatal DA denervation (B) due to removal of DA VT signals inhibiting the secretion of prolactin via activation of high-affinity D2 receptors on the prolactin secreting cells. (C) Amphetamine treated rats show a decreased halo of prolactin immunoreactivity due to the activation $\mathrm{D} 2$ receptors on the prolactin cells by the high dopaminergic tone of VT.
4.3.3. Fluid movements within the extracellular space

Tracer diffusion in the CNS can follow either an isotropic or anisotropic diffusion pattern (see Fuxe and Agnati, 1991a,b). Anisotropic diffusion in white matter has been demonstrated by magnetic resonance imaging in cats and humans (Le Bihan et al., 1993). Such a pattern is the consequence of the existence of preferential diffusion pathways in the CNS along myelinated fiber bundles and paravascular spaces (Brightman, 1965; Blasberg et al., 1975; Rennels et al., 1985, 1990; Fenstermacher and Kaye, 1988; Ichimura et al., 1991; Zhang et al., 1992; Bjelke et al., 1995; Geer and Grossman, 1997; Vorisek and Sykova, 1997).

The preferential diffusion along paravascular spaces has been shown to be facilitated by pressure gradients caused by the pulsations of arterioles (Greitz, 1993; Greitz et al., 1993). This leads to convective movements with mass movement of the fluid carrying informational signals and increases the rate of migration and thus VT signaling. Temperature gradients in the brain also give rise to convective movements in the extracellular fluid and therefore speed up VT. Of special importance are large temperature gradients that develop between inactive and active brain regions (Yablonskiy et al., 2000) and increase VT migration over large distances, while at the same time mixing and renewing extracellular fluid and improving homeostasis. Such large temperature gradients are initially brought about by the necessity to cool down the active brain regions by increasing cerebral blood flow to the active brain region in view of the lower temperature of peripheral blood. The sequence of events may be that an increased neural activity in the active brain region releases vasoactive signals that modulate the arteriolar compliance and thereby increase the cerebral blood flow in the active region (Behzadi and Liu, 2005). Among the signals that may lead to an elevated cerebral blood flow and facilitating temperature gradients, plasma/ ECF exchange, ECF renewal and thus VT migration, $\mathrm{CO}_{2}$ is of special interest since it is formed in increased amounts not only as a result of increased cellular metabolism in the active region, but also by being released by active axons as a highly diffusible VT signal (Agnati et al., 1995). Based on the existence of carbonic anhydrase II immunoreactivity in widespread systems of oligodendroglia and restricted astroglia populations in brain, it seems likely that axonal $\mathrm{CO}_{2}$ can reach this enzyme and be converted into protons and $\mathrm{HCO}_{3}$ with the $\mathrm{pH}$ shift leading to changes in ion channel and enzyme activities (Agnati et al., 1995). Thus, $\mathrm{CO}_{2}$ as a VT signal may in this way increase not only the cerebral blood flow, but also the excitability of the neuronal networks surrounding the fiber bundles and the permeability of the associated capillary networks in the active brain region. It is clear that VT can be importantly driven by modifications of metabolism in discrete neural networks of high activity, with the development of large temperature gradients where $\mathrm{CO}_{2}$ VT transmission plays an important role.

Recently, brain uncoupling proteins (UCPs) have been discovered and shown to generate heat by producing a disappearance of the $\mathrm{H}^{+}$gradient in the mitochondria (see Horvath et al., 2003). Such uncoupled mitochondria predict thermal synapses (Horvath et al., 1999) and neuroprotection (Horvath et al., 2003; Andrews et al., 2006). We have now 
obtained indications that UCP2 can enhance VT over short distances by producing small temperature gradients. Thus, in the DA/D1 mismatch region of the nucleus accumbens shell, an important region for reward, strongly UCP2-like IR compartments are in good register with the DA terminal rich compartments surrounding the D1 rich compartments lacking DA terminals and UCP2-like IR (Fuxe et al., 2005; Rivera et al., 2006; Agnati et al., 2006b). This chemical architecture is of substantial interest since thermal gradients can develop by UCP2 generation of heat only in the DA terminal rich region, leading to increased release and migration of DA into the mismatch compartment with diffusion distances up to 50$100 \mu \mathrm{m}$. Thus, long-distance DA VT may be improved and put into full operation by the thermal gradients generated by UCP2. This organization could underlie the ability to predict future reward responses (see Agnati et al., 2007 and Guidolin et al., this issue). The spatio-temporal relationships of the rapid WT and slow VT acting on the nerve cells of the D1 receptor mismatch region could lead to sensitization of these nerve cells to the exact time of the delivery of the reward following a predictive sensory cue.

Strong UCP2-like IR has also been found in discrete DA and NA terminal systems specialized for VT, with large varicosities in the cerebral cortex (DA) and the neostriatum (NA) (Rivera et al., 2006). UCP2-like IR was also present in DA and NA cell bodies and dendrites (Horvath et al., 1999, Fuxe et al., 2005; Rivera et al., 2006), where UCP2 may enhance VT by enhancing DA and NA release and migration to activate D2 and $\alpha_{2}$ autoreceptors.

\subsubsection{The cerebrospinal fluid system as a communication} channel

Based on MR imaging and radionuclide cisternography, it has been proposed that the production and absorption of CSF may occur via the brain capillaries, with direct CSF transport into the blood stream involving the paravascular spaces and the ECS of the brain (Greitz, 1993), which contributes to the bulk flow of ECF and generates energy gradients to enhance VT migration (see Agnati et al., 2006b). Also, the ventricular ependyma does not possess tight junctions and shows enrichment of aquaporin-4 through which water can pass, and thus allows the exchange of VT signals between the ECF and the CSF (Fenstermacher and Patlak, 1974; Brightman and Kaya, 2000; Lippoldt et al., 2000a,b).

Greitz et al. $(1991,1993)$ have proposed that the intracranial arterial pulses produce pulsatile movements in the CSF involving "piston" movements of the brain. Based on this work, the existence of cyclic pressure oscillations also within the subarachnoidal space has been assumed, and the "tide" hypothesis of VT signal migration, clearance and modulatory signal release has been introduced (Agnati et al., 2005a, 2006b). This hypothesis states that cyclic pressure oscillations exist within the subarachnoid space inducing "tide" movements (renewal of fluid like in a sponge) in the fluid of the VirchowRobin spaces of the cerebral cortex, and subsequently of the paravascular and pericapillary spaces and eventually in the ECF. Such convective movements caused by the pressure gradients of the arterial pulse will enhance VT migration and improve the homeostasis of the internal milieu of the brain, especially of the cerebral cortex.
Already in the 1970s, the CSF was proposed to play a significant role in brain communication (Morris et al., 1975), and this proposal has received further support (Bloom and Segal, 1980; Jackson, 1980; Kiser et al., 1983; Proescholdt et al., 2000). Furthermore, especially the peptides in the CSF have been regarded as information signals, which are altered in neuropsychiatric disease (Burbach, 1982; Post et al., 1982). A set of criteria have been developed for the identification of a CSF signal acting at distant target cells (Nicholson, 1999). These include:

- The messenger is found in the CSF in quantifiable amounts.

- The concentration varies with the physiology of interest in an appropriate manner.

- Removal of the messenger disrupts the physiology.

- Excess amounts affect the physiology.

- Production of the substance is upstream (in terms of CSF flow) from the receptor site.

- The target cell detects the messenger and transduces this signal to a biological response.

The CSF signals are regarded as long-distance VT signals globally modulating brain and spinal networks via their receptors (see Fuxe and Agnati, 1991a,b; Agnati et al., 2000a). It should be considered that VT communication via CSF has a special importance in brain development, especially prior to the synapse formation (Miyan et al., 2003). In adulthood, a number of biologically active molecules have been proposed to represent CSF signals (Segal, 2000; Brightman and Kaya, 2000). Of special interest are molecules affecting global functions such as sleep and circadian rhythms (Silver et al., 1996; Skinner and Malpaux, 1999), interleukin-1 $\beta$ modulating inflammation and sickness behavior (Krueger and Majde, 1995; Jansson, 1999; Jansson et al., 2000) and $\beta$-endorphin being essential for self and species survival (Akil et al., 1978; Bloom et al., 1978; Agnati et al., 1986a; Fuxe et al., 1988a; see Höistad et al., 2005). For a role of CSF signals in diseases of the nervous system, see Fishman (1992).

\section{The integration of WT and VT via receptor-receptor interactions}

Wiring transmission includes not only synaptic transmission, but also gap junctions and membrane juxtapositions (see Shepherd, 1991, 1994). For a recent review of the morphofunctional organization of WT communication, see Agnati et al. (1986a). Special gap junctions are the electrical synapses, and the existence of mixed synapses should be underlined where both electrical and chemical transmissions take place (Nagy et al., 2004).

The differential properties of WT and VT are summarized in Tables 1 and 2 (see Agnati et al., 1986a, 2006b; Fuxe and Agnati, 1991a; Agnati and Fuxe, 2000). As discussed (Agnati et al., 1994), there exist two classes of VT signals: the private code signals represented by transmitters, and the open code signals represented by electrical signals (ions). Any nerve cell by its electrical activity can modulate any other cell within the micrometer range through ion fluxes in the ECF. Hydrophilic transmitters like monoamines and peptides diffuse in the ECF 
as short- and long-distance VT signals and operate by activation of membrane receptors, while hydrophobic transmitters like NO have a preferential local role in VT by diffusing across cell membranes in an isotropic manner to activate intracellular effectors.

Slow high-affinity G-protein-coupled receptors are the major molecular target for VT signals. They decode the VT signal and modify the cell function. All central neurons are therefore under the influence of VT signals, which are continuously integrated with WT signals not only at the cytoplasmatic and nuclear level but also at the plasma membrane level. The mechanism for the integration at the membrane level may mainly be represented by intramembrane receptor-receptor interactions, mainly represented by slow high-affinity G-protein-coupled receptors and synaptic receptors, represented by both fast ion channel linked receptors and slow G-protein-coupled receptors (see Fuxe and Agnati, 1985; Agnati and Fuxe, 2000; Agnati et al., 2003a; Ciruela et al., 2006; Fuxe et al., 2007). Such an integration of WT and VT signals may be the molecular mechanism for the appearance of polymorphic networks (see Agnati and Fuxe, 2000).

Evidence for this view now exists since it has been demonstrated that DA operating via VT can fine-tune the excitatory and inhibitory WT in the brain via direct receptorreceptor interactions. The molecular mechanism is the formation of different types of DA receptor mosaics representing heteromeric receptor complexes of DA receptor subtypes (VT) and ion channel (WT) or other GPCR receptors (VT) (see Table 4). The following DA receptor mosaics containing ion channel receptors have been demonstrated: $\mathrm{GABA}_{\mathrm{A}} / \mathrm{D} 5$ (Liu et al., 2000), NMDA/D1 (Lee et al., 2002a,b), and D2/NR2B (Liu et al., 2006). Intramembrane receptor-receptor interactions at the level of the $\mathrm{D} 2$ binding pocket have also been observed between $\mathrm{GABA}_{\mathrm{A}}$ and $D 2$ receptors in striatal membranes, indicating that also this type of DA receptor mosaic may be formed (Perez de la Mora et al., 1997). The D2 autoreceptor/nicotinic heteromeric receptor complexes also exist in the striatal DA terminals (Quarta et al., 2007), and the work of Li et al. (1995) discussed the possible existence of direct interactions between nicotinic receptors and DA receptors in the basal ganglia.

\section{Table 4 - Receptor mosaics}

Reference

\begin{tabular}{ll}
\hline SSTR5/D2R & Rocheville et al., 2000 \\
A1R/D1R & Gines et al., 2000 \\
A2AR/D2R & Hillion et al., 2002 \\
& Canals et al., 2003 \\
& Kamiya et al., 2003 \\
GABA-A R/D5R & Liu et al., 2000 \\
GABA-A R/D2R heteromeric & Perez de la Mora et al., 1997 \\
$\quad$ complexes & \\
NMDAR/D1R & Lee et al., 2002a,b \\
A2AR/D3R & Torvinen et al., 2005 \\
D2 autoreceptor/nicotinic receptor & Li et al., 1995 \\
$\quad$ heteromeric complexes & Quarta et al., 2007 \\
NMDAR/D2R & Liu et al., 2006 \\
\hline
\end{tabular}

Dopamine receptor containing heteromeric receptor complexes built up of transmitter/modulator receptors activated by different ligands.
5.1. Hypothesis on receptor-connexin interactions in mixed synapses: a possible mechanism for integration between two types of WT

The co-localization of chemical and electrical synapses enables interactions between them that assist in the activity synchronization of central neurons (Tamas et al., 2000), and numerical and analytical techniques indicate that chemical and electrical synapses have complementary roles in the synchronization of interneuronal networks (Kopell and Ermentrout, 2004). It seems possible that the leak of synaptic currents across the electrical synapse diminishes the amplitude of the synaptic responses, and indications have been obtained that electrical synapses by modulating the EPSPs of chemical synapses can regulate the neuronal firing rate (Garcia-Perez et al., 2004).

To understand the function of mixed synapses, it should be noted that there may exist within them a short-term enhancement of intercellular coupling dependent on activity (Pereda and Faber, 1996), and $\mathrm{Ca}^{2+} /$ calmodulin-dependent kinase II can at the same time produce an increase of gap junctional conductance and of glutamate transmission in mixed synapses (Pereda et al., 1998). These findings indicate that the electrical component of the mixed synapse may undergo a form of potentiation similar to LTP, which may e.g., be essential for synchronization of oscillations of high frequency (see Nagy et al., 2004). Based on the work on intramembrane receptor-receptor interactions discussed above (see Agnati et al., 2000b, 2005b; Fuxe et al., 2003a, 2007), involving the formation of various types of receptor mosaics containing G-protein-coupled receptors and/or ion channel linked receptors, we now introduce the hypothesis that mixed synapses are formed to enable direct receptor-connexin interactions, which inter alia may help explain the LTP like phenomena observed in the gap junctions (Fig. 11). Activation of the receptor, of e.g., one of the glutamate receptor subtypes, may produce conformational changes of the gap junctions, namely in the participating connexin36, connexin45 or connexin57 proteins, depending on the neuronal subtype, and the same may also be true for pannexin 1 and 2 proteins, also forming electrical synapses (Sohl et al., 2005; Nagy et al., 2004). Such conformational changes in connexin and pannexin proteins may lead to alterations in the electrical conductance either by themselves and/or by altering the availability of different types of kinases to the cytosolic parts of the connexin and pannexin proteins, like $\mathrm{Ca}^{2+}$ / calmodulin-dependent kinase II (Fig. 11).

Such receptor-protein interactions may probably be receptor and protein subtype specific and exist both pre- and postsynaptically, based on the previous work on receptorreceptor interactions (see above). Dependent on the molecular composition, three types of gap junctions likely exist, described as heteromeric, heterotypic and homomeric/homotypic (see Sohl et al., 2005). The homomeric or heteromeric hemichannels are built up of one or more connexin (or pannexin) isoforms, respectively. The homotypic or heterotypic gap junctions consist of two identical or two different hemichannels, respectively. Each hemichannel consists of six connexin protein subunits. It is of interest that the connexin 


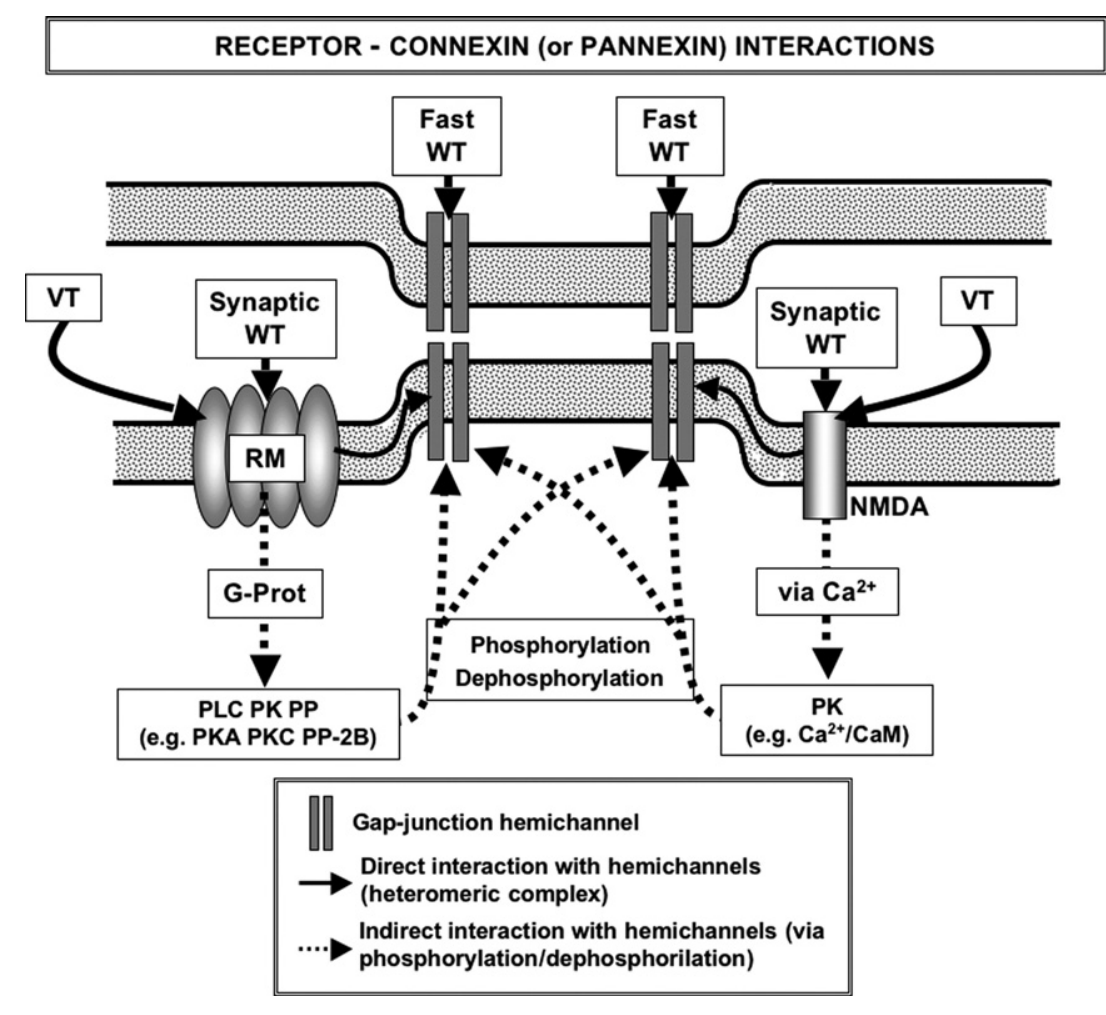

Fig. 11 - Illustration of the present hypothesis on receptor-connexin (or pannexin) interactions. Synaptic WT and VT may regulate fast WT through gap junctions in e.g., electrical synapses and mixed synapses, via a molecular mechanism causing changes in the conductance of the gap junction channels. There could exist a direct interaction with hemichannels with the formation of heteromeric complexes of receptors and connexin protein subtypes (or pannexin protein subtypes). Indirect interactions with hemichannels could also exist via phosphorylation/dephosphorylation mechanisms. Both mechanisms could exist in parallel to fine-tune the fast WT via gap junctions.

proteins differ mainly in the cytoplasmic loop and in the Cterminal tail.

These domains are therefore of special interest when exploring possible subtype specific receptor-connexin protein interactions, considering connexin36, 45 and 57 proteins known to exist in the electrical synapses. It is also reasonable that the heteromeric versus homomeric electrical synapses can differentially participate in the receptor-connexin (pannexin) interactions. Another type of receptor-connexin interaction could be via a receptor modulation of the dynamic trafficking and delivery of connexons (assembly of six connexin proteins forming a hemichannel on one side of the gap junction channel) to the plasma membrane (Lauf et al., 2002). Thus, the receptor signaling may alter the gene expression of the connexin proteins, and receptors may form heteromeric complexes with the connexons or pannexons. The receptors may also alter the accrual of connexons or pannexons to the outer margins of the gap junction channel clusters and in this way modulate the strength of the electrical synapses.

It should be considered that a differential expression of the three gap junction proteins exists in brain development versus the adult brain (Dermietzel et al., 1989; Bruzzone and Dermietzel, 2006). Therefore, also receptor-connexin interactions may differ in brain development compared with adult brain. Recently, axo-axonal coupling has been intro- duced as a new mechanism for ultrafast neuronal communication (Schmitz et al., 2001). In view of the existence of receptors on pre-terminal axons (Riad et al., 2000; Jansson et al., 2002), receptor-connexin (or pannexin) interactions may also exist here, modulating this ultrafast neuronal communication.

5.2. On the role of WT and VT and their integration in the monoamine neurons

\subsubsection{The nigro-striatal dopamine system}

In 1983, Grace and Bunney demonstrated in adult rats dye coupling between nigral DA cells, suggesting that functional gap junctions may exist between them (Grace and Bunney, 1983). This indicated a new mechanism for regulation of DA cell firing via very fast WT besides their inhibitory regulation by D2 autoreceptors (Skirboll et al., 1979). Twenty years later, juvenile rats were shown to express connexin proteins in DA cells of the midbrain (Leung et al., 2002), strengthening the possibility that synchronous burst firing of DA nerve cells, strongly enhancing VT in the DA terminal networks (Gonon, 1988), may be promoted by electrical synapses (very fast WT).

Recently, functional electrical synapses between nigral DA cells were demonstrated in the postnatal period using dual whole-cell patch cell recordings, which correlated with tracer coupling analysis (Vandecasteele et al., 2005). However, 
tonically active electrically coupled DA neurons did not become synchronized, which may be related to the need of non-pulsatile and constantly maintained DA VT in the striatal target region. The impact of the very fast WT, however, was made evident by the fact that the slow nigral DA VT, with dendritically released DA activating inhibitory D2 autoreceptors, could not block the ability of one depolarizing DA cell to enhance the spontaneous firing rate of its electrically coupled DA neuron. Nevertheless, only $27 \%$ of the tonically active DA neurons show synchronization of their activity (Morris et al., 2004).

Again, to understand the interaction between the very fast WT and slow DA VT in the substantia nigra, the existence of D2-like autoreceptor-connexin protein interactions should be seriously considered. It may be that the DA VT via such interactions can uncouple the electrical synapses so efficiently that only a limited number of tonically active DA neurons can present a synchronous firing. However, it is important to note that in mathematical models of DA cell pairs, considering also excitatory NMDA mediated glutamate synaptic transmission, the electrotonic coupling is strongly predicted to promote synchronous phasic firing (Komendantov and Canavier, 2002), in agreement with the work on electrotonic coupling in the locus coeruleus discussed below.

Thus, it seems likely that very fast WT involving electrical synapses in the nigral DA cells via promotion of synchronous burst firing in clusters of nigral DA cells can enhance VT in the striatal DA terminal networks through the resulting brief peaks of DA release. DA pulses of longer duration using microdialysis have also been detected (Agnati et al., 2000b). In early Parkinson's disease, the reduction of DA VT in the substantia nigra due to degeneration of certain DA cells may lead to an increase in synchronous phasic firing of the DA cells, due to enhancement of activity in the electrical synapses as discussed above. This can substantially underlie the increases in striatal DA release and turnover observed in models of Parkinson's disease (see Fuxe, 1979; Zigmond, 2000), which serves to increase DA VT in the terminal plexa to compensate for the reduction of DA transmission (Fuxe and Agnati, 1991a). As the disease progresses, however, also the electrical synapses between DA cells will be reduced, diminishing this compensatory upregulation, since the increased synchronous phasic firing will fade and clinical symptoms develop.

\subsubsection{The locus coeruleus noradrenaline system}

As discussed, the major mode of communication of the locus coeruleus NA terminal networks in the widespread target regions of the CNS is VT, which via diffusion of NA globally modulate the activity and metabolism of large cell populations (see Fuxe and Agnati, 1991a,b). One way to increase VT in the widespread NA terminal networks would be synchronous activation of the NA nerve cells of the locus coeruleus, which also would represent an elegant way to regulate NA tone in the target areas (Christie et al., 1989; Aston-Jones et al., 1991). Such a synchronous activation could be brought about by an electrotonic coupling between the LC NA nerve cells via neuronal gap junctions representing a very fast form of WT. The first observations to support such a mechanism were made by Christie et al. (1989) showing based on paired recordings that electrotonic coupling synchronizes subthreshold activity in LC NA cells in vitro from neonatal rats. The coupling caused the synchronized occurrence of membrane potential oscillations, with the appearance of rhythmic background activity in the entire LC which became reduced with increased age. Later on, dye coupling among the LC NA cells could be demonstrated in the postnatal period (Christie and Jelinek, 1993).

In an analysis of opioid inhibition of the LC of neonatal rats using also agents blocking electrotonic coupling (Travagli et al., 1995), further support was obtained for the existence of electrotonic coupling among LC NA cells. Such a mechanism was proposed to facilitate inhibition by opioid peptides of LC cells, in addition to synchronous activation as previously proposed. In fact, morphine has been shown in vivo to reduce discharge and to enhance the burst firing pattern of LC cells in awake animals (Aston-Jones et al., 1992). However, electrotonic or dye coupling could not be demonstrated in adult rats, unless made under certain conditions.

Subsequently, synchronous activity in LC cells could be demonstrated in adult rats and shown to depend on electrotonic coupling between LC NA dendrites in peri-coerulear regions, using gap junction blockers which reduced synchronization without blocking electrical activity (Ishimatsu and Williams, 1996). The dendritic tree has been shown to extend beyond the NA cell body region (Shipley et al., 1996). The findings indicate that the electrotonic coupling in the LC may mainly serve to increase synchrony upon arrival of a strong excitatory input. In 2000, LC neurons and astroglia were also shown to be electrotonically coupled by the presence of electrical and tracer transfer between the two types of cells including the presence of gap junction proteins (AlvarezMaubecin et al., 2000). In agreement, selective depolarization of glia by activation of glutamate transporters indirectly increased LC NA cell activity.

Thus, the evidence discussed above indicates that simultaneous increases in NA VT in the widespread target areas of the LC may be made possible by synchronization of the LC activity through electrotonic coupling and synaptic transmission representing very fast and fast WT, respectively. It should be considered that the molecular mechanism discussed above on the existence of receptor-connexin interactions could assist in the strengthening of the electrotonic coupling, and thus in the synchronization of the LC NA cell firing. The relevance of synchronization via WT in the LC is made clear by the correlation of periods of high performance in a behavioral task with increases in phasic LC activity, shown to be synchronous in paired recordings (Usher et al., 1999).

Thus, through increased WT in the LC leading to synchronization of the LC NA cells, the LC NA terminal networks can become optimally activated at the same time in the different widespread target regions, including especially the entire cerebral and cerebellar cortex, and via increased NA VT activate the various adrenergic subtypes in the vast numbers of neuronal and glial cell populations, including also other non-neuronal cells. In this way, LC can via WT and VT function optimally as a survival system enhancing arousal, attention and behavioral and cognitive performance. The sleep-wakefulness function is characterized by a latency, a 
plateau and a slow decay and is therefore suitable to be regulated by the slow VT in the LC NA neurons, modulating entire networks with the reset of the activity of widespread cellular networks of several target regions.

In view of the above, it seems likely that a dysfunction of the LC NA system may contribute to attention deficit hyperactivity disorders (ADHD). It should be considered that also the precursor DA is released from the cortical NA nerve terminals and may via VT reach and activate dopamine D4 receptors located on pyramidal and non-pyramidal nerve cells found all over the cerebral cortex (Rivera, Fuxe et al., unpublished data). In addition, these receptors have a high affinity for NA (Newman-Tancredi et al., 1997), and the D4 IR is in fact more closely related to the widespread NA terminal plexa than the restricted DA terminal plexa (Rivera, Fuxe et al., unpublished data). The diffusing DA from NA nerve terminals, besides the DA from the meso-cortical DA neurons, may also reach D2-like receptors in the prefrontal cortex, which when stimulated causes an inhibition of locomotor activity (see Del Arco et al., 2007). Such VT mechanisms in cortical DA and NA communication likely explain why psychostimulant drugs releasing DA and NA are successfully used in the treatment of ADHD.

\subsubsection{The dorsal raphe 5-HT neuron system}

As discussed, the serotonergic system has been shown to play a major role in mood regulation, and the widespread 5-HT terminal networks operate mainly via VT to reset the activity of many cellular networks of the tel- and diencephalon, especially in the cerebral cortex. It is of substantial interest that, in the developing somatosensory cortex, 5-HT receptors can reduce gap junction coupling (Rorig and Sutor, 1996). It was found that 5-HT reduced the dye coupling in pyramidal cells via 5-HT2 receptors, and the uncoupling was blocked by IP3 receptor antagonists and PKC inhibitors (Rorig and Sutor, 1996). Thus, at least in development, 5-HT via VT can modulate gap junctional transmission and thus WT in the differentiating neocortex. It may be suggested that the molecular mechanism may involve 5-HT2-connexin protein (or pannexin) interactions, permitting integration of VT and WT.

Like in the locus coeruleus, it is of interest to know if there exist in the 5-HT cell bodies in the nucleus raphe dorsalis a mechanism to synchronize the firing rate of the 5-HT cells to enhance at the same time $5-\mathrm{HT}$ release and VT in several target regions. The firing pattern of $5-\mathrm{HT}$ cells is characterized by slow, regular spontaneous discharge rates of $0.5-3 \mathrm{~Hz}$ (Aghajanian and Haigler, 1974). In 1982, their correlative firing patterns were analyzed, and adjacent 5-HT cell pairs showed correlated discharges within a short time frame below $10 \mathrm{~ms}$. Thus, a synchronous firing pattern was observed between adjacent 5-HT nerve cells (Wang and Aghajanian, 1982). The mechanism was, however, unclear at this time. In 1975, dendro-dendritic gap junctions were observed in the developing dorsal raphe nucleus (Möllgard and Möller, 1975), and dendrite bundles were observed in this 5-HT cell rich nucleus (Felten and Harrigan, 1980), where gap junctions could be formed.

In 1995, dye coupling between dorsal raphe neurons from young adult rats was discovered probably mainly occurring via dendro-dendritic gap junctions (Stezhka and Lovick, 1995).
The results suggested a substantial level of electrotonic coupling between dorsal raphe cells, which may be the major mechanism for synchronous firing of the 5-HT nerve cells. In support of this view, a high degree of synchrony of firing was observed in pairs of dorsal raphe 5-HT cells (Hajos et al., 1994). Thus, very fast WT may exist in the dorsal raphe 5HT cell assembly to produce synchronization of firing of clusters of 5-HT nerve cells, enhancing 5-HT VT in several target regions (Fuxe and Agnati, 1991a,b), and in this way counteract the lowering of mood and the development of depression.

Indications of 5-HT release in the nucleus raphe dorsalis were obtained early (Fuxe and Ungerstedt, 1970; Hery et al., 1982), and 5-HT receptor activation within the nucleus could cause the inhibition of firing observed under conditions of increased extracellular 5-HT (see Wang and Aghajanian, 1982). In 1986, vesicle containing dendrites were observed in the nucleus raphe dorsalis in the cat, indicating dendritic release of 5-HT in this nucleus (Chazal and Ohara, 1986). It is suggested based on the findings of Rorig and Sutor (1996) and on the above discussion that activation of dendritic 5-HT receptors via 5-HT receptor-connexin interactions can uncouple the dendritic gap junctions, which then no longer can promote the synchronous bursting actions of excitatory glutamate inputs. Such a mechanism can contribute to the inhibition of firing observed. Thus, a novel mechanism for depression may be by producing deficits in the very fast WT in the 5 -HT cell clusters of the dorsal raphe, through interference with the neuronal gap junction conductance, in this way reducing synchronization and phasic firing. 5-HT VT in the dorsal raphe may contribute to such deficits in very fast WT.

\section{Conclusions}

(i) The work on the monoamine neurons has over many years strongly contributed to giving experimental evidence for the existence of VT in the brain and spinal cord and has contributed to the development of the theory of how VT and WT in complementary ways operate in central neurons.

(ii) The same principles of communication appear to exist in all the three monoamine neurons, with electrical and chemical synapses interacting with monoamine VT signals in clusters of monoamine cell bodies to produce synchronous bursting activity to strongly enhance the monoamine VT in the widespread terminal plexa of many target regions. In this way, an optimal function of the DA, NA and 5-HT neuron systems can be obtained.

(iii) The WT and VT modes of communication interact via direct or indirect receptor-receptor interactions at the membrane, cytoplasmic and nuclear levels in the cellular circuits.

(iv) GPCR/RTK receptor interactions may play a crucial role in mediating the GPCR-mediated VT signaling in neuronal plasticity and trophism, as exemplified in 5HT VT and depression.

(v) The hypothesis is introduced that electrical synaptic transmission (very fast WT) can be integrated with VT and chemical synaptic transmission (fast WT) via 
receptor-connexin (pannexin) protein interactions, which may be fundamental in understanding the regulation of synchronous burst activity in the transmitter-identified cell body clusters.

(vi) Knowing the integration of WT and VT will be fundamental for the understanding of brain function in health and disease.

\section{Acknowledgments}

This work has been supported by grants from the Swedish Research Council, the Knut and Alice Wallenberg Foundation and the Marianne and Marcus Wallenberg Foundation and also by a grant from the European Commission (QLG3-CT2001-01056).

\section{REFERENCES}

Aghajanian, G.K., Haigler, H.J., 1974. L-Tryptophan as a selective histochemical marker for serotonergic neurons in single-cell recording studies. Brain Res. 81, 364-372.

Agnati, L.F., Fuxe, K., 1996. The impact of histological techniques in revealing brain function. Volume transmission: From fluorescence histochemistry to confocal laser microscopy. In: Fuxe, K., Hökfelt, T., Olson, L., Ottoson, D., Dahlström, A., Björklund, A. (Eds.), Molecular Mechanisms of Neuronal Communication. Wenner-Gren International Series, vol. 58. Pergamon Press, London, pp. 251-277.

Agnati, L.F., Fuxe, K., 2000. Volume transmission as a key feature of information handling in the central nervous system possible new interpretative value of the Turing's B-type machine. Prog. Brain Res. 125, 3-19.

Agnati, L.F., Andersson, K., Wiesel, F., Fuxe, K., 1979. A method to determine dopamine levels and turnover rate in discrete dopamine nerve terminal systems by quantitative use of dopamine fluorescence obtained by Falck-Hillarp methodology. J. Neurosci. Methods 1, 365-373.

Agnati, L.F., Fuxe, K., Zini, I., Lenzi, P., Hökfelt, T., 1980. Aspects on receptor regulation and isoreceptor identification. Med. Biol. 58, 182-187.

Agnati, L.F., Fuxe, K., Zoli, M., Rondanini, C., Ögren, S.-O., 1982. New vistas on synaptic plasticity: Mosaic hypothesis of the engram. Med. Biol. 60, 183-190.

Agnati, L.F., Fuxe, K., Benfenati, F., Celani, M.F., Battistini, N., Mutt, V., Cavicchioli, L., Galli, G., Hökfelt, T., 1983. Differential modulation by CCK- 8 and CCK- 4 of [3H]spiperone binding sites linked to dopamine and 5-hydroxytryptamine receptors in the brain of the rat. Neurosci. Lett. 35, 179-183.

Agnati, L.F., Fuxe, K., Zoli, M., Ozini, I., Toffano, G., Ferraguti, F., 1986a. A correlation analysis of the regional distribution of central enkephalin and beta-endorphin immunoreactive terminals and of opiate receptors in adult and old male rats. Evidence for the existence of two main types of communication in the central nervous system: The volume transmission and the wiring transmission. Acta Physiol. Scand. 128, 201-207.

Agnati, L.F., Fuxe, K., Zoli, M., Pich, E.M., Benfenati, F., Zini, I., Goldstein, M., 1986b. Aspects on the information handling by the central nervous system: Focus on cotransmission in the aged rat brain. Prog. Brain Res. 68, 291-301.

Agnati, L.F., Tiengo, M., Ferraguti, F., Biagini, G., Benfenati, F., Benedetti, C., Rigoli, M., Fuxe, K., 1991. Pain, analgesia, and stress: An integrated view. Clin. J. Pain. 7 (Suppl. 1), S23-S37.
Agnati, L.F., Bjelke, B., Fuxe, K., 1992. Volume transmission in the brain. Am. Sci. 80, 362-373.

Agnati, L.F., Zoli, M., Biagini, G., Bjelke, B., Fuxe, K., Benfenati, F., 1993. Neurophysiological aspects of pain. Anaesth. Pharmacol. Rev. 2, 101-113.

Agnati, L.F., Cortelli, P., Biagini, G., Bjelke, B., Fuxe, K., 1994. Different classes of volume transmission signals exist in the central nervous system and are affected by metabolic signals, temperature gradients and pressure waves. NeuroReport 6, 9-12.

Agnati, L.F., Tinner, B., Staines, W.A., Vaananen, K., Fuxe, K., 1995. On the cellular localization and distribution of carbonic anhydrase II immunoreactivity in the rat brain. Brain Res. 676 (1), 10-24.

Agnati, L.F., Fuxe, K., Nicholson, C., Sykova, E. (Eds.), 2000a. Volume Transmission Revisited. Elsevier, Amsterdam.

Agnati, L.F., Zoli, M., Ferrari, R., Di Paola, L., Torri, C., Fuxe, K., Zini, I., 2000b. Evidence for the existence of pulses of dopamine in the extracellular space of the rat striatum. Prog. Brain Res. 125, 303-308.

Agnati, L.F., Ferré, S., Lluis, C., Franco, R., Fuxe, K., 2003a. Molecular mechanisms and therapeutical implications of intramembrane receptor/receptor interactions among heptahelical receptors with examples from the striatopallidal GABA neurons. Pharmacol. Rev. 55, 509-550.

Agnati, L.F., Franzén, O., Ferré, S., Leo, G., Franco, R., Fuxe, K., 2003b. Possible role of intramembrane receptor-receptor interactions in memory and learning via formation of long-lived heteromeric complexes: Focus on motor learning in the basal ganglia. J. Neural Transm. 1-28.

Agnati, L.F., Genedani, S., Lenzi, P.L., Leo, G., Mora, F., Ferré, S., Fuxe, K., 2005a. Energy gradients for the homeostatic control of brain ECF composition and for VT signal migration: Introduction of the tide hypothesis. J. Neural Transm. 112, 45-63.

Agnati, L.F., Tarakanov, A.O., Ferré, S., Fuxe, K., Guidolin, D., 2005 b. Receptor-receptor interactions, receptor mosaics, and basic principles of molecular network organization: Possible implications for drug development. J. Mol. Neurosci. 26, 193-208.

Agnati, L.F., Ferré, S., Fuxe, K., 2006a. On the neurobiological basis of consciousness the multiple mirror network hypothesis. In: Locks, J.T. (Ed.), New Research on Consciousness. Nova Science Publishers, Inc., Hauppauge, NY, pp. 65-81.

Agnati, L.F., Leo, G., Zanardi, A., Genedani, S., Rivera, A., Fuxe, K., Guidolin, D., 2006b. Volume transmission and wiring transmission from cellular to molecular networks: History and perspectives. Acta Physiol. (Oxford) 187, 329-344.

Agnati, L.F., Zunarelli, E., Genedani, S., Fuxe, K., 2006c. On the existence of a global molecular network enmeshing the whole central nervous system: Physiological and pathological implications. Curr. Protein Pept. Sci. 7, 3-15.

Agnati, L.F., Guidolin, D., Fuxe, K., 2007. The brain as a system of nested but partially overlapping networks. Heuristic relevance of the model for brain physiology and pathology. J. Neural Transm. 114, 3-19.

Akil, H., Richardson, D.E., Barchas, J.D., Li, C.H., 1978. Appearance of beta-endorphin-like immunoreactivity in human ventricular cerebrospinal fluid upon analgesic electrical stimulation. Proc. Natl. Acad. Sci. U. S. A. 75, 5170-5172.

Albert, P.R., Lembo, P., Storring, J.M., Charest, A., Saucier, C., 1996. The 5-HT1A receptor: Signaling, desensitization, and gene transcription. Neuropsychopharmacology 14, 19-25.

Alheim, K., Chai, Z., Fantuzzi, G., Hasanvan, H., Malinowsky, D., Di Santo, E., Ghezzi, P., Dinarello, C.A., Bartfai, T., 1997. Hyperresponsive febrile reactions to interleukin (IL) 1alpha and IL-1beta, and altered brain cytokine mRNA and serum cytokine levels, in IL-1beta-deficient mice. Proc. Natl. Acad. Sci. U. S. A. 94, 2681-2686. 
Alvarez-Maubecin, V., Garcia-Hernandez, F., Williams, J.T., Van Bockstaele, E.J., 2000. Functional coupling between neurons and glia. J. Neurosci. 20, 4091-4098.

Amara, S.G., Kuhar, M.J., 1993. Neurotransmitter transporters: Recent progress. Annu. Rev. Neurosci. 16, 73-93.

Andén, N.E., Carlsson, A., Dahlström, A., Fuxe, K., Hillarp, N.A., Larsson, K., 1964a. Demonstration and mapping out of nigro-neostriatal dopamine neurons. Life Sci. 3, 523-530.

Andén, N.E., Jukes, M.G., Lundberg, A., 1964b. Spinal reflexes and monoamine liberation. Nature 202, 1222-1223.

Andén, N.E., Dahlström, A., Fuxe, K., Larsson, K., 1965a. Further evidence for the presence of nigro-neostriatal dopamine neurons in the rat. Am. J. Anat. 116, 329-333.

Andén, N.E., Dahlström, A., Fuxe, K., Larsson, K., 1965b. Mapping out of catecholamine and 5-hydroxytryptamine neurons innervating the telencephalon and diencephalon. Life Sci. 4, 1275-1279.

Andén, N.E., Dahlström, A., Fuxe, K., Larsson, K., Olson, L., Ungerstedt, U., 1966a. Ascending monoamine neurons to the telencephalon and diencephalon. Acta Physiol. Scand. 67, 313-326.

Andén, N.E., Dahlström, A., Fuxe, K., Larsson, K., 1966b. Functional role of the nigro-neostriatal dopamine neurons. Acta Pharmacol. Toxicol. (Copenh.) 24, 263-274.

Andén, N.E., Dahlström, A., Fuxe, K., Olson, L., Ungerstedt, U., 1966c. Ascending noradrenaline neurons from the pons and the medulla oblongata. Experientia 22, 44-45.

Andén, N.E., Fuxe, K., Larsson, K., 1966d. Effect of large mesencephalic-diencephalic lesions on the noradrenalin, dopamine and 5-hydroxytryptamine neurons of the central nervous system. Experientia 22, 842-843.

Andén, N.E., Corrodi, H., Fuxe, K., Hökfelt, T., 1968. Evidence for a central 5-hydroxytryptamine receptor stimulation by lysergic acid diethylamide. Br. J. Pharmacol. 34, 1-7.

Andén, N.E., Butcher, S.G., Corrodi, H., Fuxe, K., Ungerstedt, U., 1970. Receptor activity and turnover of dopamine and noradrenaline after neuroleptics. Eur. J. Pharmacol. 11, 303-314

Andén, N.E., Corrodi, H., Fuxe, K., 1971. Hallucinogenic drugs of the indolealkylamine type and central monoamine neurons J. Pharmacol. Exp. Ther. 179, 236-249.

Andersson, K., Fuxe, K., Eneroth, P., Nyberg, F., Roos, P., 1981. Rat prolactin and hypothalamic catecholamine nerve terminal systems. Evidence for rapid and discrete increases in dopamine and noradrenaline turnover in the hypophysectomized male rat. Eur. J. Pharmacol. 76, 261-265.

Andersson, K., Fuxe, K., Eneroth, P., Isaksson, O., Nyberg, F., Roos, P., 1983. Rat growth hormone and hypothalamic catecholamine nerve terminal systems. Evidence for rapid and discrete reductions in dopamine and noradrenaline levels and turnover in the median eminence of the hypophysectomized male rat. Eur. J. Pharmacol. 95, 271-275

Andersson, K., Fuxe, K., Agnati, L.F., Eneroth, P., Camurri, M., 1984. Luteinizing hormone-releasing hormone increases dopamine turnover in the lateral palisade zone of the median eminence and reduces noradrenaline turnover in the nuc. preopticus medialis of the hypophysectomized male rat. Neurosci. Lett. 45, 253-258.

Andersson, K., Eneroth, P., Roos, P., 1985a. Effects of TRH and a rat TSH preparation on discrete hypothalamic and forebrain catecholamine nerve terminal networks in the hypophysectomized male rat. Eur. J. Pharmacol. 111, 295-307.

Andersson, K., Fuxe, K., Agnati, L.F., 1985b. Determinations of catecholamine half-lives and turnover rates in discrete catecholamine nerve terminal systems of the hypothalamus, the preoptic region and the forebrain by quantitative histofluorimetry. Acta Physiol. Scand. 123, 411-426.
Andersson, P.B., Perry, V.H., Gordon, S., 1992. The acute inflammatory response to lipopolysaccharide in CNS parenchyma differs from that in other body tissues Neuroscience 48, 169-186.

Andrews, Z.B., Rivera, A., Elsworth, J.D., Roth, R.H., Agnati, L., Gago, B., Abizaid, A., Schwartz, M., Fuxe, K., Horvath, T.L., 2006. Uncoupling protein-2 promotes nigrostriatal dopamine neuronal function. Eur. J. Neurosci. 24, 32-36.

Anthony, D.C., Bolton, S.J., Fearn, S., Perry, V.H., 1997. Age-related effects of interleukin-1 beta on polymorphonuclear neutrophil-dependent increases in blood-brain barrier permeability in rats. Brain 120 (Pt. 3), 435-444.

Aoki, C., 1992. Beta-adrenergic receptors: Astrocytic localization in the adult visual cortex and their relation to catecholamine axon terminals as revealed by electron microscopic immunocytochemistry. J. Neurosci. 12, 781-792.

Aoki, C., Pickel, V.M., 1992. Ultrastructural relations between beta-adrenergic receptors and catecholaminergic neurons. Brain Res. Bull. 29, 257-263.

Aoki, C., Venkatesan, C., Go, C.G., Mong, J.A., Dawson, T.M., 1994. Cellular and subcellular localization of NMDA-R1 subunit immunoreactivity in the visual cortex of adult and neonatal rats. J. Neurosci. 14, 5202-5222.

Aoki, C., Venkatesan, C., Go, C.G., Forman, R., Kurose, H., 1998. Cellular and subcellular sites for noradrenergic action in the monkey dorsolateral prefrontal cortex as revealed by the immunocytochemical localization of noradrenergic receptors and axons. Cereb. Cortex 8, 269-277.

Artigas, F., Romero, L., de Montigny, C., Blier, P., 1996. Acceleration of the effect of selected antidepressant drugs in major depression by 5-HT1A antagonists. Trends Neurosci. 19, 378-383.

Aston-Jones, G., 2005. Brain structures and receptors involved in alertness. Sleep Med. 6 (Suppl. 1), S3-S7.

Aston-Jones, G., Bloom, F.E., 1981a. Norepinephrine-containing locus coeruleus neurons in behaving rats exhibit pronounced responses to non-noxious environmental stimuli. J. Neurosci. 1, 887-900.

Aston-Jones, G., Bloom, F.E., 1981b. Activity of norepinephrine-containing locus coeruleus neurons in behaving rats anticipates fluctuations in the sleep-waking cycle. J. Neurosci. 1, 876-886.

Aston-Jones, G., Cohen, J.D., 2005a. Adaptive gain and the role of the locus coeruleus-norepinephrine system in optimal performance. J. Comp. Neurol. 493, 99-110.

Aston-Jones, G., Cohen, J.D., 2005b. An integrative theory of locus coeruleus-norepinephrine function: Adaptive gain and optimal performance. Annu. Rev. Neurosci. 28, 403-450.

Aston-Jones, G., Shipley, M.T., Chouvet, G., Ennis, M., van Bockstaele, E., Pieribone, V., Shiekhattar, R., Akaoka, H., Drolet, G., Astier, B., et al., 1991. Afferent regulation of locus coeruleus neurons: Anatomy, physiology and pharmacology. Prog. Brain Res. 88, 47-75.

Aston-Jones, G., Rajkowski, J., Kubiak, P., Akaoka, H., 1992. Acute morphine induces oscillatory discharge of noradrenergic locus coeruleus neurons in the waking monkey. Neurosci. Lett. 140, 219-224.

Attwell, D., Barbour, B., Szatkowski, M., 1993. Nonvesicular release of neurotransmitter. Neuron 11, 401-407.

Azmitia, E.C., 2001. Modern views on an ancient chemical: Serotonin effects on cell proliferation, maturation, and apoptosis. Brain Res. Bull. 56, 413-424.

Azmitia, E.C., Whitaker-Azmitia, P.M., 1991. Awakening the sleeping giant: Anatomy and plasticity of the brain serotonergic system. J. Clin. Psychiatry 52, 4-16.

Azmitia, E.C., Gannon, P.J., Kheck, N.M., Whitaker-Azmitia, P.M., 1996. Cellular localization of the 5-HT1A receptor in primate brain neurons and glial cells. Neuropsychopharmacology 14, $35-46$. 
Baker, D., Shen, H., Kalivas, P.W., 2001. Cystine/glutamate exchange serves as the source for extracellular glutamate: Modifications by repeated cocaine administration. In: O'Connor, W.T., Lowry, J.P., O'Connor, J.J., O’Neill, R.D. (Eds.), Monitoring Molecules in Neuroscience. University College Dublin, Dublin, pp. 289-290.

Barinaga, M., 1993. Secrets of secretion revealed. Science 260, 487-489.

Barres, B.A., Chun, L.L., Corey, D.P., 1990. Ion channels in vertebrate glia. Annu. Rev. Neurosci. 13, 441-474.

Baude, A., Shigemoto, R., 1998. Cellular and subcellular distribution of substance $P$ receptor immunoreactivity in the dorsal vagal complex of the rat and cat: A light and electron microscope study. J. Comp. Neurol. 402, 181-196.

Beaudet, A., Descarries, L., 1978. The monoamine innervation of rat cerebral cortex: Synaptic and nonsynaptic axon terminals. Neuroscience 3, 851-860.

Behzadi, Y., Lui, T.T., 2005. An arteriolar compliance model of the cerebral blood flow response to neural stimulus. Neuroimage. 25 (4), 1100-1111.

Bellido, I., Diaz-Cabiale, Z., Jimenez-Vasquez, P.A., Andbjer, B., Mathé, A.A., Fuxe, K., 2002. Increased density of galanin binding sites in the dorsal raphe in a genetic rat model of depression. Neurosci. Lett. 317, 101-105.

Belluardo, N., Wu, G., Mudo, G., Hansson, A.C., Pettersson, R., Fuxe, K., 1997. Comparative localization of fibroblast growth factor receptor-1, -2 , and -3 mRNAs in the rat brain: In situ hybridization analysis. J. Comp. Neurol. 379, 226-246.

Ben-Jonathan, N., Oliver, C., Weiner, H.J., Mical, R.S., Porter, J.C., 1977. Dopamine in hypophysial portal plasma of the rat during the estrous cycle and throughout pregnancy. Endocrinology 100, 452-458.

Bennett, M.V., Goodenough, D.A., 1978. Gap junctions, electrotonic coupling, and intercellular communication. Neurosci. Res. Program Bull. 16, 1-486.

Berghuis, P., Dobszay, M.B., Wang, X., Spano, S., Ledda, F., Sousa, K.M., Schulte, G., Ernfors, P., Mackie, K., Paratcha, G., Hurd, Y.L., Harkany, T., 2005. Endocannabinoids regulate interneuron migration and morphogenesis by transactivating the TrkB receptor. Proc. Natl. Acad. Sci. U. S. A. 102, 19115-19120.

Bjelke, B., Fuxe, K., 1993. Intraventricular beta-endorphin accumulates in DARPP-32 immunoreactive tanycytes. NeuroReport 5, 265-268.

Bjelke, B., Fuxe, K., Agnati, L.F., 1988. Survival of adenohypophyseal homologous transplants in the rat striatum associated with prolactin-like immunoreactivity in the surrounding neuropil of the striatum. Neurosci. Lett. 93, 139-145.

Bjelke, B., Fuxe, K., Agnati, L.F., 1989. Increased diffusion of prolactin-like material into the brain neuropil from homologous adenohypophyseal transplants in the rat neostriatum after a 6-OH-dopamine induced degeneration of the mesostriatal dopamine neurons. Neurosci. Lett. 107, 33-38.

Bjelke, B., England, R., Nicholson, C., Rice, M.E., Lindberg, J., Zoli, M., Agnati, L.F., Fuxe, K., 1995. Long distance pathways of diffusion for dextran along fibre bundles in brain. Relevance for volume transmission. NeuroReport 6, 1005-1009.

Bjelke, B., Goldstein, M., Tinner, B., Andersson, C., Sesack, S.R., Steinbusch, H.W., Lew, J.Y., He, X., Watson, S., Tengroth, B., Fuxe, K., 1996. Dopaminergic transmission in the rat retina: Evidence for volume transmission. J. Chem. Neuroanat. 12, $37-50$.

Blasberg, R.G., Patlak, C., Fenstermacher, J.D., 1975. Intrathecal chemotherapy: Brain tissue profiles after ventriculocisternal perfusion. J. Pharmacol. Exp. Ther. 195, 73-83.

Bloom, F., Segal, D., 1980. Endorphins in the cerebrospinal fluid. In: Wood, J.H. (Ed.), Neurobiology of Cerebrospinal Fluid. Plenum Press, New York.
Bloom, F., Battenberg, E., Rossier, J., Ling, N., Guillemin, R., 1978. Neurons containing beta-endorphin in rat brain exist separately from those containing enkephalin: Immunocytochemical studies. Proc. Natl. Acad. Sci. U. S. A. 75, 1591-1595.

Bonica, J.J., 1990. Evolution and current status of pain programs. J. Pain Symptom. Manage 5, 368-374.

Boudin, H., Pelaprat, D., Rostene, W., Pickel, V.M., Beaudet, A., 1998. Correlative ultrastructural distribution of neurotensin receptor proteins and binding sites in the rat substantia nigra. J. Neurosci. 18, 8473-8484.

Bowers, C.W., 1994. Superfluous neurotransmitters? Trends Neurosci. 17, 315-320.

Branton, W.D., Mayeri, E., Brownell, P., Simon, S.B., 1978. Evidence for local hormonal communication between neurones in aplysia. Nature 274, 70-72.

Brightman, M.W., 1965. The distribution within the brain of ferritin injected into cerebrospinal fluid compartments: II. Parenchymal distribution. Am. J. Anat. 117, 193-219.

Brightman, M.W., Kaya, M., 2000. Permeable endothelium and the interstitial space of brain. Cell. Mol. Neurobiol. 20, 111-130.

Brownlees, J., Williams, C.H., 1993. Peptidases, peptides, and the mammalian blood-brain barrier. J. Neurochem. 60, 793-803.

Bruzzone, R., Dermietzel, R., 2006. Structure and function of gap junctions in the developing brain. Cell Tissue Res. 326, 239-248.

Buma, P., Nieuwenhuys, R., 1988. Ultrastructural characterization of exocytotic release sites in different layers of the median eminence of the rat. Cell Tissue Res. 252, 107-114.

Bunnemann, B., Fuxe, K., Bjelke, B., Ganten, D., 1991. The brain renin-angiotensin-system and its possible involvement in volume transmission. In: Fuxe, K., Agnati, L.F. (Eds.), Volume Transmission in the Brain: Novel Mechanisms for Neural Transmission. Raven Press, New York, pp. 131-158.

Burbach, J.P., 1982. Neuropeptides and cerebrospinal fluid. Ann. Clin. Biochem. 19 (Pt. 4), 269-277.

Burbach, J.P., De Kloet, E.R., Schotman, P., De Wied, D., 1981. Proteolytic conversion of beta-endorphin by brain synaptic membranes. Characterization of generated beta-endorphin fragments and proposed metabolic pathway. J. Biol. Chem. 256, 12463-12469.

Butcher, L., Engel, J., Fuxe, K., 1970. L-dopa induced changes in central monoamine neurons after peripheral decarboxylase inhibition. J. Pharm. Pharmacol. 22, 313-316.

Caberlotto, L., Tinner, B., Bunnemann, B., Agnati, L., Fuxe, K., 1998. On the relationship of neuropeptide Y Y1 receptor-immunoreactive neuronal structures to the neuropeptide Y-immunoreactive nerve terminal networks. A double immunolabelling analysis in the rat brain. Neuroscience 86, 827-845.

Caillé, I., Dumartin, B., Bloch, B., 1996. Ultrastructural localization of D1 dopamine receptor immunoreactivity in rat striatonigral neurons and its relation with dopaminergic innervation. Brain Res. 730, 17-31.

Canales, J.J., 2005. Stimulant-induced adaptations in neostriatal matrix and striosome systems: Transiting from instrumental responding to habitual behavior in drug addiction. Neurobiol. Learn. Mem. 83, 93-103.

Canals, M., Marcellino, D., Fanelli, F., Ciruela, F., de Benedetti, P., Goldberg, S.R., Neve, K., Fuxe, K., Agnati, L.F., Woods, A.S., Ferre, S., Lluis, C., Bouvier, M., Franco, R., 2003. Adenosine A2A-dopamine D2 receptor-receptor heteromerization: Qualitative and quantitative assessment by fluorescence and bioluminescence energy transfer. J. Biol. Chem. 278, $46741-46749$.

Carlsson, A., 1988. The current status of the dopamine hypothesis of schizophrenia. Neuropsychopharmacology 1, 179-186.

Carlsson, A., Lindqvist, M., 1963. Effect of chlorpromazine or 
haloperidol on formation of 3methoxytyramine and normetanephrine in mouse brain. Acta Pharmacol. Toxicol. (Copenh.) 20, 140-144.

Carlsson, A., Falck, B., Hillarp, N.A., 1962. Cellular localization of brain monoamines. Acta Physiol. Scand., Suppl. 56, 1-28.

Carlsson, A., Falck, B., Fuxe, K., Hillarp, N.A., 1964. Cellular localization of monoamines in the spinal cord. Acta Physiol. Scand. 60, 112-119.

Carlsson, A., Fuxe, K., Ungerstedt, U., 1968. The effect of imipramine on central 5-hydroxytryptamine neurons. J. Pharm. Pharmacol. 20, 150-151.

Carlsson, A., Corrodi, H., Fuxe, K., Hökfelt, T., 1969a. Effect of antidepressant drugs on the depletion of intraneuronal brain 5-hydroxytryptamine stores caused by 4-methyl-alpha-ethyl-meta-tyramine. Eur. J. Pharmacol. 5, 357-366.

Carlsson, A., Jonason, J., Lindqvist, M., Fuxe, K., $1969 b$. Demonstration of extraneuronal 5-hydroxytryptamine accumulation in brain following membrane-pump blockade by chlorimipramine. Brain Res. 12, 456-460.

Carr, D.B., Sesack, S.R., 2000. Projections from the rat prefrontal cortex to the ventral tegmental area: Target specificity in the synaptic associations with mesoaccumbens and mesocortical neurons. J. Neurosci. 20, 3864-3873.

Castren, E., 2004. Neurotrophic effects of antidepressant drugs. Curr. Opin. Pharmacol. 4, 58-64.

Chadi, G., Tinner, B., Agnati, L.F., Fuxe, K., 1993. Basic fibroblast growth factor (bFGF, FGF-2) immunoreactivity exists in the noradrenaline, adrenaline and 5-HT nerve cells of the rat brain. Neurosci. Lett. 160, 171-176.

Charney, D.S., 1998. Monoamine dysfunction and the pathophysiology and treatment of depression. J. Clin. Psychiatry 59 (Suppl. 14), 11-14.

Chazal, G., Ohara, P.T., 1986. Vesicle-containing dendrites in the nucleus raphe dorsalis of the cat. A serial section electron microscopic analysis. J. Neurocytol. 15, 777-787.

Chen, K.C., Höistad, M., Kehr, J., Fuxe, K., Nicholson, C., 2002. Quantitative dual-probe microdialysis: Mathematical model and analysis. J. Neurochem. 81, 94-107.

Christie, M.J., Jelinek, H.F., 1993. Dye-coupling among neurons of the rat locus coeruleus during postnatal development. Neuroscience 56, 129-137.

Christie, M.J., Williams, J.T., North, R.A., 1989. Electrical coupling synchronizes subthreshold activity in locus coeruleus neurons in vitro from neonatal rats. J. Neurosci. 9, 3584-3589.

Ciruela, F., Casado, V., Rodrigues, R.J., Lujan, R., Burgueno, J., Canals, M., Borycz, J., Rebola, N., Goldberg, S.R., Mallol, J., Cortes, A., Canela, E.I., Lopez-Gimenez, J.F., Milligan, G., Lluis, C., Cunha, R.A., Ferre, S., Franco, R., 2006. Presynaptic control of striatal glutamatergic neurotransmission by adenosine A1-A2A receptor heteromers. J. Neurosci. 26, 2080-2087.

Colotta, F., Re, F., Muzio, M., Bertini, R., Polentarutti, N., Sironi, M., Giri, J.G., Dower, S.K., Sims, J.E., Mantovani, A., 1993. Interleukin-1 type II receptor: A decoy target for IL-1 that is regulated by IL-4. Science $261,472-475$.

Coyle, J.T., Duman, R.S., 2003. Finding the intracellular signaling pathways affected by mood disorder treatments. Neuron 38, $157-160$

Cuello, A.C., 1983. Nonclassical neuronal communications. Fed. Proc. 42, 2912-2922.

Dahlström, A., Fuxe, K., 1964a. Evidence for the existence of monoamine-containing neurons in the central nervous system. I. Demonstration of monoamines in the cell bodies of brain stem neurons. Acta Physiol. Scand., Suppl. (Suppl. 232), 1-55.

Dahlström, A., Fuxe, K., 1964b. A method for the demonstration of monoamine-containing nerve fibres in the central nervous system. Acta Physiol. Scand. 60, 293-294.

Dahlström, A., Fuxe, K., 1965. Evidence for the existence of monoamine neurons in the central nervous system: II. Experimentally induced changes in the intraneuronal amine levels of bulbospinal neuron systems. Acta Physiol. Scand., Suppl. (Suppl. 247), 1-36.

Dahlström, A., Fuxe, K., Kernell, D., Sedvall, G., 1965. Reduction of the monoamine stores in the terminals of bulbospinal neurones following stimulation in the medulla oblongata. Life Sci. 4, 1207-1212.

Daly, J., Fuxe, K., Jonsson, G., 1973. Effects of intracerebral injections of 5,6-dihydroxytryptamine on central monoamine neurons: Evidence for selective degeneration of central 5-hydroxytryptamine neurons. Brain Res. 49, 476-482.

Daly, J., Fuxe, K., Jonsson, G., 1974. 5,7-Dihydroxytryptamine as a tool for the morphological and functional analysis of central 5-hydroxytryptamine neurons. Res. Commun. Chem. Pathol. Pharmacol. 7, 175-187.

Dana, C., Vial, M., Leonard, K., Beauregard, A., Kitabgi, P., Vincent, J.P., Rostene, W., Beaudet, A., 1989. Electron microscopic localization of neurotensin binding sites in the midbrain tegmentum of the rat. I. Ventral tegmental area and the interfascicular nucleus. J. Neurosci. 9, 2247-2257.

Davis, T.P., Konings, P.N., 1993. Peptidases in the CNS: Formation of biologically active, receptor-specific peptide fragments. Crit. Rev. Neurobiol. 7, 163-174.

DeFelipe, J., Jones, E.G., 1992. Santiago Ramon y Cajal and methods in neurohistology. Trends Neurosci. 15, 237-246.

Del Arco, A., Segovia, G., Fuxe, K., Mora, F., 2003. Changes in dialysate concentrations of glutamate and GABA in the brain: An index of volume transmission mediated actions? J. Neurochem. 85, 23-33.

Del Arco, A., Mora, F., Mohammed, A.H., Fuxe, K., 2007. Stimulation of D2 receptors in the prefrontal cortex reduces PCP-induced hyperactivity, acetylcholine release and dopamine metabolism in the nucleus accumbens. J. Neural Transm. 114, 32-36.

Dermietzel, R., Traub, O., Hwang, T.K., Beyer, E., Bennett, M.V., Spray, D.C., Willecke, K., 1989. Differential expression of three gap junction proteins in developing and mature brain tissues. Proc. Natl. Acad. Sci. U. S. A. 86, 10148-10152.

Descarries, L., 1998. The hypothesis of an ambient level of acetylcholine in the central nervous system. J. Physiol. (Paris) 92, 215-220.

Descarries, L., Mechawar, N., 2000. Ultrastructural evidence for diffuse transmission by monoamine and acetylcholine neurons of the central nervous system. Prog. Brain Res. 125, 27-47.

Descarries, L., Beaudet, A., Watkins, K.C., 1975. Serotonin nerve terminals in adult rat neocortex. Brain Res. 100, 563-588.

Descarries, L., Watkins, K.C., Lapierre, Y., 1977. Noradrenergic axon terminals in the cerebral cortex of rat. III. Topometric ultrastructural analysis. Brain Res. 133, 197-222.

Descarries, L., Seguela, P., Watkins, K.C., 1991. Nonjunctional relationships on monoamine axon terminals in the cerebral cortex of adult rat. In: Fuxe, K., Agnati, L.F. (Eds.), Volume Transmission in the Brain: Novel Mechanisms of Neuronal Transmission. Raven Press, New York, pp. 53-63.

Descarries, L., Watkins, K.C., Garcia, S., Bosler, O., Doucet, G., 1996. Dual character, asynaptic and synaptic, of the dopamine innervation in adult rat neostriatum: A quantitative autoradiographic and immunocytochemical analysis. J. Comp. Neurol. 375, 167-186.

De Wied, D., Jolles, J., 1982. Neuropeptides derived from pro-opiocortin: Behavioral, physiological, and neurochemical effects. Physiol. Rev. 62, 976-1059.

Diaz, J., Levesque, D., Lammers, C.H., Griffon, N., Martres, M.P., Schwartz, J.C., Sokoloff, P., 1995. Phenotypical characterization 
of neurons expressing the dopamine D3 receptor in the rat brain. Neuroscience 65, 731-745.

Djamgoz, M.B., Wagner, H.J., 1992. Localization and function of dopamine in the adult vertebrate retina. Neurochem. Int. 20, 139-191.

Dournaud, P., Boudin, H., Schonbrunn, A., Tannenbaum, G.S., Beaudet, A., 1998. Interrelationships between somatostatin sst2A receptors and somatostatin-containing axons in rat brain: Evidence for regulation of cell surface receptors by endogenous somatostatin. J. Neurosci. 18, 1056-1071.

D'Sa, C., Duman, R.S., 2002. Antidepressants and neuroplasticity. Bipolar Disord. 4, 183-194.

Duggan, A.W., Hope, P.J., Jarrott, B., Schaible, H.G., Fleetwood-Walker, S.M., 1990. Release, spread and persistence of immunoreactive neurokinin A in the dorsal horn of the cat following noxious cutaneous stimulation. Studies with antibody microprobes. Neuroscience 35, 195-202.

Duggan, A.W., Schaible, H.G., Hope, P.J., Lang, C.W., 1992. Effect of peptidase inhibition on the pattern of intraspinally released immunoreactive substance P detected with antibody microprobes. Brain Res. 579, 261-269.

Duman, R.S., 2002. Pathophysiology of depression: The concept of synaptic plasticity. Eur. Psychiatry 17 (Suppl. 3), 306-310.

Duman, R.S., Heninger, G.R., Nestler, E.J., 1997. A molecular and cellular theory of depression. Arch. Gen. Psychiatry 54, 597-606.

Duman, R.S., Nakagawa, S., Malberg, J., 2001. Regulation of adult neurogenesis by antidepressant treatment.

Neuropsychopharmacology 25, 836-844.

Eblen, F., Graybiel, A.M., 1995. Highly restricted origin of prefrontal cortical inputs to striosomes in the macaque monkey. J. Neurosci. 15, 5999-6013.

Everitt, B.J., Robbins, T.W., 2005. Neural systems of reinforcement for drug addiction: From actions to habits to compulsion. Nat. Neurosci. 8, 1481-1489.

Falck, B., Hillarp, N.A., Thieme, G., Torp, A., 1962. Fluorescence of catacholamines and related compounds condensed with formaldehyde. J. Histochem. Cytochem. 10, 348-354.

Farde, L., Wiesel, F.A., Halldin, C., Sedvall, G., 1988. Central D2-dopamine receptor occupancy in schizophrenic patients treated with antipsychotic drugs. Arch. Gen. Psychiatry 45, $71-76$.

Felten, D.L., Harrigan, P., 1980. Dendrite bundles in nuclei raphe dorsalis and centralis superior of the rabbit: A possible substrate for local control of serotonergic neurons. Neurosci. Lett. 16, 275-280.

Fenstermacher, J., Patlak, C., 1974. The exchange of material between CSF and brain. In: Cserr, H.F., Fenstermacher, J., Fencl, E. (Eds.), Fluid Environment of the Brain. Academic Press, New York, pp. 201-214.

Fenstermacher, J., Kaye, T., 1988. Drug “diffusion” within the brain. Ann. N. Y. Acad. Sci. 531, 29-39.

Ferguson, S.S., 2003. Receptor tyrosine kinase transactivation: Fine-tuning synaptic transmission. Trends Neurosci. 26, 119-122.

Ferré, S., O'Connor, W.T., Svenningsson, P., Björklund, L., Lindberg, J., Tinner, B., Strömberg, I., Goldstein, M., Ögren, S.O., Ungerstedt, U., Fredholm, B.B., Fuxe, K., 1996. Dopamine D1 receptor-mediated facilitation of GABAergic neurotransmission in the rat strioentopenduncular pathway and its modulation by adenosine A1 receptor-mediated mechanisms. Eur. J. Neurosci. 8, 1545-1553.

Fishman, R.A., 1992. Cerebrospinal Fluid in Diseases of the Nervous System. Saunders, Philadelphia.

Follesa, P., Gale, K., Mocchetti, I., 1994. Regional and temporal pattern of expression of nerve growth factor and basic fibroblast growth factor mRNA in rat brain following electroconvulsive shock. Exp. Neurol. 127, 37-44.

Forssberg, H., Fernell, E., Waters, S., Waters, N., Tedroff, J., 2006. Altered pattern of brain dopamine synthesis in male adolescents with attention deficit hyperactivity disorder. Behav. Brain Funct. 2, 40.

Fuxe, K., 1963. Cellular localization of monoamines in the median eminence and in the infundibular stem of some mammals. Acta Physiol. Scand. 58, 383-384.

Fuxe, K., 1964. Cellular localization of monoamines in the median eminence and the infundibular stem of some mammals. Z. Zellforsch. Mikrosk. Anat. 61, 710-724.

Fuxe, K., 1965a. Evidence for the existence of monoamine neurons in the central nervous system. 3 . The monoamine nerve terminal. Z. Zellforsch. Mikrosk. Anat. 65, 573-596.

Fuxe, K., 1965b. Evidence for the existence of monoamine neurons in the central nervous system. IV. Distribution of monoamine nerve terminals in the central nervous system. Acta Physiol. Scand. 64 (Suppl. 247), 39-85.

Fuxe, K., 1970. Biological and pharmacological theories, discussion. In: Bobon, D.P., Janssen, P.A.J., Bobon, J. (Eds.), The Neuroleptics. S. Karger, Basel, pp. 121-122.

Fuxe, K., 1979. Dopamine receptor agonists in brain research and as therapeutic agents. Trends Neurosci. 2, 1-4.

Fuxe, K., Agnati, L.F., 1985. Receptor-receptor interactions in the central nervous system. A new integrative mechanism in synapses. Med. Res. Rev. 5, 441-482.

Fuxe, K., Agnati, L.F., 1991a. Two principle modes of electrochemical communication in the brain: Volume versus wiring transmission. In: Fuxe, K., Agnati, L.F. (Eds.), Volume Transmission in the Brain: Novel

Mechanisms of Neuronal Transmission. Raven Press, New York, pp. 1-9.

Fuxe, K., Agnati, L.F. (Eds.), 1991b. Volume Transmission in the Brain, Novel Mechanisms for Neural Transmission. Raven Press, New York.

Fuxe, K., Agnati, L.F., 2006. The neurotransmitter era in neuropsychopharmacology in the perspective of neuroscience. In: Ban, T.A., Ucha Udabe, R. (Eds.), The Neurotransmitter Era in Neuropsychopharmacology. Editorial Polemos, Buenos Aires, pp. 219-246.

Fuxe, K., Gunne, L.M., 1964. Depletion of the amine stores in brain catecholamine terminals on amygdaloid stimulation. Acta Physiol. Scand. 62, 493-494.

Fuxe, K., Hanson, C.F., 1967. Central catecholamine neurons and conditioned avoidance behaviour. Psychopharmacologia 11, 439-447.

Fuxe, K., Hökfelt, T., 1966. Further evidence for the existence of tubero-infundibular dopamine neurons. Acta Physiol. Scand. $66,245-246$.

Fuxe, K., Jonsson, G., 1967. A modification of the histochemical fluorescence method for the improved localization of 5-hydroxytryptamine. Histochemie 11, 161-166.

Fuxe, K., Jonsson, G., 1973. The histochemical fluorescence method for the demonstration of catecholamines.

Theory, practice and application. J. Histochem. Cytochem. 21, 293-311.

Fuxe, K., Jonsson, G., 1974. Further mapping of central 5-hydroxytryptamine neurons: Studies with the neurotoxic dihydroxytryptamines. Adv. Biochem. Psychopharmacol. 10, $1-12$.

Fuxe, K., Lidbrink, P., 1973. Biogenic amine aspects of sleep and waking. In: Koella, W.P., Levin, P. (Eds.), Sleep: Physiology, Biochemistry, Psychology, Pharmacology, Clinical Implications. Karger, Basel, pp. 12-26.

Fuxe, K., Ungerstedt, U., 1967. Localization of 5-hydroxytryptamine uptake in rat brain after intraventricular injection. J. Pharm. Pharmacol. 19, 335-337.

Fuxe, K., Ungerstedt, U., 1968. Histochemical studies on the distribution of catecholamines and 5-hydroxytryptamine after intraventricular injections. Histochemie 13, 16-28.

Fuxe, K., Ungerstedt, U., 1970. Histochemical, biochemical and functional studies on central monoamine neurons after acute 
and chronic amphetamine administration. In: Costa, E., Garattini, S. (Eds.), Amphetamines and Related Compounds. Raven Press, New York, pp. 257-288.

Fuxe, K., Goldstein, M., Hökfelt, T., Joh, T.H., 1970a. Immunohistochemical localization of dopamine-hydroxylase in the peripheral and central nervous system. Res. Commun. Chem. Pathol. Pharmacol. 1, 627-636.

Fuxe, K., Hökfelt, T., Jonsson, G., Ungerstedt, U., 1970 b. Fluorescence microscopy in neuroanatomy. In: Nauta, W.J.H., Ebbesson, S.O.E. (Eds.), Contemporary Research Methods in Neuroanatomy. Springer-Verlag, Berlin, pp. 275-314.

Fuxe, K., Hökfelt, T., Ungerstedt, U., 1970c. Morphological and functional aspects of central monoamine neurons. Int. Rev. Neurobiol. 13, 93-126.

Fuxe, K., Everitt, B.J., Agnati, L.F., Fredholm, B., Jonsson, G., 1976. On the biochemistry and the pharmacology of hallucinogens. In: Kemali, D., Bartholini, G., Richther, D. (Eds.), Schizophrenia Today. Pergamon Press, London, pp. 135-157.

Fuxe, K., Agnati, L., Eneroth, P., Gustafsson, J.A., Hökfelt, T., Löfstrom, A., Skett, B., Skett, P., 1977a. The effect of nicotine on central catecholamine neurons and gonadotropin secretion. I. Studies in the male rat. Med. Biol. 55, 148-157.

Fuxe, K., Hökfelt, T., Eneroth, P., Gustafsson, J.A., Skett, P., 1977b. Prolactin-like immunoreactivity: Localization in nerve terminals of rat hypothalamus. Science 196, 899-900.

Fuxe, K., Ögren, S.-O., Agnati, L.F., Gustafsson, J.A., Jonsson, G., 1977c. On the mechanism of action of the antidepressant drug amitriptyline and nortriptyline. Evidence for 5-hydroxytrytamine receptor blocking activity. Neurosci. Lett. 6, 339-343.

Fuxe, K., Löfstrom, A., Hökfelt, T., Ferland, L., Andersson, K., Agnati, L., Eneroth, P., Gustafsson, J.A., Skett, P., 1978. Influence of central catecholamines on LHRH-containing pathways. Clin. Obstet. Gynaecol. 5, 251-269.

Fuxe, K., Agnati, L.F., Andersson, K., Locatelli, V., Eneroth, P., Hökfelt, T., Mutt, V., McDonald, T., El Etreby, M.F., Zini, I., Calza, L., 1980a. Concepts in neuroendocrinology with emphasis on neuropeptide-monoamine interactions in neuroendrocrine regulation. In: Brambilla, F., Racagni, G., De Wied, D. (Eds.), Progress in Psychoneuroendocrinology. Elsevier/North Holland Biomedical Press, Amsterdam, pp. 47-61.

Fuxe, K., Andersson, K., Locatelli, V., Agnati, L.F., Hökfelt, T., Skirboll, L., Mutt, V., 1980b. Cholecystokinin peptides produce marked reduction of dopamine turnover in discrete areas in the rat brain following intraventricular injection. Eur. J. Pharmacol. 67, 329-331.

Fuxe, K., Andersson, K., Locatelli, V., Mutt, V., Lundberg, J., Hökfelt, T., Agnati, L.F., Eneroth, P., Bolme, P., 1980c. Neuropeptides and central catecholamine systems: Interactions in neuroendocrine and central cardiovascular regulation. Adv. Biochem. Psychopharmacol. 22, 37-50.

Fuxe, K., Agnati, L.F., Benfenati, F., Cimmino, M., Algeri, S., Hökfelt, T., Mutt, V., 1981. Modulation by cholecystokinins of $3 \mathrm{H}$-spiroperidol binding in rat striatum: Evidence for increased affinity and reduction in the number of binding sites. Acta Physiol. Scand. 113, 567-569.

Fuxe, K., Agnati, L.F., Andersson, K., Calza, L., Benfenati, F., Zini, I., Battistini, N., Kohler, C., Ögren, S-O., Hökfelt, T., 1983a. Analysis of transmitter-identified neurons by morphometry and quantitative microfluorimetry. Evaluations of the actions of psychoactive drugs, especially sulpiride. In: Ackenheil, M., Matussek, N. (Eds.), Special Aspects of Psychopharmacology. Espansion Scientifique Francaise, Paris, pp. 13-32.

Fuxe, K., Agnati, L.F., Benfenati, F., Andersson, K., Camurri, M., Zoli, M., 1983b. Evidence for the existence of a dopamine receptor of the D-1 type in the rat median eminence. Neurosci. Lett. 43, 185-190.

Fuxe, K., Agnati, L.F., Benfenati, F., Celani, M., Zini, I., Zoli, M., Mutt, V., 1983c. Evidence for the existence of receptor-receptor interactions in the central nervous system. Studies on the regulation of monoamine receptors by neuropeptides. J. Neural Transm., Suppl. 18, 165-179.

Fuxe, K., Ögren, S.-O., Agnati, L.F., Benfenati, F., Fredholm, B., Andersson, K., Zini, I., Eneroth, P., 1983d. Chronic antidepressant treatment and central 5-HT synapses. Neuropharmacology 22, 389-400.

Fuxe, K., Agnati, L.F., Andersson, K., Eneroth, P., Härfstrand, A., Goldstein, M., Bernardi, B., Vale, W., Yu, Y., Gustafsson, J.A., 1985. The external layer of the median eminence and the paravetricular hypothalamic nucleus represent two important levels of integration in the neuroendocrine regulation. Studies on peptide catacholamine interactions give evidence for the existance of "medianosomes". In: del Pozo, E., Fluckiger, E. (Eds.), Dopamine and Neuroendocrine Active Substances. Academic Press, London, pp. 11-18.

Fuxe, K., Agnati, L.F., Härfstrand, A., Andersson, K., Mascagni, F., Zoli, M., Kalia, M., Battistini, N., Benfenati, F., Hökfelt, T., et al., 1986. Studies on peptide comodulator transmission. New perspective on the treatment of disorders of the central nervous system. Prog. Brain Res. 66, 341-368.

Fuxe, K., Agnati, L., Zoli, M., Cintra, A., Härfstrand, A., von Euler, G., Grimaldi, R., Kalia, M., Eneroth, P., 1988a. The opioid peptide sytems: Their organization and role in volume transmission and neuroendocrine regulation. In: Illes, P., Farsang, C. (Eds.), Regulatory Roles of Opioid Peptides. VCH, Weinheim, pp. 33-68.

Fuxe, K., Agnati, L.F., Cintra, A., Andersson, K., Eneroth, P., Härfstrand, A., Zoli, M., Goldstein, M., 1988b. Studies on central D1 receptors role in volume transmission, neuroendrocrine regulation and release of noradrenaline. Adv. Exp. Med. Biol. 235, 83-119.

Fuxe, K., von Euler, G., Agnati, L.F., Ögren, S.-O., 1988c. Galanin selectively modulates 5 -hydroxytryptamine $1 \mathrm{~A}$ receptors in the rat ventral limbic cortex. Neurosci. Lett. 85, 163-167.

Fuxe, K., Hedlund, P.B., von Euler, G., Lundgren, K., Martire, M., Ögren, S-O., Eneroth, P., Agnati, L.F., 1991. Galanin/5-HT interactions in the rat central nervous system. Relevance for depression. In: Hökfelt, T., Bartfai, T., Jacobowitz, D., Ottoson, D. (Eds.), Galanin. A New Multifunctional Peptide in the Neuroendocrine System, vol. 58. MacMillan Press, London, pp. 221-235.

Fuxe, K., Tinner, B., Zoli, M., Pettersson, R.F., Baird, A., Biagini, G. Chadi, G., Agnati, L.F., 1996. Computer-assisted mapping of basic fibroblast growth factor immunoreactive nerve cell populations in the rat brain. J. Chem. Neuroanat. 11, 13-35.

Fuxe, K., Agnati, L.F., Jacobsen, K., Hillion, J., Canals, M., Torvinen, M., Tinner-Staines, B., Staines, W., Rosin, D., Terasmaa, A., Popoli, P., Leo, G., Vergoni, V., Lluis, C., Ciruela, F., Franco, R., Ferré, S., 2003a. Receptor heteromerization in adenosine A2A receptor signaling: Relevance for striatal function and Parkinson's disease. Neurology 61, S19-S23.

Fuxe, K., Jacobsen, K.X., Höistad, M., Tinner, B., Jansson, A., Staines, W.A., Agnati, L.F., 2003b. The dopamine D1 receptor-rich main and paracapsular intercalated nerve cell groups of the rat amygdala: Relationship to the dopamine innervation. Neuroscience 119, 733-746.

Fuxe, K., Rivera, A., Jacobsen, K.X., Höistad, M., Leo, G., Horvath, T.L., Staines, W., De la Calle, A., Agnati, L.F., 2005. Dynamics of volume transmission in the brain. Focus on catecholamine and opioid peptide communication and the role of uncoupling protein 2. J. Neural Transm. 112, 65-76.

Fuxe, K., Manger, P., Genedani, S., Agnati, L., 2006. The nigrostriatal DA pathway and Parkinson's disease. J. Neural Transm. 71-83.

Fuxe, K., Canals, M., Torvinen, M., Marcellino, D., Terasmaa, A., Genedani, S., Leo, G., Guidolin, D., Diaz-Cabiale, Z., Rivera, A., Lundström, L., Langel, U., Narvaez, J., Tanganelli, S., Lluis, C., Ferré, S., Woods, A., Franco, R., Agnati, L.F., 2007. Intramembrane receptor-receptor interactions: A novel 
principle in molecular medicine. J. Neural Transm. 114, 49-75.

Gally, J.A., Montague, P.R., Reeke Jr., G.N., Edelman, G.M., 1990. The NO hypothesis: Possible effects of a short-lived, rapidly diffusible signal in the development and function of the nervous system. Proc. Natl. Acad. Sci. U. S. A. 87, 3547-3551.

Galter, D., Unsicker, K., 1999. Regulation of the transmitter phenotype of rostral and caudal groups of cultured serotonergic raphe neurons. Neuroscience 88, 549-559.

Garcia-Perez, E., Vargas-Caballero, M., Velazquez-Ulloa, N., Minzoni, A., De-Miguel, F.F., 2004. Synaptic integration in electrically coupled neurons. Biophys. J. 86, 646-655.

Garris, P.A., Ciolkowski, E.L., Pastore, P., Wightman, R.M., 1994. Efflux of dopamine from the synaptic cleft in the nucleus accumbens of the rat brain. J. Neurosci. 14, 6084-6093.

Garthwaite, J., Garthwaite, G., Palmer, R.M., Moncada, S., 1989. NMDA receptor activation induces nitric oxide synthesis from arginine in rat brain slices. Eur. J. Pharmacol. 172, 413-416.

Geer, C.P., Grossman, S.A., 1997. Interstitial fluid flow along white matter tracts: A potentially important mechanism for the dissemination of primary brain tumors. J. Neuro-Oncol. 32, 193-201.

Geffen, L.B., Jessell, T.M., Cuello, A.C., Iversen, L.L., 1976. Release of dopamine from dendrites in rat substantia nigra. Nature 260, 258-260.

Gerfen, C.R., 1984. The neostriatal mosaic: Compartmentalization of corticostriatal input and striatonigral output systems. Nature 311, 461-464.

Gerfen, C.R., 1993. Functional organization of the striatum: Relevance to actions of psychostimulant drugs of abuse. NIDA Res. Monogr. 125, 82-91.

Gerfen, C.R., 2000. Molecular effects of dopamine on striatal-projection pathways. Trends Neurosci. 23, S64-S70.

Gines, S., Hillion, J., Torvinen, M., Le Crom, S., Casado, V., Canela, E.I., Rondin, S., Lew, J.Y., Watson, S., Zoli, M., Agnati, L.F., Verniera, P., Lluis, C., Ferré, S., Fuxe, K., Franco, R., 2000. Dopamine D1 and adenosine A1 receptors form functionally interacting heteromeric complexes. Proc. Natl. Acad. Sci. U. S. A. $97,8606-8611$.

Golding, D.W., 1994. A pattern confirmed and refined-synaptic, nonsynaptic and parasynaptic exocytosis. BioEssays 16, 503-508.

Gonon, F.G., 1988. Nonlinear relationship between impulse flow and dopamine released by rat midbrain dopaminergic neurons as studied by in vivo electrochemistry. Neuroscience 24, 19-28.

Gonzalez, M.M., Aston-Jones, G., 2006. Circadian regulation of arousal: Role of the noradrenergic locus coeruleus system and light exposure. Sleep 29, 1327-1336.

Grace, A.A., Bunney, B.S., 1983. Intracellular and extracellular electrophysiology of nigral dopaminergic neurons-3. Evidence for electrotonic coupling. Neuroscience 10, 333-348.

Granon, S., Changeux, J.P., 2006. Attention-deficit/hyperactivity disorder: A plausible mouse model? Acta Paediatr. 95, 645-649.

Graybiel, A.M., Ragsdale Jr., C.W., 1978. Histochemically distinct compartments in the striatum of human, monkeys, and cat demonstrated by acetylthiocholinesterase staining. Proc. Natl. Acad. Sci. U. S. A. 75, 5723-5726.

Graybiel, A.M., Canales, J.J., Capper-Loup, C., 2000. Levodopa-induced dyskinesias and dopamine-dependent stereotypies: A new hypothesis. Trends Neurosci. 23, S71-S77.

Greitz, D., 1993. Cerebrospinal fluid circulation and associated intracranial dynamics. A radiologic investigation using MR imaging and radionuclide cisternography. Acta Radiol., Suppl. 386, 1-23.

Greitz, D., Nordell, B., Ericsson, A., Stålberg, F., Thomsen, C., 1991. Notes on the driving forces of the CSF circulation with special emphasis on the piston action of the brain. Neuroradiology 33, 178-181.

Greitz, D., Franck, A., Nordell, B., 1993. On the pulsatile nature of intracranial and spinal CSF-circulation demonstrated by MR imaging. Acta Radiol. 34, 321-328.

Grewal, J.S., Luttrell, L.M., Raymond, J.R., 2001. G protein-coupled receptors desensitize and down-regulate epidermal growth factor receptors in renal mesangial cells. J. Biol. Chem. 276, 27335-27344.

Guillemin, R., 1978. Peptides in the brain: The new endocrinology of the neuron. Science 202, 390-402.

Gwinn, R.P., Kondratyev, A., Gale, K., 2002. Time-dependent increase in basic fibroblast growth factor protein in limbic regions following electroshock seizures. Neuroscience 114, 403-409.

Hackel, P.O., Zwick, E., Prenzel, N., Ullrich, A., 1999. Epidermal growth factor receptors: Critical mediators of multiple receptor pathways. Curr. Opin. Cell Biol. 11, 184-189.

Hajos, M., Gartside, S.E., Sharp, T., 1994. Electrophysiological characteristics of serotenergic neurons located in the nucleus raphe dorsalis (NRD) and medialis (NRM) of the anasesthetised rat. 3rd IUPHAR Satellite Meeting on Serotonin.

Hamberger, B., Malmfors, T., Sachs, C., 1965. Standardization of paraformaldehyde and of certain procedures for the histochemical demonstration of catecholamines. J. Histochem. Cytochem. 13, 147.

Hansra, N., Arya, S., Quick, M.W., 2004. Intracellular domains of a rat brain GABA transporter that govern transport. J. Neurosci. 24, 4082-4087.

Haskins, J.T., Price, C.H., Blankenship, J.E., 1981. A light and electron microscopic investigation of the neurosecretory bag cells of aplysia. J. Neurocytol. 10, 729-747.

Hayaishi, O., 1991. Molecular mechanisms of sleep-wake regulation: Roles of prostaglandins D2 and E2. FASEB J. 5, 2575-2581.

Hedlund, P.B., Fuxe, K., 1996. Galanin and 5-HT1A receptor interactions as an integrative mechanism in 5-HT neurotransmission in the brain. Ann. N. Y. Acad. Sci. 780, 193-212.

Hedlund, P.B., Yanaihara, N., Fuxe, K., 1992. Evidence for specific $\mathrm{N}$-terminal galanin fragment binding sites in the rat brain. Eur. J. Pharmacol. 224, 203-205.

Hedlund, P.B., Finnman, U.B., Yanaihara, N., Fuxe, K., 1994. Galanin-(1-15), but not galanin-(1-29), modulates 5-HT1A receptors in the dorsal hippocampus of the rat brain: Possible existence of galanin receptor subtypes. Brain Res. 634, 163-167.

Heimer, L., 2000. Basal forebrain in the context of schizophrenia. Brain Res. Brain Res. Rev. 31, 205-235.

Herkenham, M., 1987. Mismatches between neurotransmitter and receptor localizations in brain: Observations and implications. Neuroscience 23, 1-38.

Hery, F., Faudon, M., Ternaux, J.P., 1982. In vivo release of serotonin in two raphe nuclei (raphe dorsalis and magnus) of the cat. Brain Res. Bull. 8, 123-129.

Hillion, J., Canals, M., Torvinen, M., Casado, V., Scott, R., Terasmaa, A., Hansson, A., Watson, S., Olah, M.E., Mallol, J., Canela, E.I., Zoli, M., Agnati, L.F., Ibanez, C.F., Lluis, C., Franco, R., Ferre, S., Fuxe, K., 2002. Coaggregation, cointernalization, and codesensitization of adenosine A2A receptors and dopamine D2 receptors. J. Biol. Chem. 277, 18091-18097.

Hoffman, B.J., Hansson, S.R., Mezey, E., Palkovits, M., 1998. Localization and dynamic regulation of biogenic amine transporters in the mammalian central nervous system. Front. Neuroendocrinol. 19, 187-231.

Höistad, M., 2004. Migration of Molecules in the Brain. Doctor of Medical Sciences Thesis. Karolinska Institutet, Stockholm, pp. 82.

Höistad, M., Kehr, J., Andbjer, B., Jansson, A., Fuxe, K., 2000. Intracerebral infusion of $\mathrm{H}$-dopamine and $\mathrm{H}$-mannitol in the striatum of halothane-anaesthetized male rats. A dual-probe microdialysis study of long-distance diffusion. Eur. J. Neurosci. 12, 2505-2514. 
Höistad, M., Chen, K.C., Nicholson, C., Fuxe, K., Kehr, J., 2002. Quantitative dual-probe microdialysis: Evaluation of [3H] mannitol diffusion in agar and rat striatum. J. Neurochem. 81, 80-93.

Höistad, M., Samskog, J., Jacobsen, K.X., Olsson, A., Hansson, H.A., Brodin, E., Fuxe, K., 2005. Detection of beta-endorphin in the cerebrospinal fluid after intrastriatal microinjection into the rat brain. Brain Res. 1041, 167-180.

Hornykiewicz, O., 1963. The tropical localization and content of noradrenalin and dopamine (3-hydroxytyramine) in the substantia nigra of normal persons and patients with Parkinson's disease. Wien. Klin. Wochenschr. 75, 309-312.

Horvath, T.L., Warden, C.H., Hajos, M., Lombardi, A., Goglia, F., Diano, S., 1999. Brain uncoupling protein 2: Uncoupled neuronal mitochondria predict thermal synapses in homeostatic centers. J. Neurosci. 19, 10417-10427.

Horvath, T.L., Diano, S., Barnstable, C., 2003. Mitochondrial uncoupling protein 2 in the central nervous system: Neuromodulator and neuroprotector. Biochem. Pharmacol. 65, 1917-1921.

Hoyer, D., Hannon, J.P., Martin, G.R., 2002. Molecular, pharmacological and functional diversity of 5-HT receptors. Pharmacol. Biochem. Behav. 71, 533-554.

Hubbard, S.R., 2004. Juxtamembrane autoinhibition in receptor tyrosine kinases. Nat. Rev., Mol. Cell Biol. 5, 464-471.

Hurd, Y.L., 2006. Perspectives on current Directions in the neurobiology of addiction disorders relevant to genetic risk factors. CNS Spectr. 11, 855-862.

Iadecola, C., 1998. Neurogenic control of the cerebral microcirculation: Is dopamine minding the store? Nat. Neurosci. 1, 263-265.

Ichimura, T., Fraser, P.A., Cserr, H.F., 1991. Distribution of extracellular tracers in perivascular spaces of the rat brain. Brain Res. 545, 103-113.

Ishimatsu, M., Williams, J.T., 1996. Synchronous activity in locus coeruleus results from dendritic interactions in pericoerulear regions. J. Neurosci. 16, 5196-5204.

Ivanov, I.S., Schultz, K.P., Palmero, R.C., Newcorn, J.H., 2006. CNS Spectr. 11, 864-877.

Iversen, L., 2000. Neurotransmitter transporters: Fruitful targets for CNS drug discovery. Mol. Psychiatry 5, 357-362.

Jackson, I.M.D., 1980. Significance and function of neuropeptides in the cerebrospinal fluid. In: Wood, J.H. (Ed.), Neurobiology of Cerebrospinal Fluid. Plenum Press, New York, pp. 625-650.

Jacobs, B.L., Azmitia, E.C., 1992. Structure and function of the brain serotonin system. Physiol. Rev. 72, 165-229.

Jacobsen, K.X., Höistad, M., Staines, W.A., Fuxe, K., 2006. The distribution of dopamine $\mathrm{D} 1$ receptor and mu-opioid receptor-1 receptor immunoreactivities in the amygdala and interstitial nucleus of the posterior limb of the anterior commissure: Relationships to tyrosine hydroxylase and opioid peptide terminal systems. Neuroscience 141, 2007-2018.

Jacobson, M., 1993. Foundations of Neuroscience. Plenum Press, New York.

Jan, L.Y., Jan, Y.N., 1982. Peptidergic transmission in sympathetic ganglia of the frog. J. Physiol. 327, 219-246.

Jan, Y.N., Jan, L.Y., 1983. Some features of peptidergic transmission. Prog. Brain Res. 58, 49-59.

Jansson, A., 1999. Experimental Studies on the Sources, Pathways and Targets for Volume Transmission in the Rat Brain. Doctor of Medical Sciences Thesis. Karolinska Institutet, Stockholm, pp. 61.

Jansson, A., Tinner, B., Steinbusch, H.W., Agnati, L.F., Fuxe, K., 1998. On the relationship of 5-hydroxytryptamine neurons to 5-hydroxytryptamine $2 \mathrm{~A}$ receptor-immunoreactive neuronal processes in the brain stem of rats. A double immunolabelling analysis. NeuroReport 9, 2505-2511.

Jansson, A., Goldstein, M., Tinner, B., Zoli, M., Meador-Woodruff,
J.H., Lew, J.Y., Levey, A.I., Watson, S., Agnati, L.F., Fuxe, K., 1999. On the distribution patterns of D1, D2, tyrosine hydroxylase and dopamine transporter immunoreactivities in the ventral striatum of the rat. Neuroscience 89, 473-489.

Jansson, A., Lippoldt, A., Mazel, T., Bartfai, T., Ögren, S.-O., Sykova, E., Agnati, L.F., Fuxe, K., 2000. Long distance signalling in volume transmission. Focus on clearance mechanisms. Prog. Brain Res. 125, 399-413.

Jansson, A., Tinner, B., Bancila, M., Verge, D., Steinbusch, H.W., Agnati, L.F., Fuxe, K., 2001. Relationships of 5-hydroxytryptamine immunoreactive terminal-like varicosities to 5-hydroxytryptamine-2A receptor-immunoreactive neuronal processes in the rat forebrain. J. Chem. Neuroanat. 22, 185-203.

Jansson, A., Descarries, L., Cornea-Hebert, V., Riad, M., Verge, D., Bancila, M., Agnati, L.F., Fuxe, K., 2002. Transmitter-receptor mismatches in central dopamine seratonin and neuropeptide systems. In: Walz, W. (Ed.), The Neuronal Environment: Brain Homeostasis in Health and Disease. Humana Press, Totowa, NJ, pp. 83-107.

Jansson, A., Tinner-Staines, B., Mazel, T., Andbjer, B., Malinowsky, D., Bartfai, T., Zoli, M., Agnati, L., Sykova, E., Fuxe, K., submitted for publication. Local microinjections of interleukin-1beta into the neostriatum: implications for volume transmission.

Jentsch, J.D., Roth, R.H., 1999. The neuropsychopharmacology of phencyclidine: From NMDA receptor hypofunction to the dopamine hypothesis of schizophrenia. Neuropsychopharmacology 20, 201-225.

Jonsson, G., Einarsson, P., Fuxe, K., Hallman, H., 1975. Microspectrofluorimetric analysis of the formaldehyde induced fluorescence in midbrain raphe neurons. Med. Biol. 53, 25-39.

Jouvet, M., 1972. The role of monoamines and acetylcholine-containing neurons in the regulation of the sleep-waking cycle. Ergeb. Physiol. 64, 166-307.

Kamiya, T., Saitoh, O., Yoshioka, K., Nakata, H., 2003. Oligomerization of adenosine A2A and dopamine D2 receptors in living cells. Biochem. Biophys. Res. Commun. 306, 544-549.

Kang, H., Schuman, E.M., 1995. Long-lasting neurotrophin-induced enhancement of synaptic transmission in the adult hippocampus. Science 267, 1658-1662.

Kapur, S., Mamo, D., 2003. Half a century of antipsychotics and still a central role for dopamine D2 receptors. Prog. Neuro-psychopharmacol. Biol. Psychiatry 27, 1081-1090.

Kempermann, G., Kronenberg, G., 2003. Depressed new neurons-Adult hippocampal neurogenesis and a cellular plasticity hypothesis of major depression. Biol. Psychiatry 54, 499-503.

Kiianmaa, K., Fuxe, K., 1977. The effects of 5,7-dihydroxytryptamine-induced lesions of the ascending 5-hydroxytryptamine pathways on the sleep wakefulness cycle. Brain Res. 131, 287-301.

Kim, J.S., Kornhuber, H.H., Schmid-Burgk, W., Holzmuller, B., 1980. Low cerebrospinal fluid glutamate in schizophrenic patients and a new hypothesis on schizophrenia. Neurosci. Lett. 20, 379-382.

Kimelberg, H., 1988. Glial Cell Receptors. Raven Press, New York.

Kiser, R.S., Jackson, S., Smith, R., Rees, L.H., Lowry, P.J., Besser, G.M., 1983. Endorphin-related peptides in rat cerebrospinal fluid. Brain Res. 288, 187-192.

Kitayama, I.T., Otani, M., Murase, S., 2004. Contribution of the stress-induced degeneration of the locus coeruleus noradrenergic neurons to the pathophysiology of depression: A study on an animal model. Acta Neuropsychiatr. 16, 190-199.

Komendantov, A.O., Canavier, C.C., 2002. Electrical coupling between model midbrain dopamine neurons: Effects on firing pattern and synchrony. J. Neurophysiol. 87, 1526-1541.

Koob, G., Sandman, C., Strand, F. (Eds.), 1990. A Decade of 
Neuropeptides: Past. Present and Future. The New York Academy of Sciences, New York.

Kopell, N., Ermentrout, B., 2004. Chemical and electrical synapses perform complementary roles in the synchronization of interneuronal networks. Proc. Natl. Acad. Sci. U. S. A. 101, 15482-15487.

Kotecha, S.A., Oak, J.N., Jackson, M.F., Perez, Y., Orser, B.A., Van Tol, H.H., MacDonald, J.F., 2002. A D2 class dopamine receptor transactivates a receptor tyrosine kinase to inhibit NMDA receptor transmission. Neuron 35, 1111-1122.

Krueger, J.M., Majde, J.A., 1995. Cytokines and sleep. Int. Arch. Allergy Immunol. 106, 97-100.

Kuhar, M.J., Unnerstall, J.R., De Souza, E.B., 1985. Receptor mapping in neuropharmacology by autoradiography: Some technical problems. NIDA Res. Monogr. 62, 1-12.

Laruelle, M., Abi-Dargham, A., van Dyck, C.H., Gil, R., D'Souza, C.D., Erdos, J., McCance, E., Rosenblatt, W., Fingado, C., Zoghbi, S.S., Baldwin, R.M., Seibyl, J.P., Krystal, J.H., Charney, D.S., Innis, R.B., 1996. Single photon emission computerized tomography imaging of amphetamine-induced dopamine release in drug-free schizophrenic subjects. Proc. Natl. Acad. Sci. U. S. A. 93, 9235-9240.

Laruelle, M., Kegeles, L.S., Abi-Dargham, A., 2003. Glutamate, dopamine, and schizophrenia: From pathophysiology to treatment. Ann. N. Y. Acad. Sci. 1003, 138-158.

Lauf, U., Giepmans, B.N., Lopez, P., Braconnot, S., Chen, S.C., Falk, M.M., 2002. Dynamic trafficking and delivery of connexons to the plasma membrane and accretion to gap junctions in living cells. Proc. Natl. Acad. Sci. U. S. A. 99, 10446-10451.

Le Bihan, D., Turner, R., Douek, P., 1993. Is water diffusion restricted in human brain white matter? An echo-planar NMR imaging study. NeuroReport 4, 887-890.

Lee, F.S., Chao, M.V., 2001. Activation of Trk neurotrophin receptors in the absence of neurotrophins. Proc. Natl. Acad. Sci. U. S. A. 98, 3555-3560.

Lee, F.J., Xue, S., Pei, L., Vukusic, B., Chery, N., Wang, Y., Wang, Y.T., Niznik, H.B., Yu, X.M., Liu, F., 2002a. Dual regulation of NMDA receptor functions by direct protein-protein interactions with the dopamine D1 receptor. Cell 111, 219-230.

Lee, F.S., Rajagopal, R., Chao, M.V., 2002b. Distinctive features of Trk neurotrophin receptor transactivation by G protein-coupled receptors. Cytokine Growth Factor Rev. 13, 11-17.

Lesch, K.P., 2001. Serotonergic gene expression and depression: Implications for developing novel antidepressants. J. Affect. Disord. 62, 57-76.

Leung, D.S., Unsicker, K., Reuss, B., 2002. Expression and developmental regulation of gap junction connexins cx26, cx32, cx43 and cx45 in the rat midbrain-floor. Int. J. Dev. Neurosci. 20, 63-75.

Levey, A.I., Hersch, S.M., Rye, D.B., Sunahara, R.K., Niznik, H.B., Kitt, C.A., Price, D.L., Maggio, R., Brann, M.R., Ciliax, B.J., et al., 1993. Localization of D1 and D2 dopamine receptors in brain with subtype-specific antibodies. Proc. Natl. Acad. Sci. U. S. A. 90, 8861-8865.

Li, X.M., Zoli, M., Finnman, U.B., Le Novere, N., Changeux, J.P., Fuxe, K., 1995. A single (-)-nicotine injection causes change with a time delay in the affinity of striatal $\mathrm{D} 2$ receptors for antagonist, but not for agonist, nor in the D2 receptor mRNA levels in the rat substantia nigra. Brain Res. 679, 157-167.

Licinio, J., Wong, M.L., 1997. Pathways and mechanisms for cytokine signaling of the central nervous system. J. Clin. Invest. 100, 2941-2947.

Lidbrink, P., Fuxe, K., 1973. Effects of intracerebral injections of 6-hydroxydopamine on sleep and waking in the rat. J. Pharm. Pharmacol. 25, 84-87.

Lindvall, O., Björklund, A., 1974. The organization of the ascending catecholamine neuron systems in the rat brain as revealed by the glyoxylic acid fluorescence method. Acta Physiol. Scand., Suppl. 412, 1-48.

Lippoldt, A., Jansson, A., Kniesel, U., Andbjer, B., Andersson, A., Wolburg, H., Fuxe, K., Haller, H., 2000a. Phorbol ester induced changes in tight and adherens junctions in the choroid plexus epithelium and in the ependyma. Brain Res. 854, 197-206.

Lippoldt, A., Liebner, S., Andbjer, B., Kalbacher, H., Wolburg, H., Haller, H., Fuxe, K., 2000b. Organization of choroid plexus epithelial and endothelial cell tight junctions and regulation of claudin-1, -2 and -5 expression by protein kinase C. NeuroReport 11, 1427-1431.

Liu, H., Brown, J.L., Jasmin, L., Maggio, J.E., Vigna, S.R., Mantyh, P.W., Basbaum, A.I., 1994. Synaptic relationship between substance $P$ and the substance $P$ receptor: Light and electron microscopic characterization of the mismatch between neuropeptides and their receptors. Proc. Natl. Acad. Sci. U. S. A. 91, 1009-1013.

Liu, F., Wan, Q., Pristupa, Z.B., Yu, X.M., Wang, Y.T., Niznik, H.B., 2000. Direct protein-protein coupling enables cross-talk between dopamine D5 and gamma-aminobutyric acid A receptors. Nature 403, 274-280.

Liu, X.Y., Chu, X.P., Mao, L.M., Wang, M., Lan, H.X., Li, M.H., Zhang, G.C., Parelkar, N.K., Fibuch, E.E., Haines, M., Neve, K.A., Liu, F., Xiong, Z.G., Wang, J.Q., 2006. Modulation of D2R-NR2B interactions in response to cocaine. Neuron 52, 897-909.

Löfström, A., Jonsson, G., Fuxe, K., 1976a. Microfluorimetric quantitation of catecholamine fluorescence in rat median eminence. I. Aspects on the distribution of dopamine and noradrenaline nerve terminals. J. Histochem. Cytochem. 24, $415-429$.

Löfström, A., Jonsson, G., Wiesel, F.A., Fuxe, K., 1976b. Microfluorimetric quantitation of catecholamine fluorescence in rat median eminence. II. Turnover changes in hormonal states. J. Histochem. Cytochem. 24, 430-442.

Lowes, V.L., Ip, N.Y., Wong, Y.H., 2002. Integration of signals from receptor tyrosine kinases and g protein-coupled receptors. Neurosignals 11, 5-19.

Luttrell, L.M., 2002. Activation and targeting of mitogen-activated protein kinases by G-protein-coupled receptors. Can. J. Physiol. Pharmacol. 80, 375-382.

Luttrell, L.M., Della Rocca, G.J., van Biesen, T., Luttrell, D.K., Lefkowitz, R.J., 1997. Gbetagamma subunits mediate Src-dependent phosphorylation of the epidermal growth factor receptor. A scaffold for $\mathrm{G}$ protein-coupled receptor-mediated Ras activation. J. Biol. Chem. 272, 4637-4644.

Luttrell, L.M., Daaka, Y., Lefkowitz, R.J., 1999. Regulation of tyrosine kinase cascades by G-protein-coupled receptors. Curr. Opin. Cell Biol. 11, 177-183.

MacLeod, R.M., Lehmeyer, J.E., 1974. Studies on the mechanism of the dopamine-mediated inhibition of prolactin secretion. Endocrinology 94, 1077-1085.

MacMillan, S.J., Mark, M.A., Duggan, A.W., 1998. The release of beta-endorphin and the neuropeptide-receptor mismatch in the brain. Brain Res. 794, 127-136.

Maeda, T., Shimizu, N., 1972. Ascending projections from the locus coeruleus and other aminergic pontine neurons at the level of the rat prosencephalon. Brain Res. 36, 19-35.

Mallei, A., Shi, B., Mocchetti, I., 2002. Antidepressant treatments induce the expression of basic fibroblast growth factor in cortical and hippocampal neurons. Mol. Pharmacol. 61, 1017-1024.

Malmfors, T., 1965. Studies on adrenergic nerves. the use of rat and mouse iris for direct observations on their physiology and pharmacology at cellular and subcellular levels. Acta Physiol. Scand., Suppl. (suppl. 248), 1-93.

Manji, H.K., Drevets, W.C., Charney, D.S., 2001. The cellular neurobiology of depression. Nat. Med. 7, 541-547. 
Manji, H.K., Gottesman, I.I., Gould, T.D., 2003. Signal transduction and genes-to-behaviors pathways in psychiatric diseases. Sci STKE e49.

Mansour, A., Lewis, M.E., Khachaturian, H., Akil, H., Watson, S.J., 1986. Pharmacological and anatomical evidence of selective $\mathrm{mu}$, delta, and kappa opioid receptor binding in rat brain. Brain Res. 399, 69-79.

Mansour, A., Khachaturian, H., Lewis, M.E., Akil, H., Watson, S.J., 1988. Anatomy of CNS opioid receptors. Trends Neurosci. 11, 308-314.

Maragnoli, M.E., Fumagalli, F., Gennarelli, M., Racagni, G., Riva, M.A., 2004. Fluoxetine and olanzapine have synergistic effects in the modulation of fibroblast growth factor 2 expression within the rat brain. Biol. Psychiatry 55, 1095-1102.

Marcellino, D., Roberts, D.C.S., Navarro, G., Filip, M., Agnati, L., Lluis, C., Franco, R., Fuxe, K., 2007. Increase in A2A receptors in the nucleus accumbens after extended cocaine self-administration and its disappearance after cocaine withdrawal. Brain Res. 1143, 208-220.

Marinissen, M.J., Gutkind, J.S., 2001. G-protein-coupled receptors and signaling networks: Emerging paradigms. Trends Pharmacol. Sci. 22, 368-376.

Martin, J.H., 1985. Cortical neurons, the EEG and the mechanisms of epilepsy. In: Kandel, E.R., Schwartz, J.H. (Eds.), Principles of Neuroscience. Elsevier, Amsterdam, pp. 636-647.

Martin, D.L., 1992. Synthesis and release of neuroactive substances by glial cells. Glia 5, 81-94.

Martin-Cora, F.J., Fornal, C.A., Jacobs, B.L., 2005. Single-unit responses of serotonergic medullary raphe neurons to cardiovascular challenges in freely moving cats. Eur. J. Neurosci. 22, 3195-3204.

Matteoli, M., Haimann, C., Torri-Tarelli, F., Polak, J.M., Ceccarelli, B., De Camilli, P., 1988. Differential effect of alpha-latrotoxin on exocytosis from small synaptic vesicles and from large dense-core vesicles containing calcitonin gene-related peptide at the frog neuromuscular junction. Proc. Natl. Acad. Sci. U. S. A. $85,7366-7370$.

Mattson, M.P., Maudsley, S., Martin, B., 2004. BDNF and 5-HT: A dynamic duo in age-related neuronal plasticity and neurodegenerative disorders. Trends Neurosci. 27, 589-594.

Mayeri, E., Rothman, B.S., Brownell, P.H., Branton, W.D., Padgett, L., 1985. Nonsynaptic characteristics of neurotransmission mediated by egg-laying hormone in the abdominal ganglion of Aplysia. J. Neurosci. 5, 2060-2077.

Meyer-Lindenberg, A., Miletich, R.S., Kohn, P.D., Esposito, G., Carson, R.E., Quarantelli, M., Weinberger, D.R., Berman, K.F., 2002. Reduced prefrontal activity predicts exaggerated striatal dopaminergic function in schizophrenia. Nat. Neurosci. 5, 267-271.

Miyan, J.A., Nabiyouni, M., Zendah, M., 2003. Development of the brain: A vital role for cerebrospinal fluid. Can. J. Physiol. Pharmacol. 81, 317-328.

Mobley, P., Greengard, P., 1985. Evidence for widespread effects of noradrenaline on axon terminals in the rat frontal cortex. Proc. Natl. Acad. Sci. U. S. A. 82, 945-947.

Möllgard, K., Möller, M., 1975. Dendrodendritic gap junctions: A developmental approach. Adv. Neurol. 12, 79-89.

Montague, P.R., Dayan, P., Sejnowski, T.J., 1996. A framework for mesencephalic dopamine systems based on predictive Hebbian learning. J. Neurosci. 16, 1936-1947.

Morris, G., Arkadir, D., Nevet, A., Vaadia, E., Bergman, H., 2004. Coincident but distinct messages of midbrain dopamine and striatal tonically active neurons. Neuron 43, 133-143.

Morris, M., Tandy, B., Sundberg, D.K., Knigge, K.M., 1975. Modification of brain and CSF LH-RH following deafferentation. Neuroendocrinology 18, 131-135.

Murase, S., Mathe, J.M., Grenhoff, J., Svensson, T.H., 1993. Effects of dizocilpine (MK-801) on rat midbrain dopamine cell activity:
Differential actions on firing pattern related to anatomical localization. J. Neural Transm. Gen. Sect. 91, 13-25.

Murphy, S., Pearce, B., 1987. Functional receptors for neurotransmitters on astroglial cells. Neuroscience 22, 381-394.

Murphy, S., Simmons, M.L., Agullo, L., Garcia, A., Feinstein, D.L., Galea, E., Reis, D.J., Minc-Golomb, D., Schwartz, J.P., 1993. Synthesis of nitric oxide in CNS glial cells. Trends Neurosci. 16, 323-328.

Nagy, J.I., Dudek, F.E., Rash, J.E., 2004. Update on connexins and gap junctions in neurons and glia in the mammalian nervous system. Brain Res. Brain Res. Rev. 47, 191-215.

Nedergaard, M., 1994. Direct signaling from astrocytes to neurons in cultures of mammalian brain cells. Science 263, 1768-1771.

Nemeroff, C.B., 1998. Psychopharmacology of affective disorders in the 21st century. Biol. Psychiatry 44, 517-525.

Nestler, E.J., Barrot, M., DiLeone, R.J., Eisch, A.J., Gold, S.J., Monteggia, L.M., 2002. Neurobiology of depression. Neuron 34, 13-25.

Newman-Tancredi, A., Audinot-Bouchez, V., Gobert, A., Millan, M.J., 1997. Noradrenaline and adrenaline are high affinity agonists at dopamine D4 receptors. Eur. J. Pharmacol. 319, 379-383.

Nibuya, M., Morinobu, S., Duman, R.S., 1995. Regulation of BDNF and trkB mRNA in rat brain by chronic electroconvulsive seizure and antidepressant drug treatments. J. Neurosci. 15, 7539-7547.

Nicholson, C., 1979. In: Schmitt, F., Worden, F. (Eds.), The Neurosciences: Fourth Study Program Cambridge, MA. The MIT Press, Cambridge, MA.

Nicholson, C., 1999. Signals that go with the flow. Trends Neurosci. 22, 143-145.

Nicholson, C., 2001. Diffusion and related transport mechanisms in brain tissue. Rep. Prog. Phys. 64, 815-884.

Nicholson, C., Phillips, J.M., 1981. Ion diffusion modified by tortuosity and volume fraction in the extracellular microenvironment of the rat cerebellum. J. Physiol. 321, 225-257.

Nicholson, C., Sykova, E., 1998. Extracellular space structure revealed by diffusion analysis. Trends Neurosci. 21, 207-215.

Nieuwenhuys, R., 1985. Chemoarchitecture of the Brain. Springer, Berlin.

Nordström, A.L., Farde, L., Wiesel, F.A., Forslund, K., Pauli, S., Halldin, C., Uppfeldt, G., 1993. Central D2-dopamine receptor occupancy in relation to antipsychotic drug effects: A double-blind PET study of schizophrenic patients. Biol. Psychiatry 33, 227-235.

Nygren, L.G., Olson, L., 1977. A new major projection from locus coeruleus: The main source of noradrenergic nerve terminals in the ventral and dorsal columns of the spinal cord. Brain Res. 132, 85-93.

Oades, R.D., Sadile, A.G., Sagvolden, T., Viggiano, D., Zuddas, A., Devoto, P., Aase, H., Johansen, E.B., Ruocco, L.A., Russell, V.A., 2005. The control of responsiveness in ADHD by catecholamines: Evidence for dopaminergic, noradrenergic and interactive roles. Dev. Sci. 8, 122-131.

Ogren, S.O., Fuxe, K., Agnati, L.F., Gustafsson, J.A., Jonsson, G., Holm, A.C., 1979. Reevaluation of the indoleamine hypothesis of depression. Evidence for a reduction of functional activity of central 5-HT systems by antidepressant drugs. J. Neural Transm. 46, 85-103.

Olson, L., Fuxe, K., 1971. On the projections from the locus coeruleus noradrealine neurons: The cerebellar innervation. Brain Res. 28, 165-171.

Olson, L., Fuxe, K., 1972. Further mapping out of central noradrenaline neuron systems: Projections of the "subcoeruleus" area. Brain Res. 43, 289-295.

Olson, L., Seiger, A., Fuxe, K., 1972. Heterogeneity of striatal and 
limbic dopamine innervation: Highly fluorescent islands in developing and adult rats. Brain Res. 44, 283-288.

Ormond, J., Hislop, J., Zhao, Y., Webb, N., Vaillaincourt, F., Dyer, J.R., Ferraro, G., Barker, P., Martin, K.C., Sossin, W.S., 2004. ApTrkl, a Trk-like receptor, mediates serotonin-dependent ERK activation and long-term facilitation in Aplysia sensory neurons. Neuron 44, 715-728.

Ouimet, C.C., Miller, P.E., Hemmings Jr., H.C., Walaas, S.I., Greengard, P., 1984. DARPP-32, a dopamine- and adenosine $3^{\prime}: 5^{\prime}$-monophosphate-regulated phosphoprotein enriched in dopamine-innervated brain regions. III. Immunocytochemical localization. J. Neurosci. 4, 111-124.

Pasquini, F., Bochet, P., Garbay-Jaureguiberry, C., Roques, B.P., Rossier, J., Beaudet, A., 1992. Electron microscopic localization of photoaffinity-labelled delta opioid receptors in the neostriatum of the rat. J. Comp. Neurol. 326, 229-244.

Patapoutian, A., Reichardt, L.F., 2001. Trk receptors: Mediators of neurotrophin action. Curr. Opin. Neurobiol. 11, 272-280.

Paut-Pagano, L., Roky, R., Valatx, J.L., Kitahama, K., Jouvet, M., 1993. Anatomical distribution of prolactin-like immunoreactivity in the rat brain. Neuroendocrinology 58 , 682-695.

Pereda, A.E., Faber, D.S., 1996. Activity-dependent short-term enhancement of intercellular coupling. J. Neurosci. 16, 983-992.

Pereda, A.E., Bell, T.D., Chang, B.H., Czernik, A.J., Nairn, A.C., Soderling, T.R., Faber, D.S., 1998. Ca2+/calmodulin-dependent kinase II mediates simultaneous enhancement of gap-junctional conductance and glutamatergic transmission. Proc. Natl. Acad. Sci. U. S. A. 95, 13272-13277.

Perez de la Mora, M., Ferre, S., Fuxe, K., 1997. GABA-dopamine receptor-receptor interactions in neostriatal membranes of the rat. Neurochem. Res. 22, 1051-1054.

Peroutka, S.J., Snyder, S.H., 1979. Multiple serotonin receptors: Differential binding of [3H]5-hydroxytryptamine, [3H]lysergic acid diethylamide and [3H]spiroperidol. Mol. Pharmacol. 16, 687-699.

Peroutka, S.J., Snyder, S.H., 1980. Regulation of serotonin2 (5-HT2) receptors labeled with $[3 \mathrm{H}]$ spiroperidol by chronic treatment with the antidepressant amitriptyline. J. Pharmacol. Exp. Ther. 215, 582-587.

Post, R.M., Gold, P., Rubinow, D.R., Ballenger, J.C., Bunney Jr., W.E., Goodwin, F.K., 1982. Peptides in the cerebrospinal fluid of neuropsychiatric patients: An approach to central nervous system peptide function. Life Sci. 31, 1-15.

Proescholdt, M.G., Hutto, B., Brady, L.S., Herkenham, M., 2000. Studies of cerebrospinal fluid flow and penetration into brain following lateral ventricle and cisterna magna injections of the tracer [14C]inulin in rat. Neuroscience 95, 577-592.

Quarta, D., Ciruela, F., Patkar, K., Borycz, J., Solinas, M., Lluis, C., Franco, R., Wise, R.A., Goldberg, S.R., Hope, B.T., Woods, A.S., Ferre, S., 2007. Heteromeric nicotinic acetylcholine-dopamine autoreceptor complexes modulate striatal dopamine release. Neuropsychopharmacology 32, 35-42.

Rajagopal, R., Chen, Z.Y., Lee, F.S., Chao, M.V., 2004. Transactivation of Trk neurotrophin receptors by G-protein-coupled receptor ligands occurs on intracellular membranes. J. Neurosci. 24, 6650-6658.

Rajkowska, G., Miguel-Hidalgo, J.J., Wei, J., Dilley, G., Pittman, S.D., Meltzer, H.Y., Overholser, J.C., Roth, B.L., Stockmeier, C.A., 1999. Morphometric evidence for neuronal and glial prefrontal cell pathology in major depression. Biol. Psychiatry 45, 1085-1098.

Rauch, B.H., Millette, E., Kenagy, R.D., Daum, G., Clowes, A.W., 2004. Thrombin- and factor Xa-induced DNA synthesis is mediated by transactivation of fibroblast growth factor receptor-1 in human vascular smooth muscle cells. Circ. Res. 94, 340-345.

Rennels, M.L., Gregory, T.F., Blaumanis, O.R., Fujimoto, K., Grady, P.A., 1985. Evidence for a 'paravascular' fluid circulation in the mammalian central nervous system, provided by the rapid distribution of tracer protein throughout the brain from the subarachnoid space. Brain Res. 326, 47-63.

Rennels, M.L., Blaumanis, O.R., Grady, P.A., 1990. Rapid solute transport throughout the brain via paravascular fluid pathways. Adv. Neurol. 52, 431-439.

Riad, M., Garcia, S., Watkins, K.C., Jodoin, N., Doucet, E., Langlois, X., el Mestikawy, S., Hamon, M., Descarries, L., 2000. Somatodendritic localization of 5-HT1A and preterminal axonal localization of 5-HT1B serotonin receptors in adult rat brain. J. Comp. Neurol. 417, 181-194.

Rice, M.E., 2000. Distinct regional differences in dopamine-mediated volume transmission. In: Agnati, L.F., Fuxe, K., Nicholson, C., Sykova, E. (Eds.), Volume Transmission Revisited, vol. 125. Elsevier, Amsterdam, pp. 277-290.

Ridet, J.L., Sandillon, F., Rajaofetra, N., Geffard, M., Privat, A., 1992. Spinal dopaminergic system of the rat: Light and electron microscopic study using an antiserum against dopamine, with particular emphasis on synaptic incidence. Brain Res. 598, 233-241.

Rivera, A., Cuellar, B., Giron, F.J., Grandy, D.K., de la Calle, A., Moratalla, R., 2002. Dopamine D4 receptors are heterogeneously distributed in the striosomes/matrix compartments of the striatum. J. Neurochem. 80, 219-229.

Rivera, A., Agnati, L.F., Horvath, T.L., Valderrama, J.J., de La Calle, A., Fuxe, K., 2006. Uncoupling protein 2/3 immunoreactivity and the ascending dopaminergic and noradrenergic neuronal systems: Relevance for volume transmission. Neuroscience 137, 1447-1461.

Robinson, T.E., Berridge, K.C., 1993. The neural basis of drug craving: An incentive-sensitization theory of addiction. Brain Res. Brain Res. Rev. 18, 247-291.

Rocheville, M., Lange, D.C., Kumar, U., Patel, S.C., Patel, R.C., Patel, Y.C., 2000. Receptors for dopamine and somatostatin: Formation of hetero-oligomers with enhanced functional activity. Science 288, 154-157.

Rorig, B., Sutor, B., 1996. Serotonin regulates gap junction coupling in the developing rat somatosensory cortex. Eur J. Neurosci. 8, 1685-1695.

Routtenberg, A., Sladek, J., Bondareff, W., 1968. Histochemical fluorescence after application of neurochemicals to caudate nucleus and septal area in vivo. Science 161, 272-274.

Rusakov, D.A., Kullmann, D.M., 1998. A tortuous and viscous route to understanding diffusion in the brain. Trends Neurosci. 21, 469-470.

Rusakov, D.A., Kullmann, D.M., Stewart, M.G., 1999. Hippocampal synapses: Do they talk to their neighbours? Trends Neurosci. 22, 382-388.

Saarelainen, T., Hendolin, P., Lucas, G., Koponen, E., Sairanen, M., MacDonald, E., Agerman, K., Haapasalo, A., Nawa, H., Aloyz, R., Ernfors, P., Castren, E., 2003. Activation of the TrkB neurotrophin receptor is induced by antidepressant drugs and is required for antidepressant-induced behavioral effects. J. Neurosci. 23, 349-357.

Salamone, J.D., Cousins, M.S., Snyder, B.J., 1997. Behavioral functions of nucleus accumbens dopamine: Empirical and conceptual problems with the anhedonia hypothesis. Neurosci. Biobehav. Rev. 21, 341-359.

Santarelli, L., Saxe, M., Gross, C., Surget, A., Battaglia, F., Dulawa, S., Weisstaub, N., Lee, J., Duman, R., Arancio, O., Belzung, C., Hen, R., 2003. Requirement of hippocampal neurogenesis for the behavioral effects of antidepressants. Science 301, 805-809.

Schaible, H.G., Hope, P.J., Lang, C.W., Duggan, A.W., 1992. Calcitonin gene-related peptide causes intraspinal spreading of substance $P$ released by peripheral stimulation. Eur. J. Neurosci. 4, 750-757.

Schloss, P., Henn, F.A., 2004. New insights into the mechanisms of antidepressant therapy. Pharmacol. Ther. 102, 47-60. 
Schmitt, F.O., 1984. Molecular regulators of brain function: A new view. Neuroscience 13, 991-1001.

Schmitz, D., Schuchmann, S., Fisahn, A., Draguhn, A., Buhl, E.H., Petrasch-Parwez, E., Dermietzel, R., Heinemann, U., Traub, R.D., 2001. Axo-axonal coupling. a novel mechanism for ultrafast neuronal communication. Neuron 31, 831-840.

Schobitz, B., De Kloet, E.R., Holsboer, F., 1994. Gene expression and function of interleukin 1, interleukin 6 and tumor necrosis factor in the brain. Prog. Neurobiol. 44, 397-432.

Schultz, W., 2002. Getting formal with dopamine and reward. Neuron 36, 241-263.

Schwartz, J.C., Diaz, J., Bordet, R., Griffon, N., Perachon, S., Pilon, C., Riday, S., Sokoloff, P., 1998. Functional implications of multiple dopamine receptor subtypes: The D1/D3 receptor coexistence. Brain Res. Rev. 26 (2-3), 236-242.

Seeman, P., Chau-Wong, M., Tedesco, J., Wong, K., 1975. Brain receptors for antipsychotic drugs and dopamine: Direct binding assays. Proc. Natl. Acad. Sci. U. S. A. 72, 4376-4380.

Segal, M.B., 2000. The choroid plexuses and the barriers between the blood and the cerebrospinal fluid. Cell. Mol. Neurobiol. 20, 183-196.

Sesack, S.R., Aoki, C., Pickel, V.M., 1994. Ultrastructural localization of D2 receptor-like immunoreactivity in midbrain dopamine neurons and their striatal targets. J. Neurosci. 14, 88-106.

Shah, B.H., Catt, K.J., 2004. GPCR-mediated transactivation of RTKs in the CNS: Mechanisms and consequences. Trends Neurosci. $27,48-53$.

Shepherd, G., 1991. Foundations of the Neuron Doctrine. Oxford Univ. Press, New York.

Shepherd, G., 1994. Neurobiology. Oxford Univ. Press, Oxford.

Sherrington, C., 1947. The FG Integrative Action of the Nervous System. Yale Univ. Press, New Haven.

Shipley, M.T., Fu, L., Ennis, M., Liu, W.L., Aston-Jones, G., 1996. Dendrites of locus coeruleus neurons extend preferentially into two pericoerulear zones. J. Comp. Neurol. 365, 56-68.

Shirayama, Y., Chen, A.C., Nakagawa, S., Russell, D.S., Duman, R.S., 2002. Brain-derived neurotrophic factor produces antidepressant effects in behavioral models of depression. J. Neurosci. 22, 3251-3261.

Silver, R., LeSauter, J., Tresco, P.A., Lehman, M.N., 1996. A diffusible coupling signal from the transplanted suprachiasmatic nucleus controlling circadian locomotor rhythms. Nature 382, 810-813.

Skinner, D.C., Malpaux, B., 1999. High melatonin concentrations in third ventricular cerebrospinal fluid are not due to Galen vein blood recirculating through the choroid plexus. Endocrinology 140, 4399-4405.

Skirboll, L.R., Grace, A.A., Bunney, B.S., 1979. Dopamine auto- and postsynaptic receptors: Electrophysiological evidence for differential sensitivity to dopamine agonists. Science 206, 80-82.

Skolnick, P., 1999. Antidepressants for the new millennium. Eur. J. Pharmacol. 375, 31-40.

Snyder, S.H., Bredt, D.S., 1991. Nitric oxide as a neuronal messenger. Trends Pharmacol. Sci. 12, 125-128.

Sohl, G., Maxeiner, S., Willecke, K., 2005. Expression and functions of neuronal gap junctions. Nat. Rev., Neurosci. 6, 191-200.

Sontheimer, H., Kettenmann, H., Backus, K.H., Schachner, M., 1988. Glutamate opens $\mathrm{Na}+/ \mathrm{K}+$ channels in cultured astrocytes. Glia 1, 328-336.

Sossin, W.S., Fisher, J.M., Scheller, R.H., 1989. Cellular and molecular biology of neuropeptide processing and packaging. Neuron 2, 1407-1417.

Steinbusch, H.W., 1981. Distribution of serotoninimmunoreactivity in the central nervous system of the rat-cell bodies and terminals. Neuroscience 6, 557-618.

Steinbusch, H.W., Nieuwenhuys, R., 1981. Localization of serotonin-like immunoreactivity in the central nervous system and pituitary of the rat, with special references to the innervation of the hypothalamus. Adv. Exp. Med. Biol. 133, 7-35.

Steinbusch, H.W., Verhofstad, A.A., Joosten, H.W., 1978. Localization of serotonin in the central nervous system by immunohistochemistry: Description of a specific and sensitive technique and some applications. Neuroscience 3, 811-819.

Steinbusch, H.W., Nieuwenhuys, R., Verhofstad, A.A., Van der Kooy, D., 1981. The nucleus raphe dorsalis of the rat and its projection upon the caudatoputamen. A combined cytoarchitectonic, immunohistochemical and retrograde transport study. J. Physiol. (Paris) 77, 157-174.

Stezhka, V.V., Lovick, T.A., 1995. Dye coupling between dorsal raphe neurones. Exp. Brain Res. 105, 383-390.

Stone, E.A., Ariano, M.A., 1989. Are glial cells targets of the central noradrenergic system? A review of the evidence. Brain Res. Brain Res. Rev. 14, 297-309.

Strömberg, I., Kehr, J., Fuxe, K., 2000. Restoration of dopamine transmission in graft reinnervated striatum. Evidence for regulation of dopamine $\mathrm{D} 2$ receptor function in regions lacking dopamine. Prog. Brain Res. 125, 309-315.

Svensson, T.H., 2000. Dysfunctional brain dopamine systems induced by psychotomimetic NMDA-receptor antagonists and the effects of antipsychotic drugs. Brain Res. Brain Res. Rev. 31, 320-329.

Sykova, E., 2004. Diffusion properties of the brain in health and disease. Neurochem. Int. 45, 453-466.

Sykova, E., Mazel, T., Simonova, Z., 1998. Diffusion constraints and neuron-glia interaction during aging. Exp. Gerontol. 33, 837-851.

Takase, L.F., Nogueira, M.I., Baratta, M., Bland, S.T., Watkins, L.R., Maier, S.F., Fornal, C.A., Jacobs, B.L., 2004. Inescapable shock activates serotonergic neurons in all raphe nuclei of rat. Behav. Brain Res. 153, 233-239.

Tamas, G., Buhl, E.H., Lorincz, A., Somogyi, P., 2000. Proximally targeted GABAergic synapses and gap junctions synchronize cortical interneurons. Nat. Neurosci. 3, 366-371.

Taylor, C., Fricker, A.D., Devi, L.A., Gomes, I., 2005. Mechanisms of action of antidepressants: From neurotransmitter systems to signaling pathways. Cell. Signal. 17, 549-557.

Tennyson, V.M., Barrett, R.E., Cohen, G., Cote, L., Heikkila, R., Mytilineou, C., 1972. The developing neostriatum of the rabbit: Correlation of fluorescence histochemistry, electron microscopy, endogenous dopamine levels, and (3 H)dopamine uptake. Brain Res. 46, 251-285.

Thureson-Klein, A.K., Klein, R.L., 1990. Exocytosis from neuronal large dense-cored vesicles. Int. Rev. Cytol. 121, 67-126.

Torvinen, M., Marcellino, D., Canals, M., Agnati, L.F., Lluis, C., Franco, R., Fuxe, K., 2005. Adenosine A2A receptor and dopamine D3 receptor interactions: Evidence of functional A2A/D3 heteromeric complexes. Mol. Pharmacol. 67, 400-407.

Travagli, R.A., Dunwiddie, T.V., Williams, J.T., 1995. Opioid inhibition in locus coeruleus. J. Neurophysiol. 74, 518-528.

Turner, C.A., Akil, H., Watson, S.J., Evans, S.J., 2006. The fibroblast growth factor system and mood disorders. Biol. Psychiatry 59, 1128-1135.

Umbriaco, D., Watkins, K.C., Descarries, L., Cozzari, C., Hartman, B.K., 1994. Ultrastructural and morphometric features of the acetylcholine innervation in adult rat parietal cortex: An electron microscopic study in serial sections. J. Comp. Neurol. $348,351-373$.

Ungerstedt, U., 1968. 6-Hydroxy-dopamine induced degeneration of central monoamine neurons. Eur. J. Pharmacol. 5, 107-110.

Ungerstedt, U., 1971. Stereotaxic mapping of the monoamine pathways in the rat brain. Acta Physiol. Scand., Suppl. 367, $1-48$.

Ungerstedt, U., Butcher, L.L., Butcher, S.G., Anden, N.E., Fuxe, K., 1969. Direct chemical stimulation of dopaminergic 
mechanisms in the neostriatum of the rat. Brain Res. 14, 461-471.

Ungless, M.A., 2004. Dopamine: The salient issue. Trends Neurosci. 27, 702-706.

Urade, Y., Kitahama, K., Ohishi, H., Kaneko, T., Mizuno, N., Hayaishi, O., 1993. Dominant expression of mRNA for prostaglandin D synthase in leptomeninges, choroid plexus, and oligodendrocytes of the adult rat brain. Proc. Natl. Acad. Sci. U. S. A. 90, 9070-9074.

Usher, M., Cohen, J.D., Servan-Schreiber, D., Rajkowski, J., Aston-Jones, G., 1999. The role of locus coeruleus in the regulation of cognitive performance. Science 283, 549-554.

Van Harreveld, A., 1972. The extracellular space in the vertebrate CNS. In: Bourne, G.H. (Ed.), The Structure and Function of Nervous Tissue. Academic Press, New York, pp. 447-511.

Vandecasteele, M., Glowinski, J., Venance, L., 2005. Electrical synapses between dopaminergic neurons of the substantia nigra pars compacta. J. Neurosci. 25, 291-298.

Vincent, B., Beaudet, A., Dauch, P., Vincent, J.P., Checler, F., 1996. Distinct properties of neuronal and astrocytic endopeptidase 3.4.24.16: A study on differentiation, subcellular distribution, and secretion processes. J. Neurosci. 16, 5049-5059.

Vizi, E., 1984. Non-Synaptic Interactions Between Neurons: Modulation of Neurochemical Transmission. John Wiley and Sons, Ltd., Chichester.

Vorisek, I., Sykova, E., 1997. Evolution of anisotropic diffusion in the developing rat corpus callosum. J. Neurophysiol. 78, 912-919.

Wang, R., 2002. Two's company, three's a crowd: Can H2S be the third endogenous gaseous transmitter? FASEB J. 16, 1792-1798.

Wang, R.Y., Aghajanian, G.K., 1982. Correlative firing patterns of serotonergic neurons in rat dorsal raphe nucleus. J. Neurosci. 2, 11-16.

Wang, Y., Tang, F.I., Chiou, A.L., Wang, J.Y., 1996. Differential sensitivity of dopamine release and clearance to 6-hydroxydopamine lesioning in rat striatum. Life Sci. 59, 1783-1792.

Westerink, B.H., De Vries, J.B., 2001. A method to evaluate the diffusion rate of drugs from a microdialysis probe through brain tissue. J. Neurosci. Methods 109, 53-58.
Whitaker-Azmitia, P.M., Murphy, R., Azmitia, E.C., 1990. Stimulation of astroglial 5-HT1A receptors releases the serotonergic growth factor, protein S-100, and alters astroglial morphology. Brain Res. 528, 155-158.

Wiesel, F.A., Fuxe, K., Hokfelt, T., Agnati, L.F., 1978. Studies on dopamine turnover in ovariectomized or hypophysectomized female rats. Effects of 17 beta-estradiol benzoate, ethynodioldiacetate and ovine prolactin. Brain Res. 148, 399-411.

Witkovsky, P., Nicholson, C., Rice, M.E., Bohmaker, K., Meller, E., 1993. Extracellular dopamine concentration in the retina of the clawed frog, Xenopus laevis. Proc. Natl. Acad. Sci. U. S. A. 90, 5667-5671.

Yablonskiy, D.A., Ackerman, J.J., Raichle, M.E., 2000. Coupling between changes in human brain temperature and oxidative metabolism during prolonged visual stimulation. Proc. Natl. Acad. Sci. U. S. A. 97, 7603-7608.

Yung, K.K., Bolam, J.P., Smith, A.D., Hersch, S.M., Ciliax, B.J., Levey, A.I., 1995. Immunocytochemical localization of D1 and D2 dopamine receptors in the basal ganglia of the rat: Light and electron microscopy. Neuroscience 65, 709-730.

Zhang, E.T., Richards, H.K., Kida, S., Weller, R.O., 1992. Directional and compartmentalised drainage of interstitial fluid and cerebrospinal fluid from the rat brain. Acta Neuropathol. (Berl.) 83, 233-239.

Zhu, P.C., Thureson-Klein, A., Klein, R.L., 1986. Exocytosis from large dense cored vesicles outside the active synaptic zones of terminals within the trigeminal subnucleus caudalis: A possible mechanism for neuropeptide release. Neuroscience 19, 43-54.

Zigmond, M.J., 2000. When it comes to communications between neurons, synapses are over-rated: Insights from an animal model of parkinsonism. Prog. Brain Res. 125, 317-326.

Zoli, M., Agnati, L.F., 1996. Wiring and volume transmission in the central nervous system: The concept of closed and open synapses. Prog. Neurobiol. 49, 363-380.

Zoli, M., Agnati, L.F., Fuxe, K., Bjelke, B., 1989. Demonstration of NPY transmitter receptor mismatches in the central nervous system of the male rat. Acta Physiol. Scand. 135, 201-202. 